\title{
Evaluation of the Performance of Houses With and Without Supplemental Dehumidification in a Hot-Humid Climate
}

P. Kerrigan

Building Science Corporation

P. Norton

Mountain Energy Partnership

October 2014 


\section{NOTICE}

This report was prepared as an account of work sponsored by an agency of the United States government. Neither the United States government nor any agency thereof, nor any of their employees, subcontractors, or affiliated partners makes any warranty, express or implied, or assumes any legal liability or responsibility for the accuracy, completeness, or usefulness of any information, apparatus, product, or process disclosed, or represents that its use would not infringe privately owned rights. Reference herein to any specific commercial product, process, or service by trade name, trademark, manufacturer, or otherwise does not necessarily constitute or imply its endorsement, recommendation, or favoring by the United States government or any agency thereof. The views and opinions of authors expressed herein do not necessarily state or reflect those of the United States government or any agency thereof.

Available electronically at http://www.osti.gov/scitech

Available for a processing fee to U.S. Department of Energy and its contractors, in paper, from:

U.S. Department of Energy

Office of Scientific and Technical Information

P.O. Box 62

Oak Ridge, TN 37831-0062

phone: 865.576.8401

fax: 865.576 .5728

email: mailto:reports@adonis.osti.gov

Available for sale to the public, in paper, from:

U.S. Department of Commerce

National Technical Information Service

5285 Port Royal Road

Springfield, VA 22161

phone: 800.553 .6847

fax: 703.605.6900

email: orders@ntis.fedworld.gov

online ordering: http://www.ntis.gov/ordering.htm 


\title{
Evaluation of the Performance of Houses With and Without Supplemental Dehumidification in a Hot-Humid Climate
}

\author{
Prepared for: \\ The National Renewable Energy Laboratory \\ On behalf of the U.S. Department of Energy's Building America Program \\ Office of Energy Efficiency and Renewable Energy \\ 15013 Denver West Parkway \\ Golden, CO 80401 \\ NREL Contract No. DE-AC36-08GO28308 \\ Prepared by: \\ Philip Kerrigan Jr., PE \\ Building Science Corporation \\ 3 Lan Drive, Suite 102 \\ Westford, MA 01886 \\ NREL Technical Monitor: Cheryn Metzger \\ Prepared under Subcontract No. KNDJ-0-40337-04
}

October 2014 
The work presented in this report does not represent performance of any product relative to regulated minimum efficiency requirements.

The laboratory and/or field sites used for this work are not certified rating test facilities. The conditions and methods under which products were characterized for this work differ from standard rating conditions, as described.

Because the methods and conditions differ, the reported results are not comparable to rated product performance and should only be used to estimate performance under the measured conditions. 


\section{Contents}

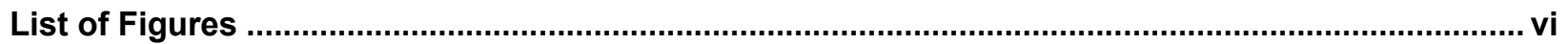

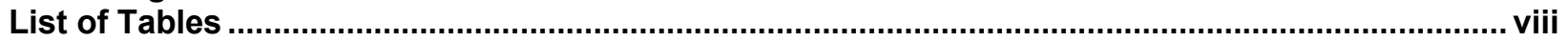

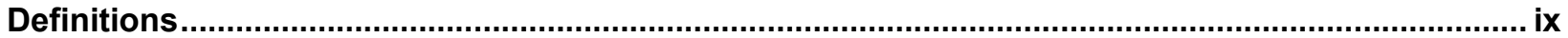

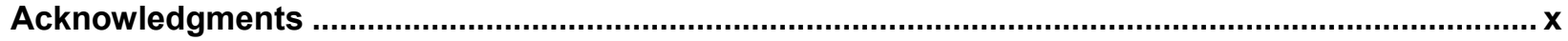

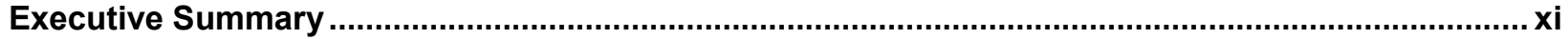

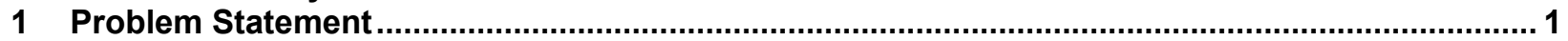

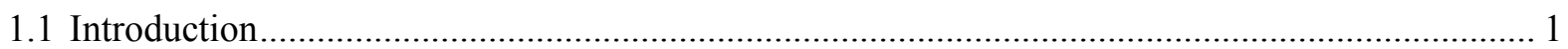

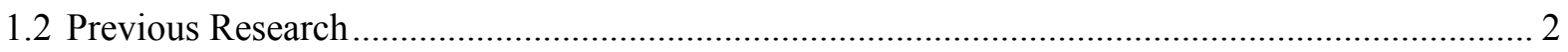

1.3 Relevance to Building America's Goals ................................................................................... 3

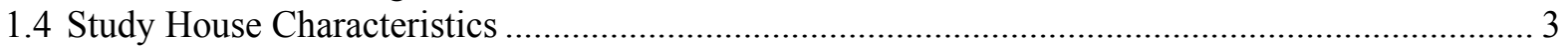

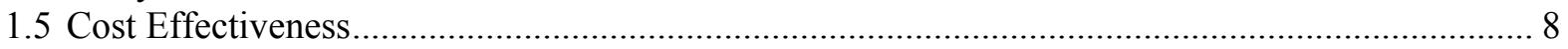

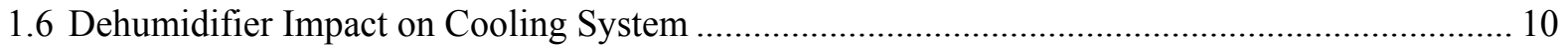

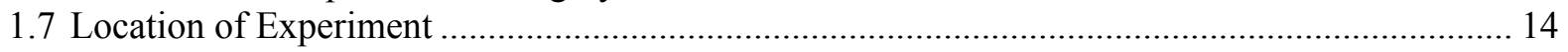

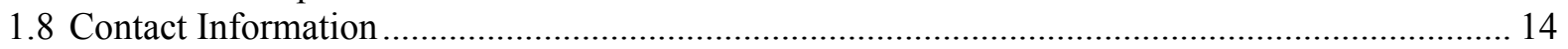

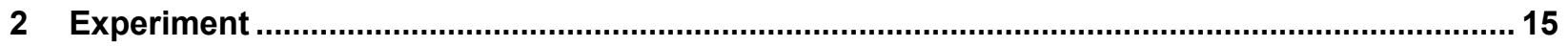

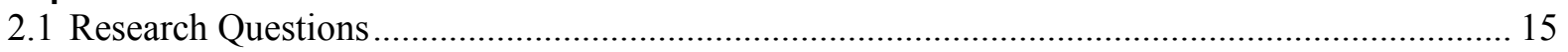

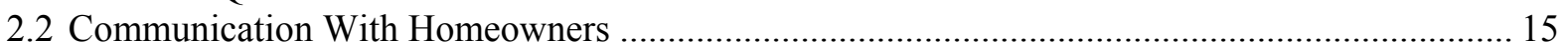

2.3 Initial Repair and Commissioning of Existing Mechanical Systems ....................................... 16

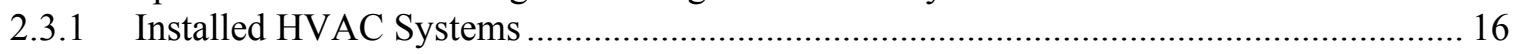

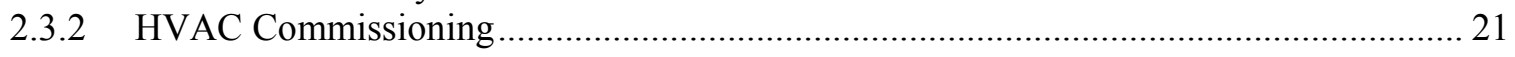

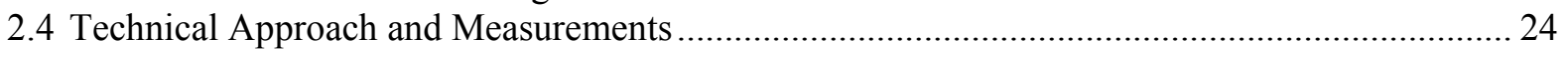

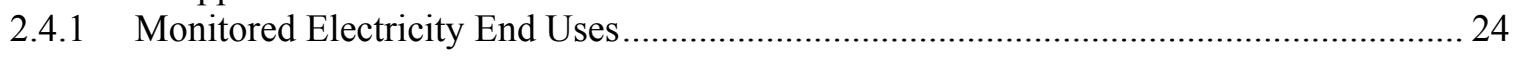

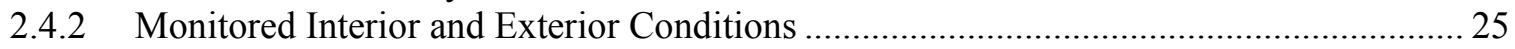

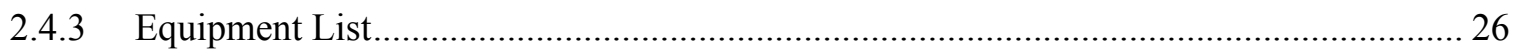

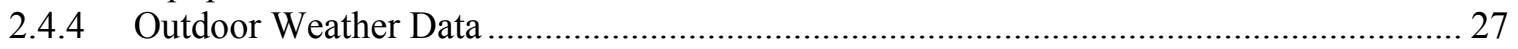

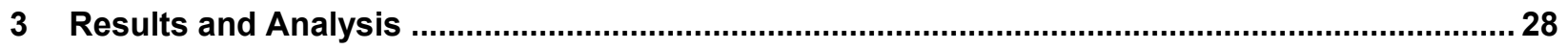

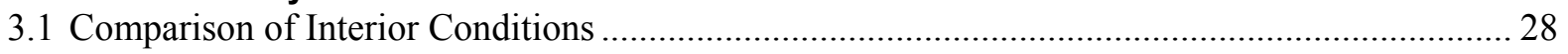

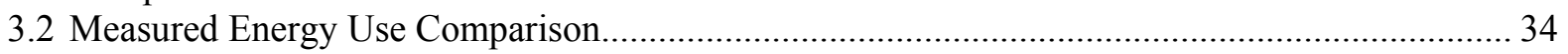

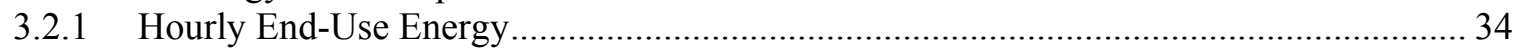

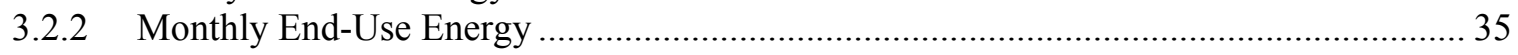

3.2.3 Comparison to Predicted Performance ........................................................................ 39

3.2.4 Equipment Operation and Impact on Humidity Control.............................................. 42

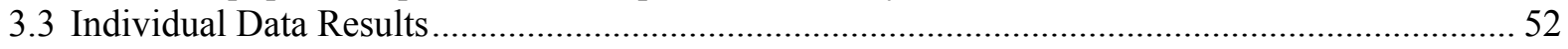

3.3.1 Project Home Again 1: House With Dehumidifier ........................................................ 52

3.3.2 Project Home Again 2: House With Dehumidifier .......................................................... 54

3.3.3 Project Home Again 3: House With Dehumidifier .......................................................... 57

3.3.4 Project Home Again 4: House With Dehumidifier ......................................................... 59

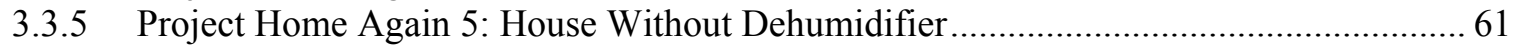

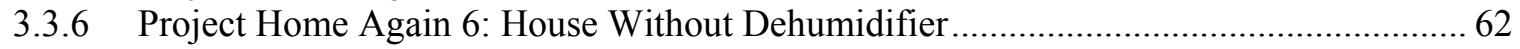

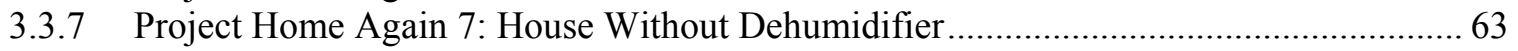

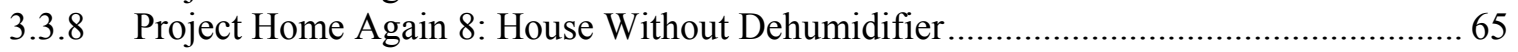

3.3.9 Broadmoor Development Corporation 1: House With Dehumidifier.................................. 66

3.3.10 Broadmoor Development Corporation 2: House With Dehumidifier................................... 67

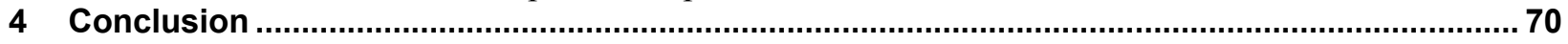

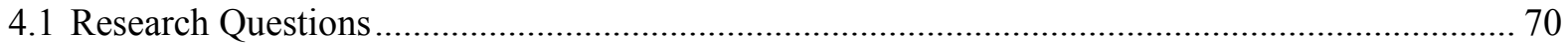

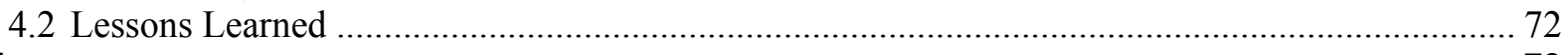

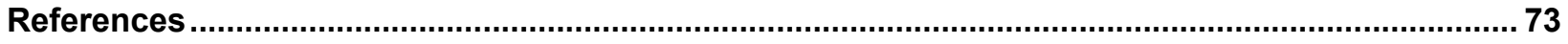

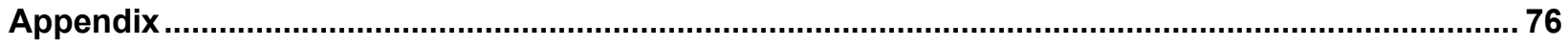




\section{List of Figures}

Figure 1. Examples of study house elevations

Figure 2. BEopt+ predicted percent source energy savings comparison between PHA homes with and without supplemental dehumidification

Figure 3. BEopt+ Predicted source energy use for PHA homes .................................................... 9

Figure 4. BEopt+ predicted percent source energy savings for the BDC homes with

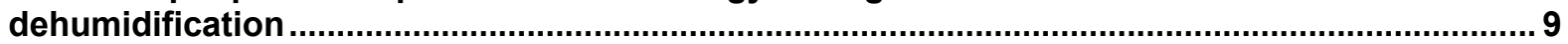

Figure 5. BEopt+ predicted source energy use for BDC homes ...................................................... 10

Figure 6. HVAC system schematic for PHA homes with ducted dehumidifier .................................. 17

Figure 7. HVAC system schematic for PHA homes with ducted dehumidifier ................................. 18

Figure 8: HVAC system schematic for BDC homes with standalone dehumidifier ..........................19

Figure 9. Example photographs of the HVAC system at a PHA house with dehumidifier ............... 19

Figure 10. Example photographs of the HVAC system at a PHA house without dehumidifier ........ 20

Figure 11. Example photographs of the HVAC system at a BDC house with dehumidifier ..............20

Figure 12. Example photographs of the fan cycler control location (circled in red) .......................21

Figure 13. Example photographs of the dehumidifier controls ........................................................2

Figure 14. Data monitoring equipment installed in unvented cathedralized attic.............................24

Figure 15. Wired T\&RH sensor installed in the return airstream of the heat pump air handler ....... 25

Figure 16. Wireless T\&RH sensor wall mounted near the thermostat and Aprilaire model 70

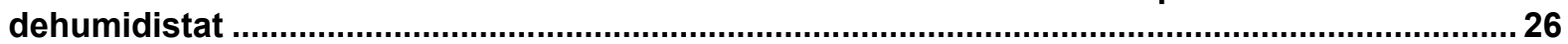

Figure 17. Frequency plot of \%RH hour bin data, grouped into the three study house types ......... 30

Figure 18. Frequency plot of DP hour bin data, grouped into the three study house types.............. 31

Figure 19. Hourly indoor DP for PHA homes with dehumidifiers ................................................. 32

Figure 20. Hourly indoor DP for PHA homes without dehumidifiers................................................ 33

Figure 21. Hourly indoor DP for BDC homes with dehumidifiers ..................................................... 33

Figure 22. Measured site energy use per end use at PHA homes ................................................. 34

Figure 23. Measured energy use per end use at BDC homes ....................................................... 35

Figure 24. Monthly heat pump energy use versus average outdoor DP for homes with dehumidifiers

Figure 25. Monthly heat pump energy use versus average outdoor DP for homes without

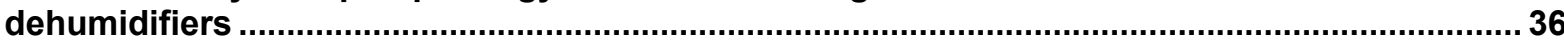

Figure 26. Monthly air handler energy use versus average outdoor DP for homes with dehumidifiers

Figure 27. Monthly air handler energy use versus average outdoor DP for homes without dehumidifiers

Figure 28. Monthly dehumidifier energy use plotted against average outdoor DP .......................... 38

Figure 29. Actual versus BEopt+ predicted energy use for various end uses in PHA homes with dehumidifiers (PHA 1-4)

Figure 30. Actual versus BEopt+ predicted energy use for various end uses in PHA homes without dehumidifiers (PHA 5-8).

Figure 31. Actual versus BEopt+ predicted energy use for various end uses in BDC homes with dehumidifiers (BDC 1 and 2)

Figure 32. Monthly hours above $60 \%$ RH for PHA homes without dehumidifiers. The open box indicates the average value for the test period.............................................................................. 43

Figure 33. Average space dry bulb temperature variations for homes without dehumidification ... 44

Figure 34. Variations in equipment energy use and interior conditions for PHA homes without dehumidification

Figure 35. Monthly hours above 60\% RH for all PHA homes ...................................................... 47

Figure 36. Monthly dehumidifier site energy use for PHA 1-4 ...................................................... 48

Figure 37. Variations in interior conditions from the mean values for all homes ............................. 49

Figure 38. Variations in interior conditions and equipment operation from the mean values for all homes

Figure 39. Variations in dehumidifier site energy use and HR from the mean values for all homes51

Figure 40. PHA 1 hourly interior temperature and \%RH plot. 
Figure 41. Hourly dehumidifier site energy use versus TSTAT \%RH for PHA 1

Figure 42. PHA 1 hourly \%RH frequency chart .......................................................................54

Figure 43. PHA 1 hourly \%RH frequency chart-hours with intended dehumidifier set point ......... 54

Figure 44. PHA 2 hourly interior temperature and \%RH plot............................................................5 55

Figure 45. PHA 2 hourly \%RH frequency chart ....................................................................... 56

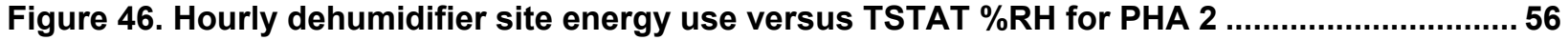

Figure 47. PHA 3 hourly interior temperature and \% RH plot........................................................... 57

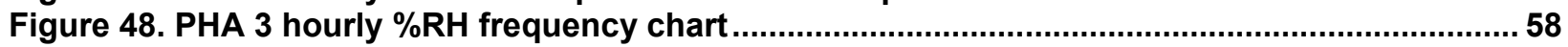

Figure 49. Hourly dehumidifier site energy use versus TSTAT \%RH for PHA 3 ............................58

Figure 50. PHA 3 air handler and supply plenum air temperature-1-min plot for January $2013 \ldots 59$

Figure 51. PHA 4 hourly interior temperature and \%RH plot.........................................................59

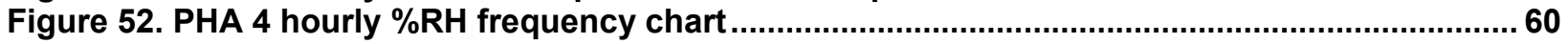

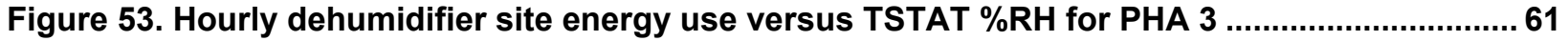

Figure 54. PHA 5 hourly interior temperature and \%RH plot........................................................61

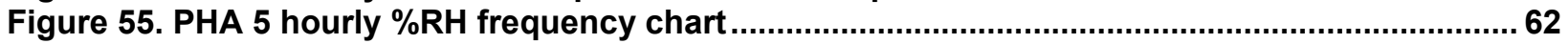

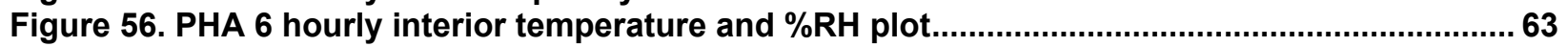

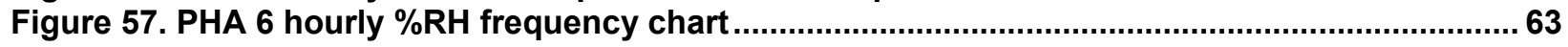

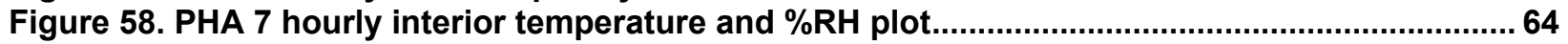

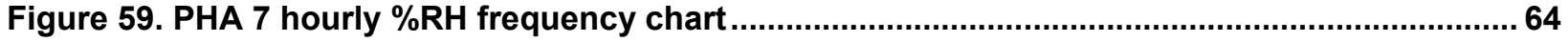

Figure 60. PHA 8 hourly interior temperature and \%RH plot..........................................................65

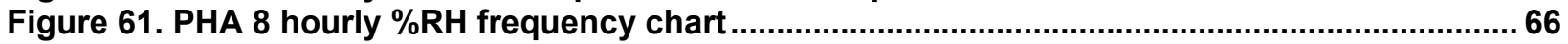

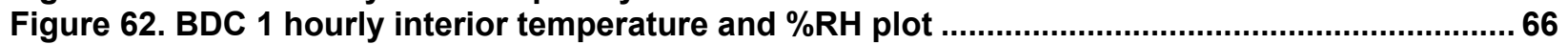

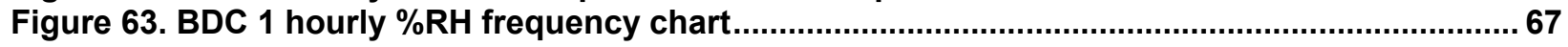

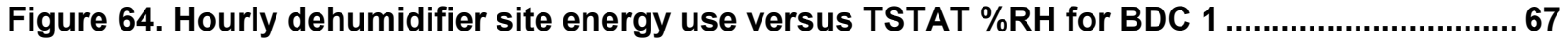

Figure 65. BDC 2 hourly interior temperature and \%RH plot ........................................................68

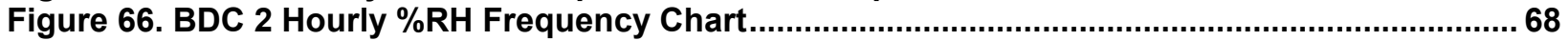

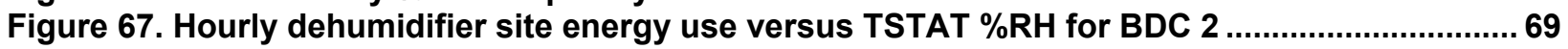

Figure 68. \%RH frequency plot for all 10 study homes, grouped into the three house types .......... 71

\section{Unless otherwise noted, all figures were created by Building Science Corporation.}




\section{List of Tables}

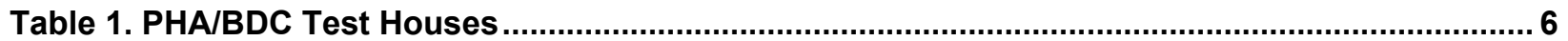

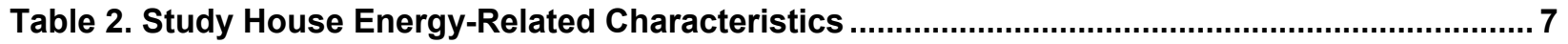

Table 3. BEopt+ Predicted Annual Indoor \%RH Bins ................................................................. 10

Table 4. Calculation of Predicted Additional Energy Used by the Aprilaire 1750 Dehumidifier ....... 12

Table 5. Calculation of Predicted Additional Energy Used by the Frigidaire FAD301NUD

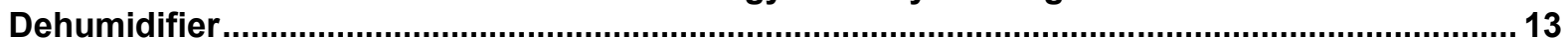

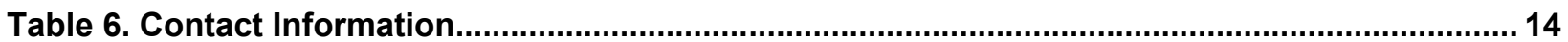

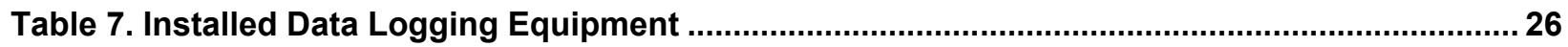

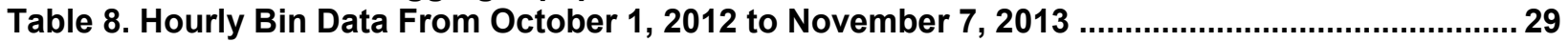

Table 9. Electricity Rate-Individual Component Charges.................................................................. 39

Table 10. Comparison of Predicted Versus Actual Dehumidifier Energy Use and Estimated Utility

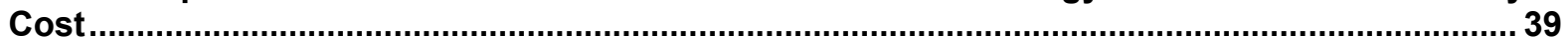

Table 11. Classification of Variations in Measurements From the Mean Values for the PHA Homes

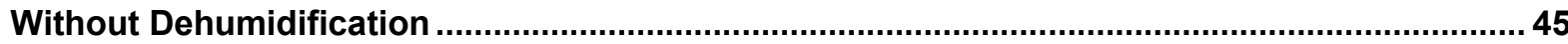

Table 12. Classification of Variations in Measurements From the Mean Values for the PHA and BDC Homes With Dehumidification

Unless otherwise noted, all tables were created by Building Science Corporation. 


\section{Definitions}

BDC

BEopt $^{\mathrm{TM}}$

BSC

$\operatorname{ccSPF}$

CFIS

CFM 50

DHW

DP

DOE

EER

HR

HSR

HVAC

$\mathrm{kWh}$

MEP

NREL

o.c.

ocSPF

PHA

RH

SEER

$\mathrm{T} \& \mathrm{RH}$

TSTAT
Broadmoor Development Corporation

Building Energy optimization program

Building Science Corporation

Closed Cell Spray Polyurethane Foam

Central Fan Integrated Supply

Cubic feet per minute at 50 Pascal test pressure

Domestic Hot Water

Dew Point Temperature

U.S. Department of Energy

Energy Efficiency Ratio

Humidity Ratio

Human Subjects Research

Heating, Ventilation, and Air Conditioning

Kilowatt-hour

Mountain Energy Partnership,

National Renewable Energy Laboratory

On Center

Open Cell Spray Polyurethane Foam

Project Home Again

Relative Humidity

Seasonal Energy Efficiency Ratio

Temperature and Relative Humidity (sensor)

Thermostat 


\section{Acknowledgments}

Building Science Corporation (BSC) would like to acknowledge, with gratitude, the direct cooperation of the National Renewable Energy Laboratory (NREL) and Mountain Energy Partnership (MEP). Through this partnership, the scope of the project was been expanded to allow for a more detailed monitoring of the houses. The data logging equipment was installed and managed by the NREL/MEP team, and BSC relied on their experience and expertise for implementing the monitoring systems. BSC would also like to acknowledge the effort of Joe Ryan, who assisted in the installation and removal of the data logging equipment and also performed a number of site visits to the homes during the course of the study to repair malfunctioning equipment.

This expanded dataset was crucial in furthering the understanding of the impact of supplemental dehumidification on low-energy homes in a hot-humid climate. 


\section{Executive Summary}

Understanding indoor humidity conditions in low-energy homes in hot-humid climates is critical to promoting long-term occupant comfort, indoor air quality and building durability. The results of this study were expected to inform the residential building community on whether supplemental dehumidification is a needed and effective investment to promote these long-term standards.

BSC seeks to research and report on the field monitoring of the performance of in-situ supplemental dehumidification systems in low-energy, high performance, homes in a hot-humid climate. The purpose of this research project was to observe and compare the humidity control performance of new, single-family, low-energy, high performance homes. Specifically, the study sought to compare the interior conditions and mechanical systems operation between two distinct groups of houses, homes with a supplemental dehumidifier installed in addition to heating, ventilation, and air conditioning (HVAC) system, and homes without any supplemental dehumidification. The subjects of the study were 10 single-family new construction homes in New Orleans, Louisiana, that were constructed from 2008-2011, with technical support from BSC under the U.S. Department of Energy Building America program (a research program on residential housing). The multiyear Project Home Again development and Broadmoor Development Corporation project offered a unique opportunity for the direct comparison of homes with and without supplemental dehumidification in similar floor plans with similar specifications.

Data logging equipment was installed at eight test homes in July 2012 and later at two more test homes in January 2013. Interior conditions and various end-use loads were monitored until November 7, 2013. The mechanical systems at each of the 10 homes were commissioned by BSC to ensure consistent operation among all of the homes and to fully comply with the intended mechanical design.

\section{Key Observations}

In terms of averages, the homes with dehumidifiers are limiting elevated levels of humidity in the living space. However, there was significant variation in humidity control between individual houses. An analysis of the equipment operation did not show a clear correlation between energy use and humidity levels.

In general, no single explanatory variable appears to provide a consistent understanding of the humidity control in each house. Indoor humidity is likely due to all of the factors we have examined, their interactions, and the specifics of how they are used by each occupant. The magnitude of this variability and the difficulty encountered in finding explanatory variables are important findings with implications for future research. Occupancy and homeowner behavior greatly influences the humidity load, and consequently the interior humidity levels.

The dehumidifiers did not negatively affect the capacity of the cooling system to adequately maintain set point. 
It should be noted that this study comprised a very small sample size $(\mathrm{n}=10)$ and may not be representative of the population at large.

It should also be noted that homeowner feedback from occupants in homes without supplemental dehumidification indicated that while the homeowner were made aware of the absence of supplemental dehumidification in their HVAC systems, BSC received no reports of comfort complaints related to elevated interior humidity levels. This is of particular interest because these homeowners became distinctly aware, through participation in the study, that their HVAC systems did not have a supplemental dehumidification component, while others who received the same house did. However, it should also be noted that the possibility exists that these homeowners were reticent to complain about houses they received, at no to low cost, as part of the Project Home Again redevelopment program.

BEoptE + software was used to evaluate the cost effectiveness of supplemental dehumidifiers in these homes and to predict the amount of hours the two home types will experience humidity levels higher than $60 \% \mathrm{RH}$. The house with a dehumidifier was predicted to use slightly more energy over the course of a year (2 MBtu/year), resulting in a decrease in source energy savings versus the Building America Benchmark from 21.8\% to 18.9\%. However, the hours above $60 \%$ $\mathrm{RH}$ were greatly reduced from 1,353 to 232 hours. The monitored energy use was compared to the BEopt+ hourly output. 


\section{Problem Statement}

\subsection{Introduction}

Building Science Corporation (BSC) seeks to research and report on in-situ performance of supplemental dehumidification systems installed in low-energy, high performance, and singlefamily new construction homes in a hot-humid climate.

Building America Best Practices Guide to Determining Climate Regions by County states the following definition for a hot-humid climate:

A Hot-Humid climate as a region that receives more than $20 \mathrm{in} .(50 \mathrm{~cm})$ of annual precipitation and where one or both of the following occur:

- A $67^{\circ} \mathrm{F}\left(19.5^{\circ} \mathrm{C}\right)$ or higher wet bulb temperature for 3,000 or more hours during the warmest six consecutive months of the year; or

- $\mathrm{A} 73^{\circ} \mathrm{F}\left(23^{\circ} \mathrm{C}\right)$ or higher wet bulb temperature for 1,500 or more hours during the warmest six consecutive months of the year.

The Building America hot-humid climate zone includes the portions of IECC zones 1, 2, and 3 that are in the moist category (A) below the "warm-humid" line shown on the IECC map.

Orleans County, Louisiana, is thus classified as a hot-humid climate (Baechler et al. 2010).

Understanding indoor humidity conditions in low-energy homes in hot-humid climates is critical to promoting long-term occupant comfort, indoor air quality, and building durability. The results of this study are expected to expand the dataset and understanding on residential dehumidification in a hot-humid climate. This research seeks to inform the residential building community on whether supplemental dehumidification is an effective investment to promote these long-term goals.

There are some reservations in the residential building community on the necessity of supplemental dehumidification systems in hot-humid climates, and there are limited monitored data to guide the decision-making process for builders and real estate organizations.

BSC provided technical consulting services to both projects through the Building America program. This included design, construction, and commissioning support and focused on improving the energy efficiency and durability of affordable new single-family homes.

Project Home Again (PHA) ${ }^{1}$ is a not-for-profit development that was started by the Riggio Foundation with the goal of providing 100 homes to those whose homes were destroyed or badly damaged by Hurricane Katrina (Hahn 2010). BSC was introduced to PHA through the local real estate development firm called Green Coast Enterprises, which managed PHA and other residential projects in the region. BSC provided technical support to PHA from 2008 to 2011. Data logging equipment was installed at eight PHA homes in July 2012.

${ }^{1}$ Learn more at www.projecthomeagain.net/. 
The success of this project led to an acknowledgment of PHA on the Initiatives and Projects U.S. Department of Energy (DOE) Office of Energy Efficiency and Renewable Energy website: www1.eere.energy.gov/office eere/de neworleans_ee.html.

Broadmoor Development Corporation $(\mathrm{BDC})^{2}$ was created in 2006 as a community development corporation, available to address the neighborhood's housing needs. The BDC has established a number of critical roles in the region, including the rehabilitation of owner-occupied properties, the renovation and sale of vacant properties, and the construction of new homes for the neighborhood. BSC consulted with BDC on the design and construction of four homes in the Broadmoor neighborhood of New Orleans in 2011, as part of their cooperation with Green Coast Enterprises. These homes were funded as part of a large conglomerate housing revitalization program operated by the U.S. Department of Housing and Urban Development Neighborhood Stabilization Program $2 .^{3}$

BDC expressed interest in the monitoring of its homes after being approached by BSC. Two BDC homes were added to the New Orleans dehumidification study in mid-January 2013.

These two affordable housing organizations seek to better understand the dynamics of humidity control in affordable, low-energy, high performance houses.

\subsection{Previous Research}

Previous research has demonstrated that supplemental dehumidification in low-energy homes in hot-humid climates is instrumental in maintaining proper comfort levels year round (Rudd et al. 2005; Rudd and Henderson 2007). Various systems have been developed for supplemental humidity control in residential homes; however, common ventilation systems, such as energy recovery ventilators, do not adequately control indoor humidity levels in a hot-humid climate (Walker and Sherman 2007; Rudd 2004). Supplemental dehumidification via a ducted wholehouse dehumidifier integrated with the heating, ventilation, and air conditioning (HVAC) system has been shown to be the most effective design for controlling indoor humidity levels separate from cooling (Rudd 2004; Rudd et al. 2005). Indoor humidity levels are higher for higher occupant densities (Walker and Sherman 2007) and moisture problems can occur in smaller homes (Arena et al. 2010).

Elevated interior humidity levels can have implications for occupant comfort, indoor air quality, and the long-term durability of moisture-sensitive materials in the home (Harriman and Lstiburek 2009).

Air conditioning equipment manufacturers advertise that cooling systems can provide adequate dehumidification without the use of a separate dehumidifier, either with multistage compressors that allow for longer runtimes at part load, or even by overcooling the interior space through the existing air conditioning system. More modern systems have variable capacity; however, this has been shown to not allow for true humidity control separate from cooling (Rudd 2004; Rudd et al. 2005).

\footnotetext{
${ }^{2}$ Learn more at http://broadmoorcorp.com/

${ }^{3}$ Learn more at www.hud.gov/offices/cpd/communitydevelopment/programs/neighborhoodspg/arrafactsheet.cfm.
} 
There are very limited monitored data on the in situ performance of supplemental dehumidifiers in low-energy, high performance homes in a hot-humid climate. There are especially limited monitored data for similar home types with the only different characteristic being whether supplemental dehumidifiers were or were not added.

\subsection{Relevance to Building America's Goals}

Overall, the goal of DOE's Building America program is to "reduce home energy use by $30 \%$ $50 \%$ (compared to 2009 energy codes for new homes and pre-retrofit energy use for existing homes)." To this end, we conduct research to "develop market-ready energy solutions that improve efficiency of new and existing homes in each U.S. climate zone, while increasing comfort, safety, and durability."4

Supplemental dehumidification is recommended by BSC (Rudd et al. 2003; Rudd 2004; Rudd et al. 2005) in hot-humid climates to provide year-round humidity control to maintain both optimized occupant comfort and the long-term durability of the structure. High performance homes - due to superior insulation, better performing windows, and more efficient lighting and appliances, can be expected to have smaller sensible cooling loads than typical new homes in the same geographic region. However, measures to improve the energy performance of the home generally do not affect internal humidity loads related to occupancy. Furthermore, under conditions where the moisture content of exterior air is higher than that of interior air-a condition that occurs for a significant portion of hours in hot and humid climates - dilution ventilation has the effect of increasing moisture levels within the building. The result is that the ratio of latent cooling loads (the energy required to cool/remove moisture in the air) to sensible will typically be higher for high-performance homes in humid climates. Most air conditioning equipment does not have the capability of removing the moisture load without over cooling the space. Supplemental dehumidification can complement the capability of the air conditioning system to remove moisture from air within the conditioned space (Rudd 2009b).

\subsection{Study House Characteristics}

PHA began construction on the first of six phases in 2008. The eight homes that are included in this study are from Phases II, III, and IV, and thus were constructed from 2008 to 2009. The two BDC homes in this study were constructed in 2011. All residences are wood-framed singlefamily detached buildings that were structurally designed to adhere to the Wood Frame Construction Manual for a 130 MPH wind zone (AFPA 2006). Each house is elevated on wooden piles to $1 \mathrm{ft}$ above the base flood elevation for each site, resulting in heights ranging from $3 \mathrm{ft}$ to $8 \mathrm{ft}$ above grade. The enclosure system is highly efficient, with high density, closed cell spray polyurethane foam (ccSPF) installed in the floor joists, exterior wall cavity, and roof joists, along with ENERGY STAR ${ }^{\circledR}$-certified windows. Building commissioning testing measured an infiltration rate averaging $40 \%$ less than the target, which was $2.5 \mathrm{in} .^{2}$ of free area per $100 \mathrm{ft}^{2}$ of enclosure. The mechanical systems include a heat pump and electric water heater, and all ductwork is located within conditioned space (Kerrigan 2009). Whole-house dilution ventilation is provided via a central fan integrated supply (CFIS) ventilation system that draws outside air through a dedicated outside air duct that is connected to the return plenum (Rudd 2013a, 2009a, 2009b). ENERGY STAR-certified and ASHRAE 62.2-compliant bath fans are

\footnotetext{
${ }^{4}$ www1.eere.energy.gov/buildings/building_america/program_goals.html
} 
installed as well as a direct vent kitchen exhaust hood for point source ventilation (ASHRAE 2010). Figure 1 shows examples of the PHA and BDC study houses.

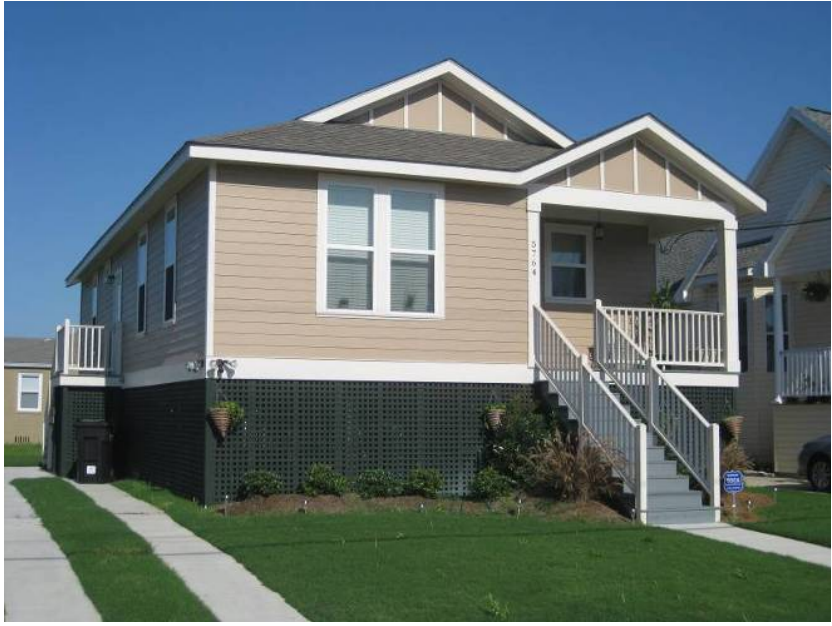

PHA study house

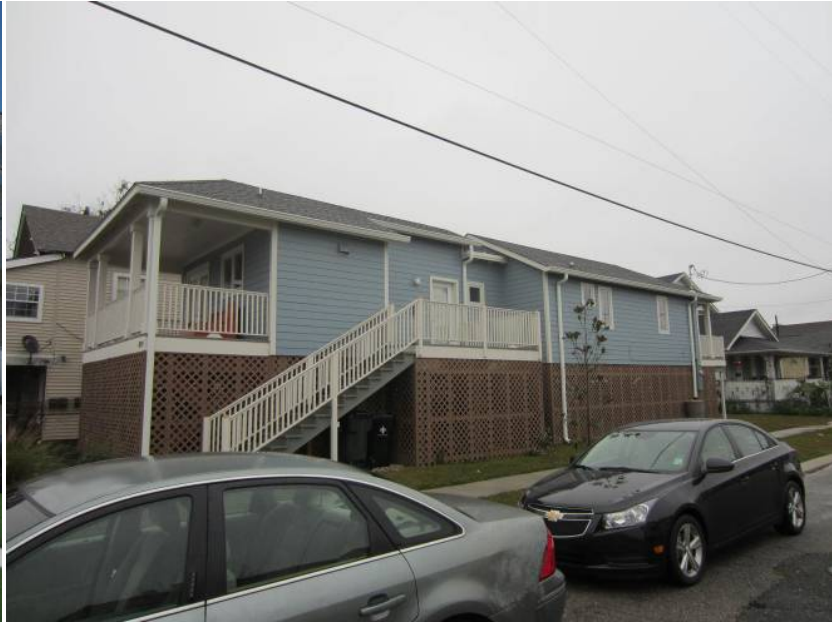

BDC study house

Figure 1. Examples of study house elevations

A more detailed discussion of the HVAC and supplemental dehumidification systems installed at the test homes is provided in Section 2.3.1 as part of a discussion of the commissioning of the study homes.

The first two phases of PHA, constructed in 2008 and 2009, were constructed with a ducted whole-house dehumidifier, the purpose of this being to ensure that indoor humidity levels could be controlled year round and not solely during the cooling season.

As a cost savings measure, PHA decided against the use of supplemental dehumidification in Phases III and beyond. The cost savings allowed the builder to upgrade the equipment from a single-stage compressor 15 SEER unit to a two-stage 15.7 SEER unit, with some additional savings left over to accommodate a reduced budget for the subsequent phases. These PHA phases were constructed with the same floor plans and specifications, save for the dehumidifiers and the two-stage heat pump. This resulted in groups of houses with the same floor plans and specifications save for the exclusion of supplemental dehumidifiers. Consequently, a unique opportunity was presented that allowed for the comparison of HVAC operation and interior conditions between similarly sized homes with and without supplemental dehumidification.

The cooperation between BDC and BSC led to the construction of four homes with standalone dehumidifiers for supplemental humidity control, two of which are included in this study.

Table 1 lists the 10 PHA and BDC houses that are part of the supplemental dehumidification study. The naming convention used for these homes is the acronym of the builder/developer and the house number as it is listed in Table 1. For example, PHA 1 references PHA study house 1.

PHA/BDC initially created a list of candidate addresses, focusing on homes with occupants who they perceived as being interested and willing to be part of the study. Around 20 homes were 
provided to BSC. The two BDC homes are smaller than the PHA houses; however, the specifications and construction quality are comparable.

BSC selected the study houses from the candidate list with a focus both on houses with similar dimensions and characteristics and homes with a similar occupant profile. See Table 1 for details. Pets are included in the occupant list as they contribute both sensible and latent loads to the conditioned space. The selected study houses represent the most consistent group of houses that was possible from the pool of candidates.

BSC composed a letter that explained the purpose of the study and also indicated that the homeowners would be financially compensated for participating in the study. The letter was sent to each address and a follow-up phone call was made to discuss the project with the occupants. All eight PHA homeowners accepted the offer, which was a testament to the effort by the developer in selecting homeowners whom they thought would be willing to partake in a study. The occupants of the two BDC homes that were added in January 2013 also expressed interested and were willing to participate.

Table 2 shows the energy-related characteristics of the three house types in the study. PHA 1-4 are the PHA homes with a ducted dehumidifier. PHA 5-8 are PHA homes that did not have any additional dehumidification equipment installed, and BDC 1 and 2 are homes with a standalone dehumidifier installed in the mechanical closet. 
Table 1. PHA/BDC Test Houses

\begin{tabular}{|c|c|c|c|c|c|c|c|}
\hline $\begin{array}{c}\text { House } \\
\quad \#\end{array}$ & Dehumidifier Type, Location & \# Occupants & Floor Plan & $\begin{array}{c}\text { Floor } \\
\text { area } \\
\left(\mathbf{f t}^{2}\right)\end{array}$ & $\begin{array}{l}\text { Surface } \\
\qquad\left(\mathbf{f t}^{2}\right)\end{array}$ & $\begin{array}{l}\text { Volume } \\
\left(\text { ftt }^{3}\right)\end{array}$ & Beds \\
\hline PHA 1 & Whole house, ducted in unvented attic & 2 adults, 1 child & Gertrude & 1316 & 4429 & 16450 & 3 \\
\hline PHA 2 & Whole house, ducted in unvented attic & 1 or 2 adults & Templeton & 1213 & 3793 & 14928 & 3 \\
\hline PHA 3 & Whole house, ducted in unvented attic & 2 adults, 2 children & Gertrude & 1316 & 4429 & 16450 & 3 \\
\hline PHA 4 & Whole house, ducted in unvented attic & $\begin{array}{c}2 \text { adults, } 2 \text { children, } 1 \\
\text { dog }\end{array}$ & Templeton & 1213 & 3793 & 14928 & 3 \\
\hline PHA 5 & None & 3 adults, 1 child & Alexander & 1316 & 4429 & 16450 & 3 \\
\hline PHA 6 & None & 1 adult, 2 dogs & Alexander & 1316 & 4429 & 16450 & 3 \\
\hline PHA 7 & None & 1 adult, 3 children & Gertrude & 1316 & 4429 & 16450 & 3 \\
\hline PHA 8 & None & 2 adults, 3 dogs & Alexander & 1316 & 4429 & 16450 & 3 \\
\hline BDC 1 & $\begin{array}{l}\text { Stand alone, in mechanical closet } \\
\text { open return }\end{array}$ & 1 adult, 1 dog, 1 cat & Greenboy & 896 & 4829 & 11755 & 2 \\
\hline BDC 2 & $\begin{array}{l}\text { Stand alone, in mechanical closet } \\
\text { open return }\end{array}$ & 1 adult & $\begin{array}{l}\text { The Little } \\
\text { Easy }\end{array}$ & 792 & 4000 & 10027 & 2 \\
\hline
\end{tabular}


Table 2. Study House Energy-Related Characteristics

\begin{tabular}{|c|c|c|c|}
\hline & PHA Homes With Dehumidifier (PHA 1-4) & PHA Homes Without Dehumidifier (PHA 5-8) & BDC Homes With Dehumidifier (BDC 1 and 2) \\
\hline \multicolumn{4}{|c|}{ Building Enclosure } \\
\hline Roof & $\begin{array}{c}\text { R-23 3.5-in. ccSPF at roof deck } \\
\text { unvented cathedralized attic }\end{array}$ & $\begin{array}{c}\text { R-23 3.5-in. ccSPF at roof deck } \\
\text { unvented cathedralized attic }\end{array}$ & $\begin{array}{l}\text { R-30 8.5-in. open cell spray polyurethane foam } \\
\text { (ocSPF) at roof deck unvented cathedralized attic }\end{array}$ \\
\hline Walls & $2 \times 6 @$ 24-in. on center R-20 3-in. ccSPF & 2×6@ 24-in. on center R-20 3-in. ccSPF & 2×6@24-in. on center R-20 5.5-in. ocSPF \\
\hline Frame Floors & R-13 2-in. ccSPF underside of subfloor & R-13 2-in. ccSPF underside of subfloor & R-13 2-in. ccSPF underside of subfloor \\
\hline \multirow[t]{2}{*}{ Windows } & $\begin{array}{c}\text { Double glazed vinyl } \\
(\mathrm{U}=0.35 \text {, solar heat gain coefficient }=0.23)\end{array}$ & $\begin{array}{c}\text { Double glazed vinyl } \\
(\mathrm{U}=0.35 \text {, solar heat gain coefficient }=0.23)\end{array}$ & $\begin{array}{c}\text { Double glazed vinyl } \\
(\mathrm{U}=0.35 \text {, solar heat gain coefficient }=0.22)\end{array}$ \\
\hline & ENERGY STAR certified & ENERGY STAR certified & ENERGY STAR certified \\
\hline Infiltration & $\begin{array}{l}\text { Average } 1.8 \text { in. }^{2} \text { leakage area } \\
\text { per } 100 \mathrm{ft}^{2} \text { envelope tested }\end{array}$ & $\begin{array}{c}\text { Average } 1.8 \text { leakage area } \\
\text { per } 100 \mathrm{ft}^{2} \text { envelope tested }\end{array}$ & $\begin{array}{l}\text { Average } 2.0 \text { in. }^{2} \text { leakage area } \\
\text { per } 100 \mathrm{ft}^{2} \text { envelope tested }\end{array}$ \\
\hline \multicolumn{4}{|c|}{ Mechanical Systems } \\
\hline Heat Pump & $\begin{array}{c}8.0 \text { or } 8.8 \text { heating season performance } \\
\text { factor } / 14 \text { or } 15 \text { SEER } \\
\text { Single-stage air source heat pump }\end{array}$ & $\begin{array}{c}9.0 \text { heating season performance factor } / 15.7 \\
\text { SEER } \\
\text { Two-stage air source heat pump }\end{array}$ & $\begin{array}{l}8.5 \text { heating season performance factor/17.0 SEER } \\
\text { Two-stage air source heat pump }\end{array}$ \\
\hline Air Handler & Variable-speed air handler in unvented attic & Variable-speed air handler in unvented attic & Variable-speed air handler in unvented attic \\
\hline DHW & Electric tank 50 gal energy factor $=0.92$ & Electric tank 50 gal energy factor $=0.92$ & Electric tank 38 gal energy factor $=0.92$ \\
\hline Ducts & $\begin{array}{l}\text { R-6 flex runouts in unvented attic } \\
\text { ducts completely inside conditioned space }\end{array}$ & $\begin{array}{l}\text { R-6 flex runouts in unvented attic } \\
\text { ducts completely inside conditioned space }\end{array}$ & $\begin{array}{l}\text { R-6 flex runouts in unvented attic } \\
\text { ducts completely inside conditioned space }\end{array}$ \\
\hline Dehumidification & $\begin{array}{l}\text { Aprilaire Model } 175090 \text { pint whole-house } \\
\text { unit; supply duct connected to HVAC supply } \\
\text { plenum; EF }=2.2 \mathrm{~L} / \mathrm{kWh}\end{array}$ & 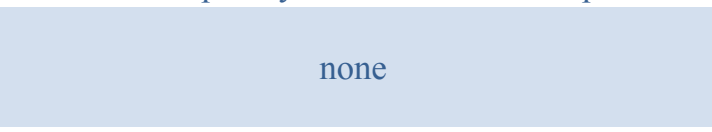 & $\begin{array}{c}\text { Frigidaire FAD301NUD } 30 \text { pint standalone unit } \\
\text { installed at open return in mechanical closet } \\
\text { energy factor }=1.4 \mathrm{~L} / \mathrm{kWh}\end{array}$ \\
\hline Ventilation & $\begin{array}{l}\text { CFIS-only fan cycling } \\
\text { Aprilaire model } 8126 \text { ventilation system } \\
33 \% \text { duty cycle: } 10 \text { min on; } 20 \text { min off } \\
\text { 50 CFM average outside air flow }\end{array}$ & $\begin{array}{c}\text { CFIS-only fan cycling } \\
\text { Aprilaire model } 8126 \text { ventilation system } \\
33 \% \text { duty cycle: } 10 \text { min on; } 20 \text { min off } \\
\text { 50 CFM average outside air flow }\end{array}$ & $\begin{array}{c}\text { CFIS-only fan cycling } \\
\text { Honeywell model Y8150 ventilation system } \\
33 \% \text { duty cycle: } 10 \text { min on; } 20 \text { min off } \\
50 \text { CFM average outside air flow }\end{array}$ \\
\hline \multicolumn{4}{|c|}{ Appliances, Lighting, Miscellaneous Electric Loads } \\
\hline Lighting & $\begin{array}{l}\text { Compact fluorescent lamp lighting package all } \\
\text { screw base }\end{array}$ & $\begin{array}{c}\text { Compact fluorescent lamp lighting package all } \\
\text { screw base }\end{array}$ & $\begin{array}{l}\text { Compact fluorescent lamp lighting package all } \\
\text { screw base }\end{array}$ \\
\hline Appliances & $\begin{array}{l}\text { ENERGY STAR fridge, dishwasher, clothes } \\
\text { washer }\end{array}$ & $\begin{array}{l}\text { ENERGY STAR fridge, dishwasher, clothes } \\
\text { washer }\end{array}$ & $\begin{array}{l}\text { ENERGY STAR fridge, dishwasher, clothes } \\
\text { washer }\end{array}$ \\
\hline
\end{tabular}

\footnotetext{
${ }^{5}$ A less efficient heat pump was installed accidentally at PHA 1. Therefore, the American Heating and Refrigeration Institute rated efficiency for the PHA 1 HVAC system is 8.0 heating season performance factor/13.7 SEER.
} 


\subsection{Cost Effectiveness}

The EnergyPlus version of BEopt ${ }^{\mathrm{TM}}$ version 2.1.0.0.0 (BEoptE+) was utilized to compare the predicted energy savings and cost effectiveness between a home with and without supplemental dehumidification. The EnergyPlus version was chosen, as it offers the option for active dehumidification in the model and thus the predicted performance can be validated with monitored data. The BEopt analysis for this study used an interior humidity set point of $60 \%$ relative humidity $(\mathrm{RH})$ for homes with supplemental dehumidification.

The installed cost of the Aprilaire 1750 dehumidifier is around $\$ 1500$. Around $\$ 500$ of this was invested in the two-stage 15.7 SEER heat pump upgrade when the dehumidifier was dropped from the design (PHA 5-8). This is reflected in the increased annualized energy-related costs (YAxis), which represents the annual net cash flow including loan payments, replacements, and utility bill payments. As a comparison, the installed cost of the Frigidaire FAD301NUD standalone dehumidifier is around $\$ 150$ (BDC 1 and 2).

Figure 2 and Figure 3 show a comparison of the BEoptE+ outputs between the two PHA house types in this study. BEoptE+ is calculating slightly higher energy savings; $18.9 \%$ versus $21.8 \%$ savings compared to the B10 Benchmark (as stipulated in the Building America House Simulation Protocols [Metzger and Hendron 2010]) for the house plan without supplemental dehumidification. This is due to the increased SEER of the heat pump and also the calculated additional energy use by the dehumidifier. As a comparison, a BEoptE + calculation was performed comparing the house with and without dehumidification, without any change in heat pump efficiency. The addition of a supplemental dehumidification to the house results in a reduction in annual source energy savings of around 1\%, and an increase in annual source energy consumption of 1.4 MMBtu/yr.

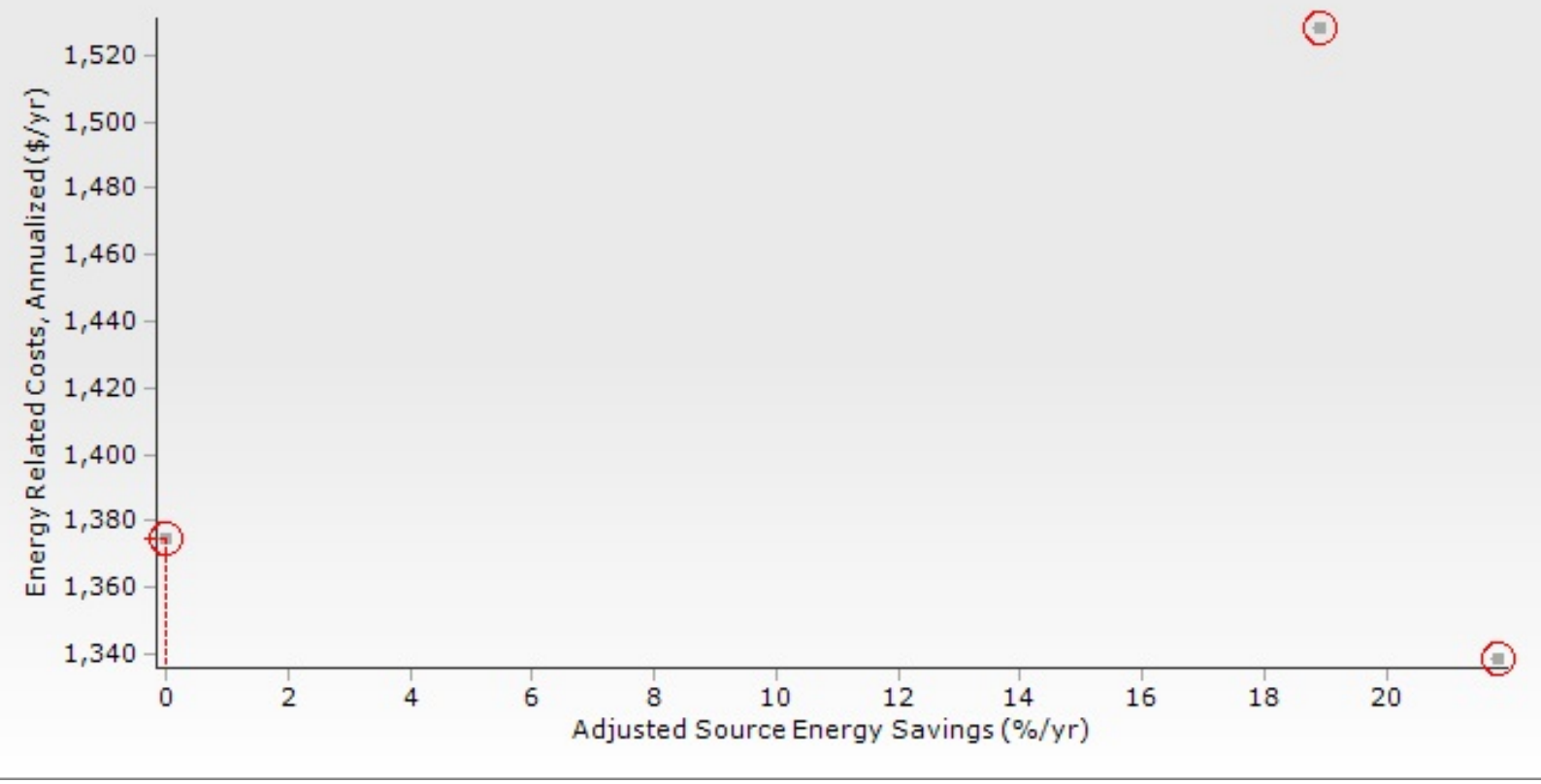

Figure 2. BEopt+ predicted percent source energy savings comparison between PHA homes with and without supplemental dehumidification 


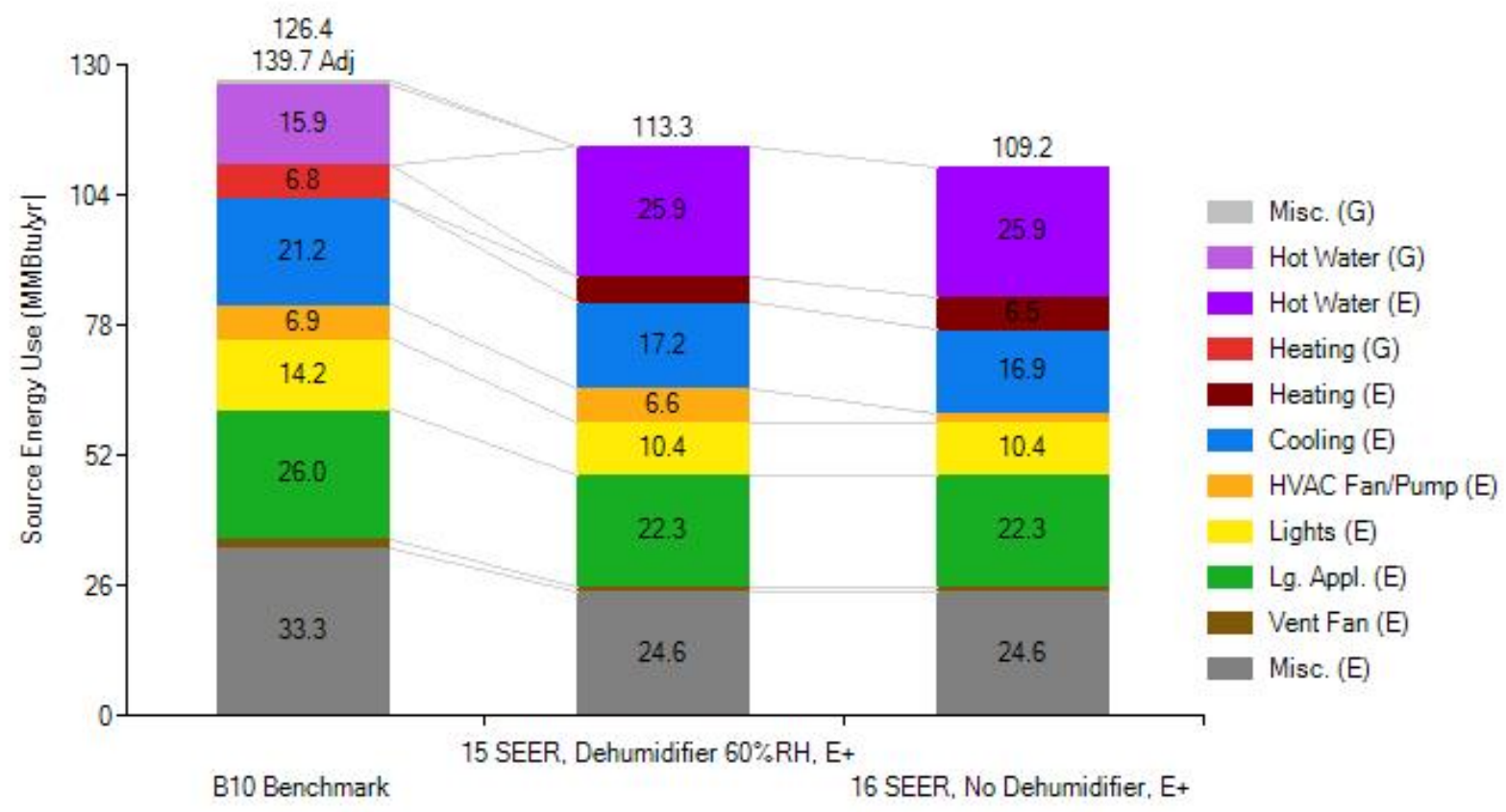

Figure 3. BEopt+ Predicted source energy use for PHA homes

Figure 4 and Figure 5 show the BEopt + predicted source energy savings and predicted site energy use broken down into major components for the BDC homes. BEopt + calculates a $28.8 \%$ annual source energy savings for the BDC houses.

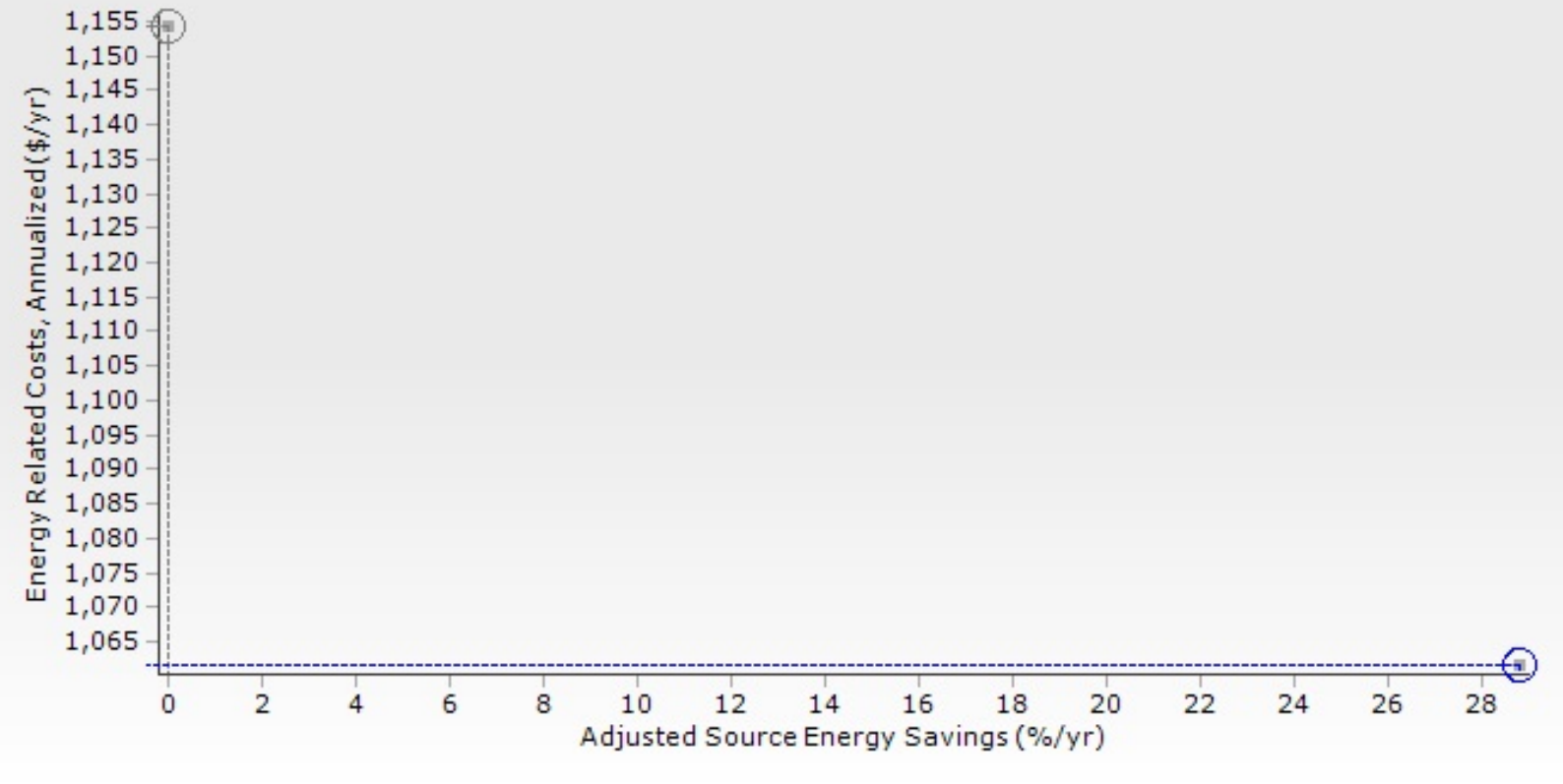

Figure 4. BEopt+ predicted percent source energy savings for the BDC homes with dehumidification 


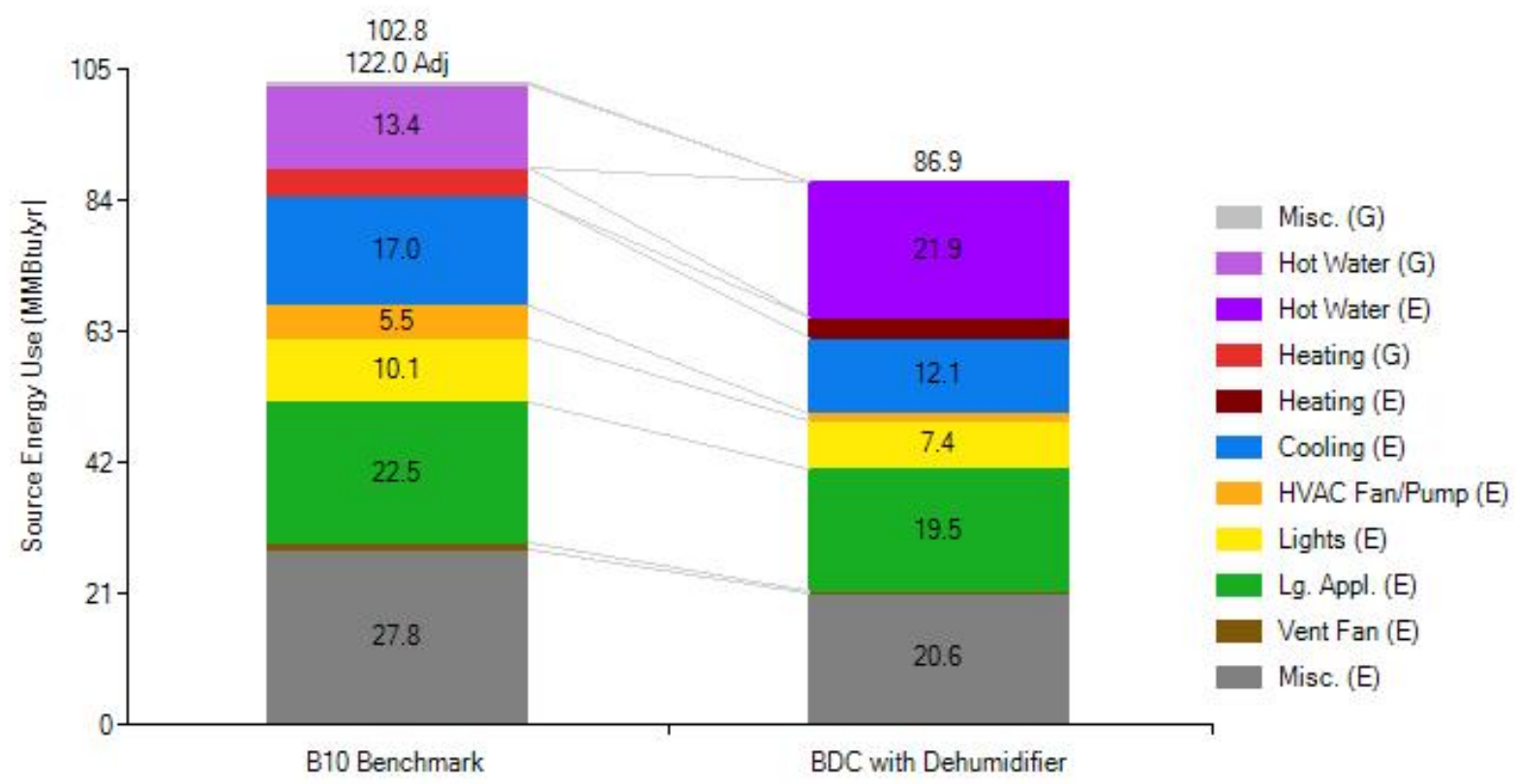

Figure 5. BEopt+ predicted source energy use for BDC homes

BEoptE + was also utilized to predict the interior humidity levels in both types of homes. Table 3 below shows the predicted number of hours that the interior $\mathrm{RH}$ will be above $60 \% \mathrm{RH}, 65 \%$ $\mathrm{RH}$, and $70 \% \mathrm{RH}$ for all three study house types.

Table 3. BEopt+ Predicted Annual Indoor \%RH Bins

\begin{tabular}{c|c|c|c}
\hline House Type & $\begin{array}{c}\text { Hours Above } \\
\mathbf{6 0 \%}\end{array}$ & $\begin{array}{c}\text { Hours Above } \\
\mathbf{6 5 \%}\end{array}$ & $\begin{array}{c}\text { Hours Above } \\
\mathbf{7 0 \%}\end{array}$ \\
\hline PHA With Dehumidifier & 232 & 3 & 0 \\
\hline PHA Without Dehumidifier & 1353 & 494 & 198 \\
BDC With Dehumidifier & 292 & 7 & 0 \\
\hline
\end{tabular}

BEoptE+ is predicting that the $\mathrm{RH}$ in the living space at homes without supplemental dehumidification will be above $60 \% \mathrm{RH}$ for around $14 \%$ of the total hours per year.

\subsection{Dehumidifier Impact on Cooling System}

It is important to understand the potential impact that a supplemental dehumidification can have on cooling operation. A dehumidifier contributes to two different components of energy use: (1) the dehumidifier draws a certain amount of electrical power to operate; and (2) the heat removed in the process of drying the air is not rejected outside the home but rather is rejected into the central supply airstream. Heat from the compressor and fan is rejected to the interior living space as well. The heat pump cooling system must then remove this heat along with the rest of the home's cooling load. It is estimated, based on monitored data in hot humid climates (Rudd et al. 2003; Rudd 2004; Rudd et al. 2005) that whole house dehumidifiers in low-energy, high 
performance, homes will operate around $10 \%$ of the year, or 876 hours, resulting in $727 \mathrm{kWh}$ in annual energy use. The additional cooling operation required to remove the introduced sensible load is estimated to be $249 \mathrm{kWh}$. Therefore, the total estimated electricity use resulting from supplemental dehumidification in low-energy, high performance homes, is $976 \mathrm{kWh} /$ year. Details on how these estimates were calculated are in Table 4. A comparison between the predicted dehumidifier operation and the monitored dehumidifier performance is in Section 3.2.3. 
Table 4. Calculation of Predicted Additional Energy Used by the Aprilaire 1750 Dehumidifier

\begin{tabular}{|c|c|c|}
\hline Variable & Value & Notes \\
\hline Estimate of run hours & 967 & Estimated $10 \%$ of 9,672 hours per year (amount of monitored hours) \\
\hline Electricity draw of unit (W) & 830 & $\begin{array}{l}\text { Calculated from } 115 \mathrm{~V}, 8 \text { Amps, } 0.9 \text { power factor } \\
\text { energy used by fan compressor etc. goes to space }\end{array}$ \\
\hline $\begin{array}{l}\text { Electricity draw of unit (Btu/h). This is } \\
\text { also equal to additional heat going into } \\
\text { the space from the fan and compressor. }\end{array}$ & 2,832 & Multiply electricity draw by $3.412 \mathrm{Btu} / \mathrm{Wh}$ \\
\hline $\begin{array}{l}\text { Heat of removed moisture added to the } \\
\text { space }(\mathrm{Btu} / \mathrm{h})\end{array}$ & 3,129 & $\begin{array}{l}\text { The Association of Home Appliance Manufacturers rated capacity } \\
\text { (at } 80^{\circ} \mathrm{F} \text { and } 60 \% \mathrm{RH} \text { ) is } 90 \text { pints } / \text { day }=3.912 \mathrm{lb} / \mathrm{h} \\
\text { derated by } 20 \% \text { because of lower temperature actual conditions }=3.129 \mathrm{lb} / \mathrm{h} \\
\text { Multiply by } 1000 \mathrm{Btu} / \mathrm{lb} \text { of water to get the heat of space moisture removal }\end{array}$ \\
\hline $\begin{array}{l}\text { Total heat going into the space when } \\
\text { dehumidifier is running }(\mathrm{Btu} / \mathrm{h})\end{array}$ & 5,961 & $\begin{array}{l}\text { Add the electricity draw of the unit to the heat of moisture removed from the } \\
\text { space }\end{array}$ \\
\hline $\begin{array}{l}\text { Amount of power used by cooling system } \\
\text { to remove this heat }(W)\end{array}$ & 284 & $\begin{array}{l}\text { 2-ton } 12 \text { SEER rated heat pump estimated energy efficiency ratio (EER) }=21 \\
\text { during milder conditions when the dehumidifier is expected to be operating, } \\
\text { from product catalog data. } \\
\text { Divide Btu/h by EER } 21 \text { to get Watts } \\
\text { EER is ratio of output cooling in Btu/h over Watts of electricity use }\end{array}$ \\
\hline Yearly energy used for this cooling ( $\mathrm{kWh}$ ) & 275 & $\begin{array}{l}\text { Multiply additional cooling power by the estimated run hours } \\
\text { then convert to } \mathrm{kWh}\end{array}$ \\
\hline $\begin{array}{l}\text { Additional energy used by compressor, } \\
\text { fans }(\mathrm{kW})\end{array}$ & 803 & $\begin{array}{c}\text { Multiply electricity draw of dehumidification unit by the estimated run } \\
\text { hours, then convert to } \mathrm{kWh}\end{array}$ \\
\hline $\begin{array}{l}\text { Total annual electrical energy used by the } \\
\text { dehumidifier and the cooling system to } \\
\text { remove the heat introduced into the space } \\
\text { by the dehumidifier ( } \mathrm{kWh} \text { ) }\end{array}$ & 1,077 & $\begin{array}{l}\text { Add the yearly electricity draw of the dehumidification unit } \\
\text { to the extra electricity used by the heat pump for cooling }\end{array}$ \\
\hline
\end{tabular}


Similarly, the same calculations can be applied to the Frigidaire FAD301NUD stand alone dehumidifier.

Table 5. Calculation of Predicted Additional Energy Used by the Frigidaire FAD301NUD Dehumidifier

\begin{tabular}{|c|c|c|}
\hline Variable & Value & Notes \\
\hline Estimate of run hours & 706 & Estimated $10 \%$ of 7,056 hours per year (amount of monitored hours) \\
\hline Electricity draw of unit (W) & 450 & $\begin{array}{l}\text { From specification sheet } \\
\text { Energy used by fan compressor etc. goes to space }\end{array}$ \\
\hline $\begin{array}{l}\text { Electricity draw of unit }(\mathrm{Btu} / \mathrm{h}) \text { This is } \\
\text { also equal to additional heat going into } \\
\text { the space from the fan and compressor. }\end{array}$ & 1,535 & Multiply electricity draw by 3.412 Btu/Watt-h \\
\hline $\begin{array}{l}\text { Heat of removed moisture added to the } \\
\text { space }(\mathrm{Btu} / \mathrm{h})\end{array}$ & 1,043 & $\begin{array}{l}\text { The Association of Home Appliance Manufacturers rated capacity } \\
\left(\text { at } 80^{\circ} \mathrm{F} \text { and } 60 \% \mathrm{RH}\right) \text { is } 90 \text { pints } / \text { day }=1.304 \mathrm{lb} / \mathrm{h} \\
\text { derated by } 20 \% \text { because of lower temperature actual conditions }=1.043 \mathrm{lb} / \mathrm{h} \text {. } \\
\text { Multiply by } 1000 \mathrm{Btus} / \mathrm{lb} \text { of } \mathrm{H}_{2} \mathrm{O} \text { to get the heat of space moisture removal. }\end{array}$ \\
\hline $\begin{array}{l}\text { Total heat going into the space when } \\
\text { dehumidifier is running }(\text { Btu/h) }\end{array}$ & 2,579 & $\begin{array}{l}\text { Add the electricity draw of the unit to the heat of moisture removed from the } \\
\text { space }\end{array}$ \\
\hline $\begin{array}{l}\text { Amount of power used by cooling system } \\
\text { to remove this heat }(W)\end{array}$ & 123 & $\begin{array}{l}\text { 2-ton } 12 \text { EER rated heat pump estimated EER }=21 \text { during milder conditions } \\
\text { when the dehumidifier is expected to be operating, from product catalog } \\
\text { data. } \\
\text { Divide Btu/h by EER } 21 \text { to get Watts. } \\
\text { EER is ratio of output cooling in Btu/h over Watts of electrical use. }\end{array}$ \\
\hline Yearly energy used for this cooling ( $k W h$ ) & 87 & $\begin{array}{l}\text { Multiply additional cooling power by the estimated run hours } \\
\text { then convert to } \mathrm{kWh}\end{array}$ \\
\hline $\begin{array}{l}\text { Additional energy used by compressor, } \\
\text { fans }(\mathrm{kW})\end{array}$ & 318 & $\begin{array}{l}\text { Multiply electricity draw of dehumidification unit by the estimated run } \\
\text { hours, then convert to } \mathrm{kWh}\end{array}$ \\
\hline $\begin{array}{l}\text { Total annual electrical energy used by the } \\
\text { dehumidifier and the cooling system to } \\
\text { remove the heat introduced into the space } \\
\text { by the dehumidifier ( } \mathrm{kWh} \text { ) }\end{array}$ & 404 & $\begin{array}{l}\text { Add the yearly electricity draw of the dehumidification unit } \\
\text { to the extra electricity used by the heat pump for cooling }\end{array}$ \\
\hline
\end{tabular}




\subsection{Location of Experiment}

The 10 homes in this study are scattered around the Gentilly region of New Orleans, Louisiana. Eight homes were selected with assistance from PHA. Two additional homes were added to the study in January 2013 from BDC and these homes are also located in the immediate vicinity of the PHA study houses.

\subsection{Contact Information}

Table 6 lists the contact information for the project partners.

Table 6. Contact Information

\begin{tabular}{c|l|l|l}
\hline $\begin{array}{c}\text { Company } \\
\text { Name }\end{array}$ & \multicolumn{1}{|c|}{ Team Member } & \multicolumn{1}{c}{ Email } & \multicolumn{1}{c}{ Phone } \\
\hline BSC & Philip Kerrigan Jr., PE & $\underline{\text { phil@buildingscience.com }}$ & (978) 589-5100 \\
BSC & $\begin{array}{l}\text { Betsy Pettit, FAIA } \\
\text { betsy@buildingscience.com }\end{array}$ & (978) 589-5100 \\
BSC & $\begin{array}{l}\text { Joseph Lstiburek, Ph.D., } \\
\text { P.Eng. }\end{array}$ & joe@buildingscience.com & $(978) 589-5100$ \\
$\begin{array}{c}\text { Mountain } \\
\text { Energy } \\
\text { Partnership } \\
\text { (MEP) }\end{array}$ & Paul Norton & paul@paulnorton.net & \\
$\begin{array}{c}\text { PHA } \\
\begin{array}{c}\text { Green Coast } \\
\text { Enterprises }\end{array}\end{array}$ & Oji Alexander & oalexander@projecthomeagain.net & (504) 529-3522 \\
BDC & Santiago Burgos & $\underline{\text { reuben@greencoastenterprises.com }}$ & (504) 281-4372 \\
\hline
\end{tabular}




\section{Experiment}

\subsection{Research Questions}

BSC sought to address the following research questions through this research project:

- Quantify whether, and the extent to which, indoor humidity levels are elevated in homes without supplemental dehumidification compared to homes with supplemental dehumidification?

- How much variability in interior \%RH is observed from house to house? Is variability correlated with hot water use, clothes dryer operation, or cooking activities? Are there other explanations for variation in \% $\mathrm{RH}$ ?

- How much and when is supplemental dehumidification needed to control indoor RH to about $55 \%$, but less than $60 \%$, in these homes throughout the year?

- What metric is most appropriate for evaluating the extent of humidity problems and the success of supplemental humidity control?

\subsection{Communication With Homeowners}

BSC, along with assistance from Joe Ryan, the local subcontractor who is a part of the research team, maintained correspondence with the homeowners throughout the study. BSC conducted interviews with the occupants of each house at the beginning of the study. The purpose of these interviews was to gather information on occupant behavior, especially particular facets of operation that were difficult, or not possible, to measure with the monitoring equipment package that was employed. All homeowners were informed that they were under no obligation to share information on their behavior if they were not comfortable. Each homeowner was also assured during the interview, as was also stated in the initial introductory letter, that no personal information would be included in the data or any report. The occupants were also informed that the reimbursement would be provided to them in the form of a check when the equipment was removed at the end of the study. All homeowners were comfortable with the interviews and expressed interest in the study and gratitude for the reimbursement. The interviews yielded information on basic occupancy behavior, such as the number of occupants, their hours of occupancy, basic information on cooking habits, whether the point source exhaust fans are used and how often, whether windows are opened on occasion and how often, what set points they prefer, etc. Information that was acquired through interviews and proved to be helpful in interpreting the data is discussed in Section 3.

BSC sought to maintain communication with the homeowners throughout the study period. For example, BSC conducted phone calls to remind homeowners to replace the air handler filter every 3 months. However, establishing contact with the homeowners via telephone proved difficult throughout the study. Phone calls were seldom answered and rarely returned; therefore, the majority of correspondence was conducted through voicemail messages. Joe Ryan conducted site visits as needed to address problems with the equipment or to address any concerns that were brought up by the homeowners. Mr. Ryan eventually became the primary liaison between the homeowners and the research team. 
The homeowners were informed that there are no limiting parameters with respect to the thermostat set points. Occupants were instructed to operate the HVAC system as they normally would. BSC did request, with the understanding that there was no obligation on behalf of the homeowners, that the dehumidifier settings not be changed during the study. However, the monitored data, and interviews with the occupants, showed that the dehumidifier settings were altered in two of the PHA homes during the study. This is examined in more detail in the analysis section of the report. BSC considered requesting that the dehumidifier settings be restored to the original set point; however, the National Renewable Energy Laboratory (NREL) advised against this due to the laboratory's policy on human subjects research (HSR). NREL conveyed to BSC that the overall study could be classified as HSR, according to Title 24 of the Code of Federal Regulations, Part 46 (45CFR 46) (HHS 2009). The purpose of this regulation is to protect human test subjects in research. Instructing a homeowner to adjust the dehumidifier settings may be interpreted as a violation of this regulation, thus requiring federal oversight and a regimented application procedure. Therefore BSC did not intervene with respect to the configuration of the dehumidifiers.

\subsection{Initial Repair and Commissioning of Existing Mechanical Systems}

Some HVAC repair work and commissioning were required at each house to prepare for the study. The intent of this work was to ensure that the HVAC systems at all homes were operating consistently, especially the CFIS ventilation systems.

\subsubsection{Installed HVAC Systems}

There are some differences with respect to the configuration and installation of the HVAC system at each of the three house types.

Ventilation Note: All homes in the study must comply with ASHRAE Standard 62.2, which mandates that these homes should have the capacity to ventilate continuously 30-40 CFM of outside air for the homes in this study (ASHRAE 2010). The standard was changed in 2013, thus increasing outside air ventilation rates to 45-70 CFM for the study houses. BSC advocates against ventilating low-energy, high performance, homes at the rate stipulated by ASHRAE Standard 62.2 with a CFIS ventilation system. A CFIS ventilation system is more effective than the traditional exhaust only design (Rudd and Bergey 2013; Rudd 2013b). The longstanding ventilation specification for CFIS systems that has been implemented in thousands of homes across the country has been to set the outside airflow to 50 CFM during high speed cooling, and to configure the fan cycling controls to operate for 10 minutes out of every half hour. This was the original recommended specification for the PHA and BDC homes and the homes were checked to ensure all were operating as such.

\subsubsection{Project Home Again Houses 1-4}

The HVAC systems for the PHA houses with dehumidifiers are located completely in the unvented cathedralized attic. An Aprilaire model 1750 ducted whole-house dehumidifier is installed such that the output of the dehumidifier is connected to the supply plenum of the HVAC system. The dehumidifier draws intake air from the main living space through a ceiling-mounted return grille. The dehumidifier has a dedicated condensate drain. A dehumidistat is located adjacent to the thermostat in the main living space. The dehumidistat displays the current $\% \mathrm{RH}$ and the controls offer seven humidity set points. 
An insulated 6-in. outside air duct is connected to the return plenum of the HVAC system, and is routed to the outside through a gable wall or through an exterior wall via a dropped soffit. An inline damper box with filter and manual damper (used to adjust flow in the outside air duct) is present in the outside air duct.

An Aprilaire VCS 8126 ventilation control system is installed as a fan cycler along with an electrically operated motorized damper on the outside air duct. The fan cycler is configured to operate on a $10 \mathrm{~min}$ on/20 min off duty cycle (33\%). The ventilation dial control is located on the return plenum. See Figure 6 for a mechanical schematic. An ASHRAE Standard 62.2compliant bath fan was also installed to provide the capability to ventilate the space at the 2010 ASHRAE 62.2 levels (36-43 CFM for PHA 1-8), should the homeowner elect to operate it as such.

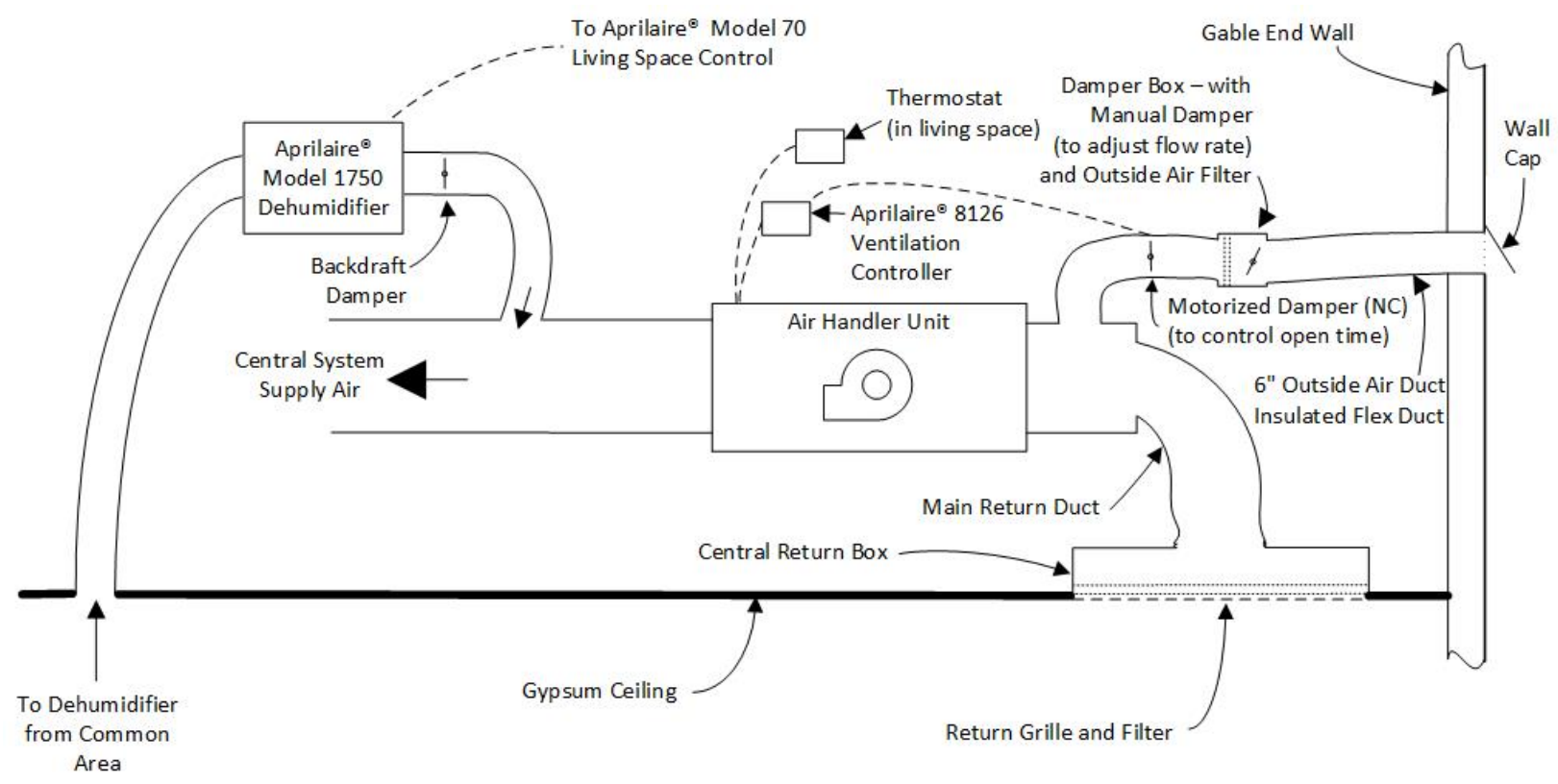

Figure 6. HVAC system schematic for PHA homes with ducted dehumidifier

\subsubsection{Project Home Again Houses 5-8}

These are PHA homes without dehumidifiers. The HVAC system is configured the same as PHA $1-4$, but without the ducted whole-house dehumidifier. See Figure 7. 


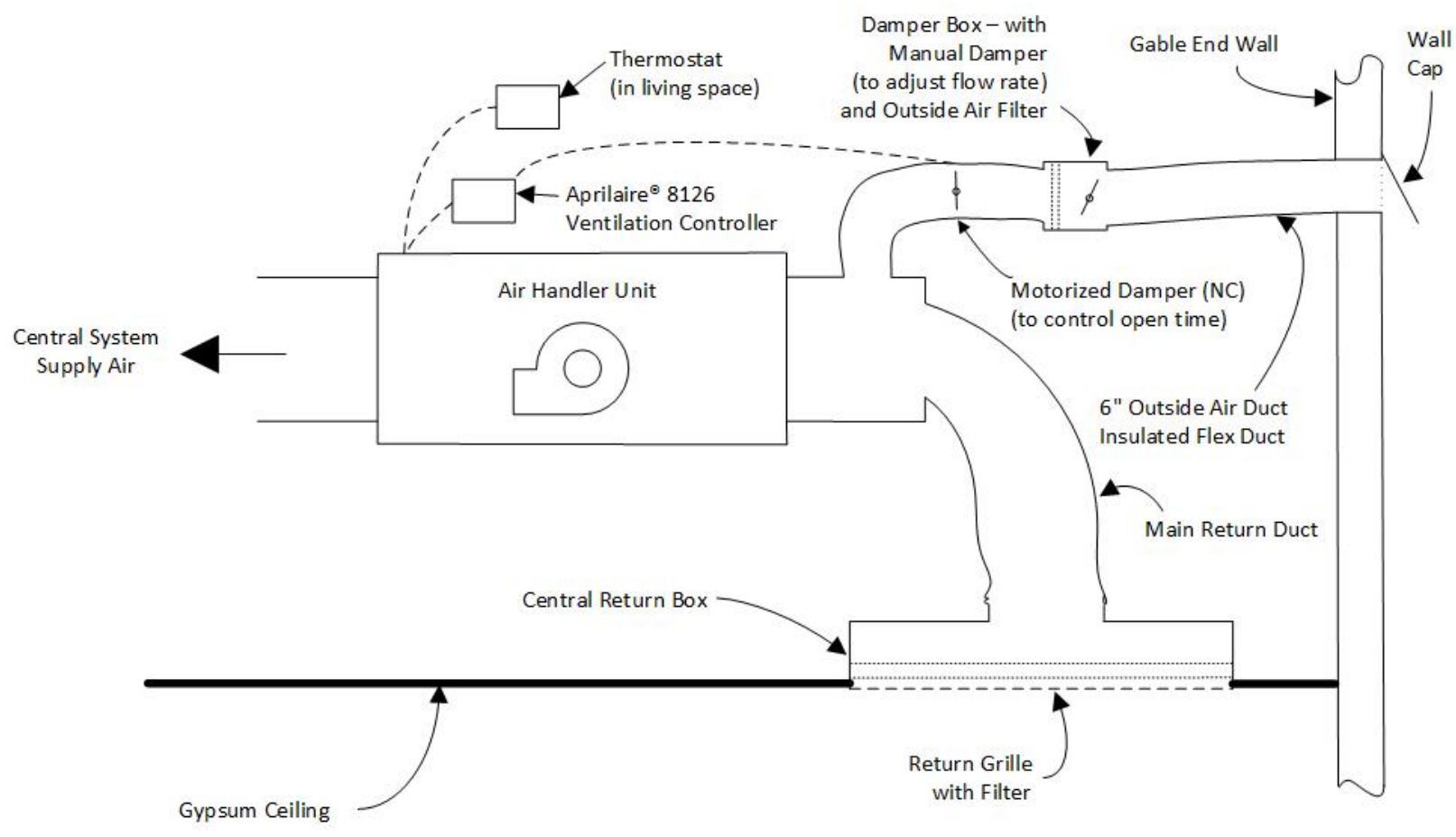

Figure 7. HVAC system schematic for PHA homes with ducted dehumidifier

\subsubsection{Broadmoor Development Corporation Houses 1 and 2}

BDC houses utilize different floor plans, which are about $30 \%-40 \%$ smaller than the PHA study houses. The mechanical system for each home is located in a mechanical closet in the main living space. The ductwork is located completely in the unvented cathedralized attic. It was observed during the installation of the data logging equipment that the air handler was oversized compared to the heat pump in both homes. A 3-ton air handler, with a nominally delivered CFM of 1200 CFM was installed with a 2-ton heat pump. BSC was able to adjust the air handler dipswitch settings to the lowest flow; however, the resulting flow settings were still elevated compared to the PHA homes (heating flow of 1010 CFM and cooling flow of 900 CFM or 450 $\mathrm{CFM} /$ ton versus 350 cooling CFM/ton at the PHA homes).

A Frigidaire FAD301NUD standalone dehumidifier is located in the open return plenum of the HVAC system, with a dedicated condensate drain. This dehumidifier is operated by the onboard controls only, a turn dial, and does not have a humidity display.

An insulated 6-in. outside air duct is connected to the open return plenum of the HVAC system, and is routed through the floor and terminates under the exposed floor in the crawlspace. An inline damper box with filter and manual damper is present in the outside air duct and is located in the open return plenum.

A Honeywell Y8150 Fresh Air Ventilation System is installed as a fan cycler along with an electrically operated motorized damper on the outside air duct. The fan cycler is configured to operate on a $10 \mathrm{~min}$ on/20 min off duty cycle (33\%). The ventilation dial control is located on the return plenum. See Figure 8 for a mechanical schematic. An ASHRAE Standard 62.2- 
compliant bath fan was also installed to provide the capability to ventilate the space at the 2010 ASHRAE 62.2 rate (30-32 CFM at BDC 1 and 2), should the homeowner elect to operate it as such.

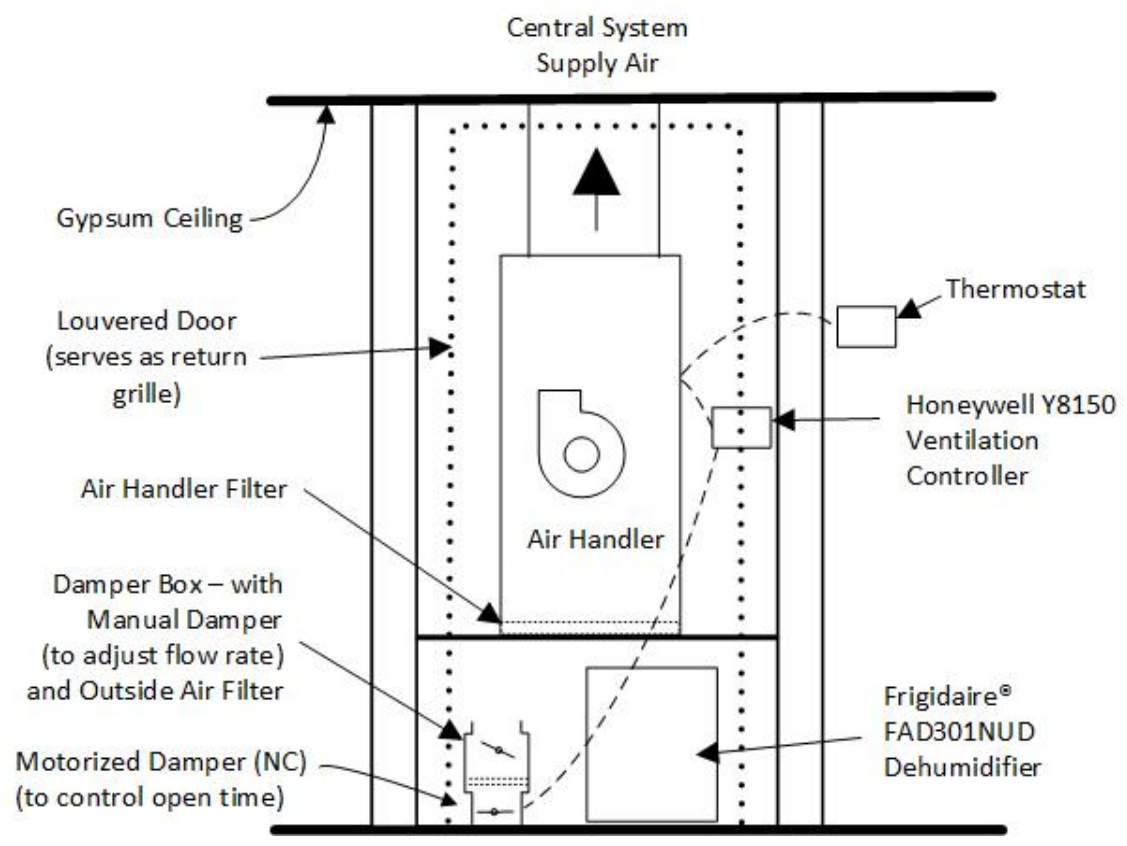

Figure 8: HVAC system schematic for BDC homes with standalone dehumidifier

Figure 9 through Figure 13 show photos of the installed HVAC systems and ventilation controls for each of the three study house types.

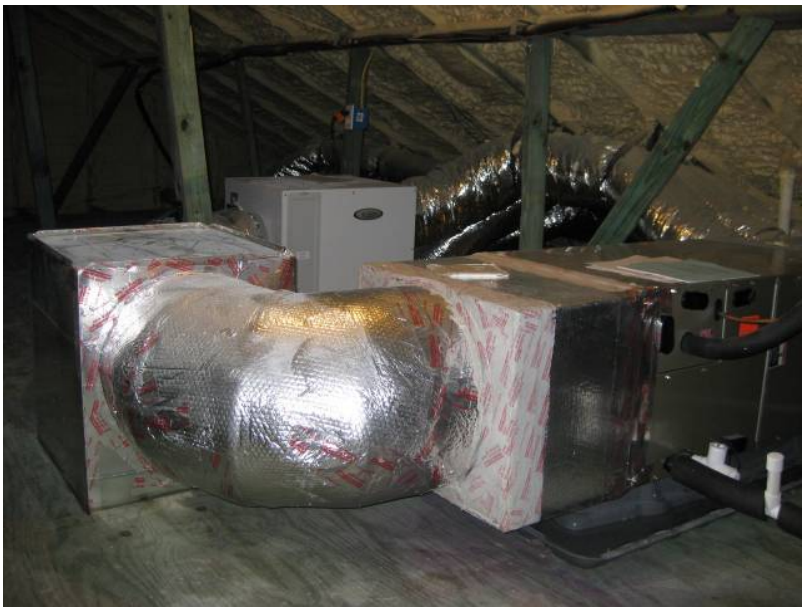

HVAC system and dehumidifier located in unvented cathedralized attic

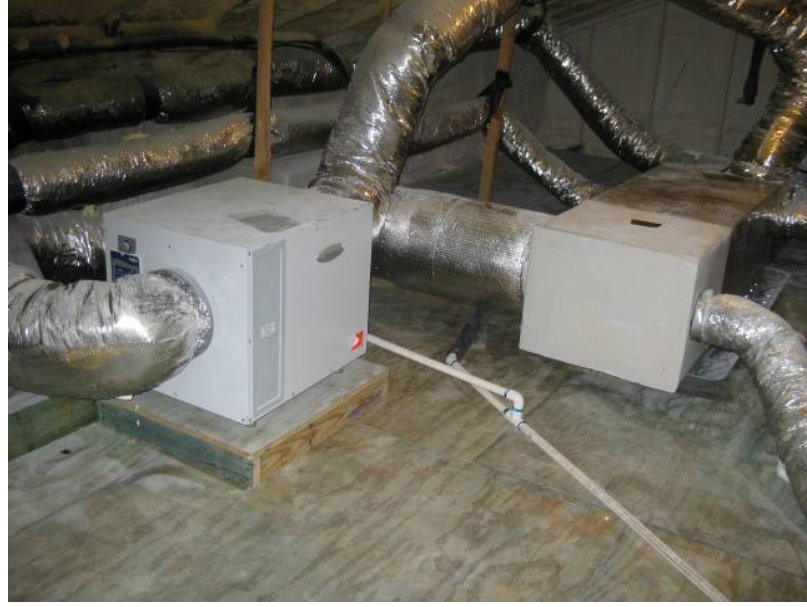

Another photograph, showing condensate line from dehumidifier

Figure 9. Example photographs of the HVAC system at a PHA house with dehumidifier 


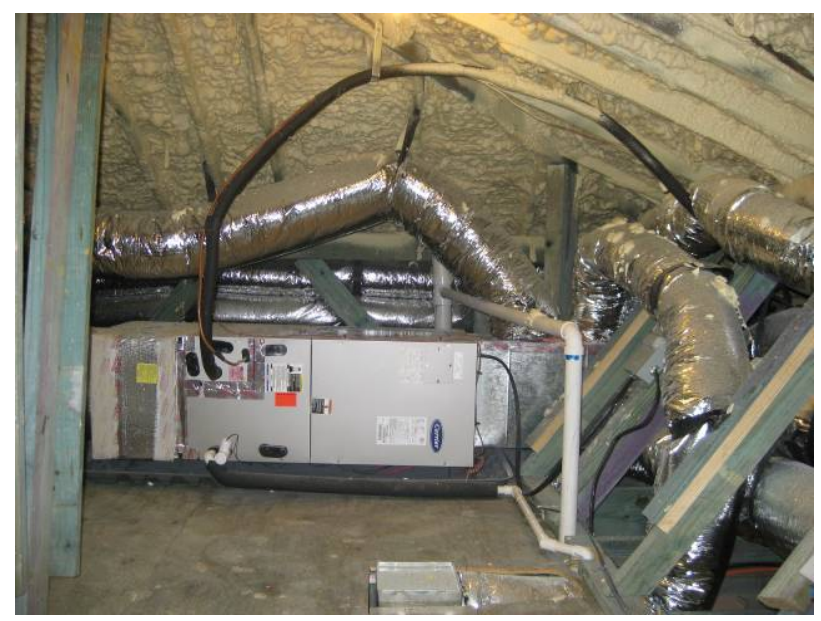

HVAC system located in unvented cathedralized attic

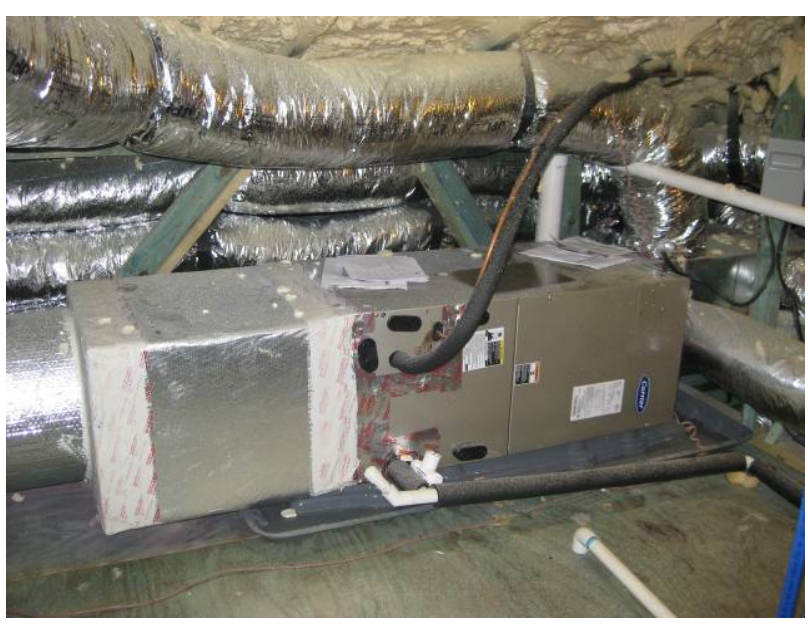

Closer photograph of horizontally oriented air handler

Figure 10. Example photographs of the HVAC system at a PHA house without dehumidifier

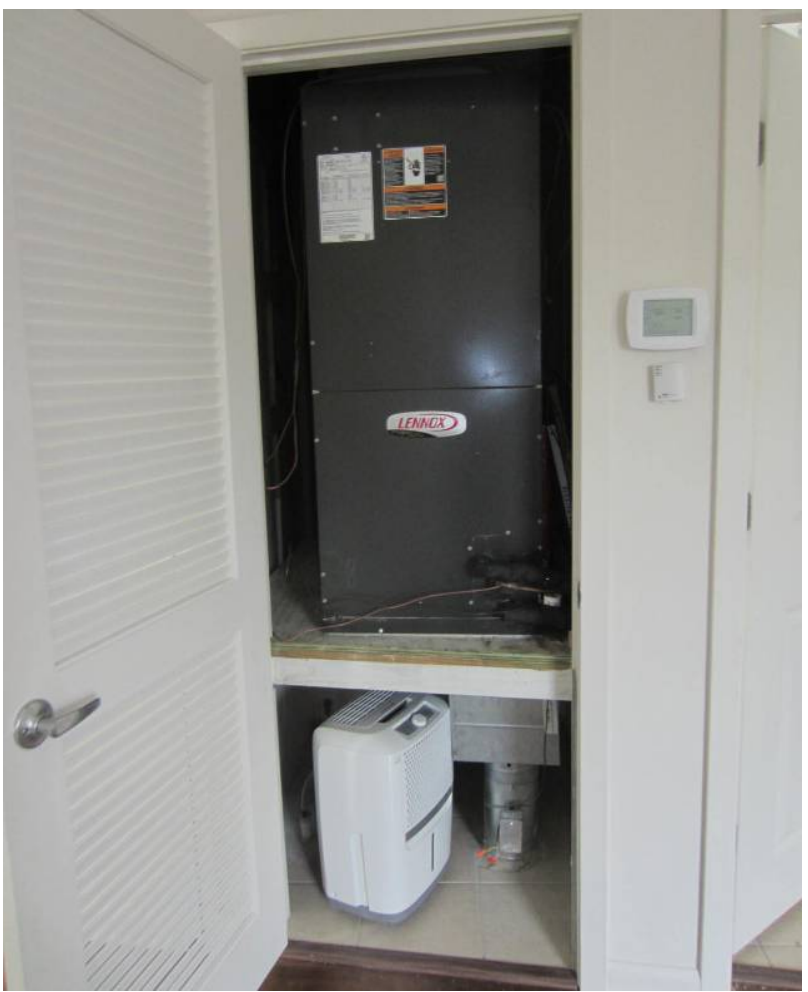

HVAC system located in a mechanical closet in the main living space. Note louvered door for return airflow.

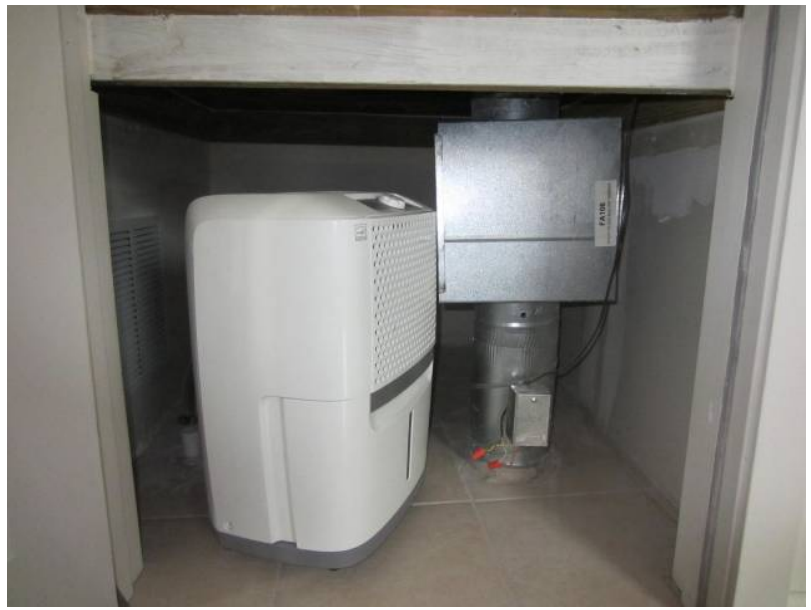

Close-up of open return with standalone dehumidifier and outside air duct. Note the filter/manual damper box and the motorized damper underneath.

Figure 11. Example photographs of the HVAC system at a BDC house with dehumidifier 


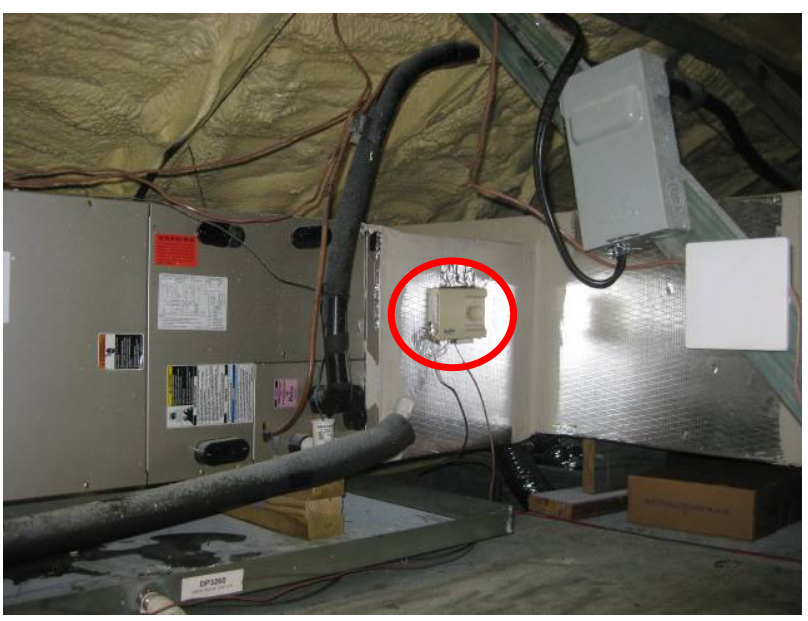

PHA houses: Aprilaire 8120 ventilation control installed on the return plenum

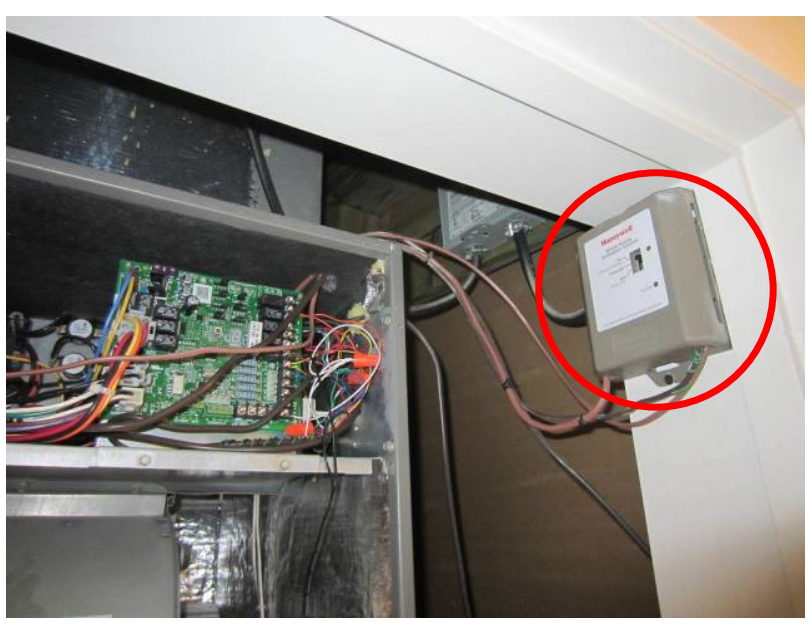

BDC houses: Honeywell W8150 ventilation control installed on the inside of the door

Figure 12. Example photographs of the fan cycler control location (circled in red)

\subsubsection{HVAC Commissioning}

BSC performed a number of HVAC related commissioning operations. The objective of this work was to ensure that all 10 HVAC systems were operating as similarly to each other as possible, so as to minimize the impact each system on the performance of the houses.

\subsubsection{Air Handler Flow Configuration}

It was observed that some of the HVAC equipment was not calibrated exactly to the preferred settings. BSC modified the following air handler settings to improve the performance of the HVAC systems.

\subsection{Cubic Feet per Minute per Ton}

The cooling CFM was reduced from 400 to $350 \mathrm{CFM} /$ ton. This increases humidity removal during cooling operation.

\subsection{Air Handler On/Off Delay}

The air handler on/off delay was changed from the standard 90 seconds to 0 seconds. This function is typically enabled in air handlers in order to allow the air handler to operate after the outdoor unit has turned off to capture any remaining heat as the evaporator coils warms. However, a major drawback to this operation is that condensation on the coil begins to evaporate as the coil temperature rises, thus reintroducing moisture back into the living space. BSC strongly recommends against an air handler delay in hot-humid climates.

\subsection{Fan Only Speed}

The fan-only speed was increased from "low" to "medium." Air handlers are typically shipped from the factory with the fan-only speed set to low. However, with CFIS ventilation, the fan only speed is, when there isn't a call for cooling or heating, to draw outside air and mix the interior air. Therefore, fan-only operation is a critical component of the overall whole-house ventilation 
strategy. The fan-only speed was increased to "medium" such that the outside air rate and distribution can be more consistent with ventilation that occurs during a cooling or heating cycle.

Note: Ideally, the fan only speed would be set to "high" speed. Then an equal amount of fresh air would be introduced to living space at a consistent rate in all three operating modes: cooling, heating and ventilation. However, the fan speed cannot be set to high when the air handler is paired with a two-stage heat pump (as was installed at PHA 5-8 and BDC 1 and 2). Technical support staff from the air handler manufacturer stated that setting the Fan Only speed to high would result in problems with low stage heat pump operation. Therefore, the fan speed was set to "medium" in all the air handlers in order to maintain consistent performance.

The dipswitch adjustments represented a modification that should have enhanced humidity control in the homes without supplemental dehumidification. These settings are typical BSC recommendations for an HVAC system in a hot-humid climate zone.

\subsubsection{Register and Exhaust Airflow}

In addition to equalizing the operational parameters of the HVAC systems, the following commissioning tasks were performed:

1. Outside airflow was measured and adjusted to 50 CFM in high speed cooling mode.

2. Airflow was measured at each register in cooling, heating and fan only (fan cycling) mode.

3. Bath exhaust fan airflow was measured CFM. Airflow from the bath fan that was upgraded to meet the ASHRAE 62.2 ventilation standard was also measured to ensure that the actual exhaust rate exceeded the 2010 ASHRAE 62.2 rate.

4. Kitchen range hood airflow was measured; however, some homes utilize a combination microwave hood rather than a separate oven/range hood. BSC was not able to measure the airflow through the microwave hood.

Airflow was measured with an Alnor LoFlo Balometer capture hood model 6200, from FLW, Inc.

\subsubsection{Air Handler Filter}

The HVAC systems at all 10 study houses were installed with a single central return. The return at the ceiling and it is centrally located in the main hallway. A 1-in. pleated air handler filter is installed at the central return box at the ceiling of the main space.

New air handler filters, ASHRAE Standard 52.2 rated minimum efficiency performance value 11 (ASHRAE 2012), were provided to the occupants of each house, in the interest of maintaining consistent performance between all HVAC systems in the study. BSC installed the first filter before commissioning the HVAC system, and requested that the occupants replace the filter every 3 months, and to only install the filters that were provided to them throughout the study. 


\subsubsection{Dehumidifier Configuration}

\subsection{Project Home Again Study Houses 1-4}

The wall-mounted dehumidistat, installed adjacent to the thermostat, offers seven humidity settings, represented by bars on the liquid crystal display (higher number of bars representing lower humidity set points). Each of the four dehumidistats was originally set to two bars, which corresponds to a dew point temperature (DP) of $60^{\circ} \mathrm{F}$ (the Aprilaire Model 70 dehumidistat measures DP, not \%RH). This set point is roughly equivalent to $61 \% \mathrm{RH}$ at an internal dry bulb temperature of $75^{\circ} \mathrm{F}$. Due to concerns of excessive dehumidifier runtime, from the builder, this set point was selected to attempt to minimize dehumidifier runtime while still controlling the $\% \mathrm{RH}$ to around $60 \% \mathrm{RH}$. Three bars represents a $56^{\circ} \mathrm{F}$ DP setting, resulting in an RH set point of around $53 \%$ at $75^{\circ} \mathrm{F}$ indoor dry bulb. Initial interviews with the homeowners indicated that most kept the cooling set point in the $73^{\circ} \mathrm{F}$ to $75^{\circ} \mathrm{F}$ range.

\subsection{Broadmoor Development Corporation Study Houses 1 and 2}

There is no remote dehumidistat at the BDC houses, as previously stated. Rather, humidity sensing and set point configuration are set using the onboard controls. The Frigidaire FAD301NUD 30-pint standalone dehumidifier utilizes a potentiometer dial knob for configuration the humidity set point, with no labels on humidity set point other than "off" and "continuous." The unit senses \%RH, compared to the ducted dehumidifiers that sense DP. The dehumidifier does not have a humidity display; only the dial setting can be configured. The team had to choose a dial location that best represented a \%RH set point of $60 \% \mathrm{RH}$. The dial was set to around $60 \%$ of the lowest humidity setting (or continuous operation). This setting was agreed upon by the team after analyzing interior conditions in the house from the previous day, by accessing the downloaded data from the monitoring devices.

Figure 13 shows example photographs of the dehumidifier controls.

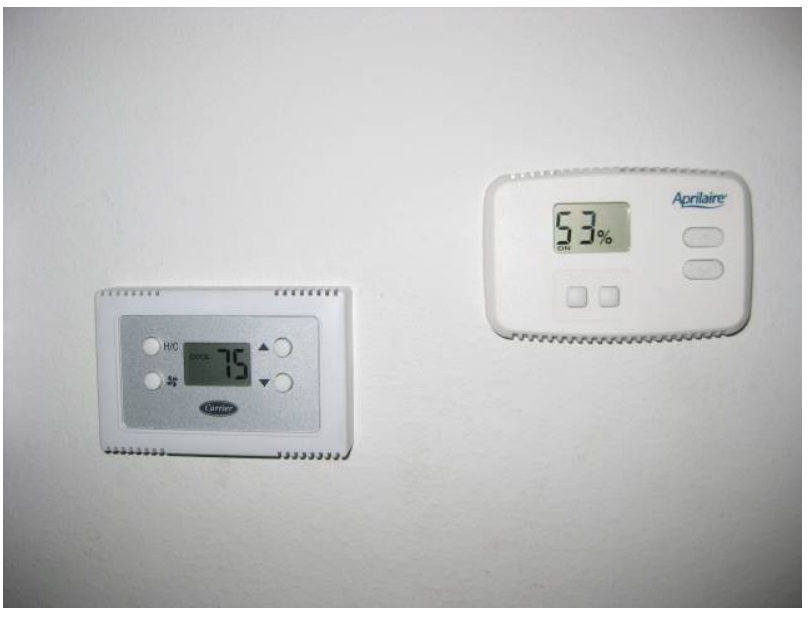

PHA houses: Aprilaire model 70 dehumidistat installed adjacent to the thermostat in the main living area

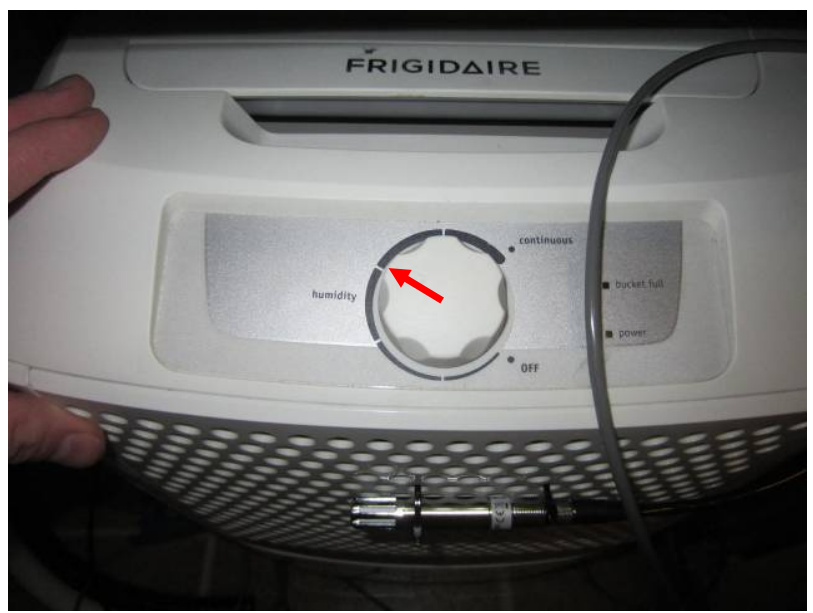

BDC houses: Dial on dehumidifier set to around $60 \%$ of lowest humidity setting, or 10 o'clock (red arrow indicates approximate setting)

Figure 13. Example photographs of the dehumidifier controls 


\subsection{Technical Approach and Measurements}

An extensive system of monitoring equipment was installed at all 10 homes to track both the performance of the major systems and the interior conditions in each residence. The equipment was supplied and installed by NREL through direct collaboration with BSC.

A multipurpose monitoring and control data logger (model CR1000X, from Campbell Scientific) was installed in the unvented cathedralized attic at each house. The data logger was situated in a weather-tight enclosure in the unvented attic (Figure 14). A cellular modem (model AirLink Raven XTV, from Sierra Wireless) was installed at in the attic at each home to allow for remote communication with the data logger.

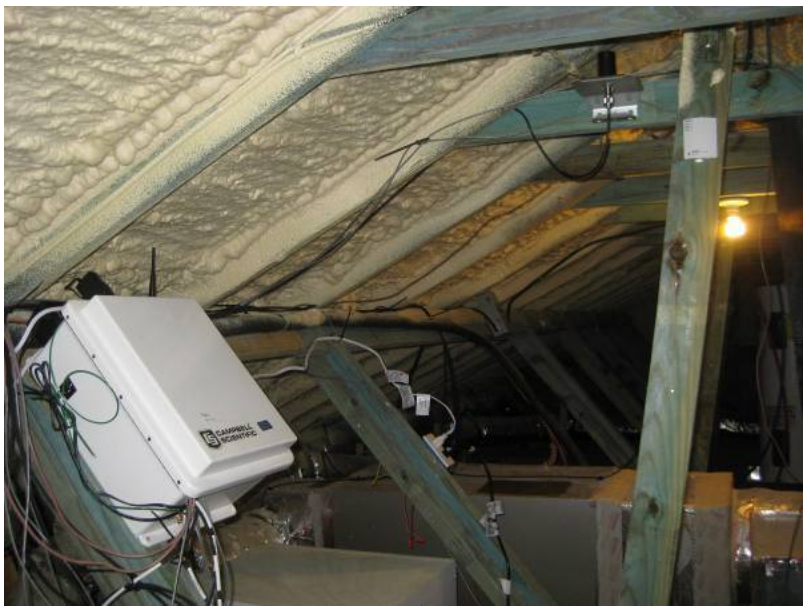

Weather-tight enclosure fastened to roof truss

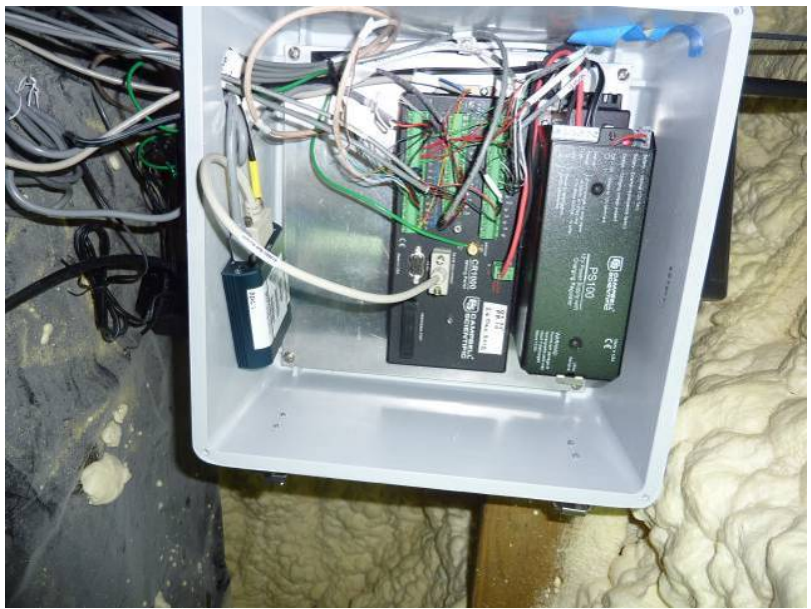

Close-up of CR1000X data logger in enclosure

Figure 14. Data monitoring equipment installed in unvented cathedralized attic

\subsubsection{Monitored Electricity End Uses}

Watt meters (WattNode Pulse model WNB-Y-208-P, from Continental Control Systems LLC) were installed at each home to measure electricity use at various end use loads. Energy consumption was measured for the whole house and for the following end uses:

\subsubsection{HVAC Systems}

- Heat pump outdoor unit

- Heat pump indoor unit (air handler fan motor)

- Supplemental dehumidifier.

\subsubsection{Other House Loads}

- Whole-house electricity consumption

- Water heater

- Clothes dryer

- Cooking range. 


\subsubsection{Current Measurements}

In addition to the energy consumption measurements listed above, there were three current measurements installed using current transducers (model SC100, from Neilson-Kuljian) as shown in Figure 15. These current measurements were used to indicate the fraction of time the device is open or on rather than the energy consumed. The three devices with current monitoring are listed below.

- Outside air damper (to ascertain open/closed status)

- Master bathroom exhaust fan motor

- Hall bathroom exhaust fan motor.

\subsubsection{Monitored Interior and Exterior Conditions}

Wired temperature/relative humidity (T\&RH) probes (model HMP50, from Vaisala) were installed in the following locations in the mechanical systems:

- Supply airstream of the heat pump air handler

- Return airstream of the heat pump air handler

- Airstream into the ducted (PHA) or standalone (BDC) dehumidifier

- Airstream out of the ducted (PHA) or standalone (BDC) dehumidifier.

See Figure 15 for an image of an example installation of the wired T\&RH sensors.

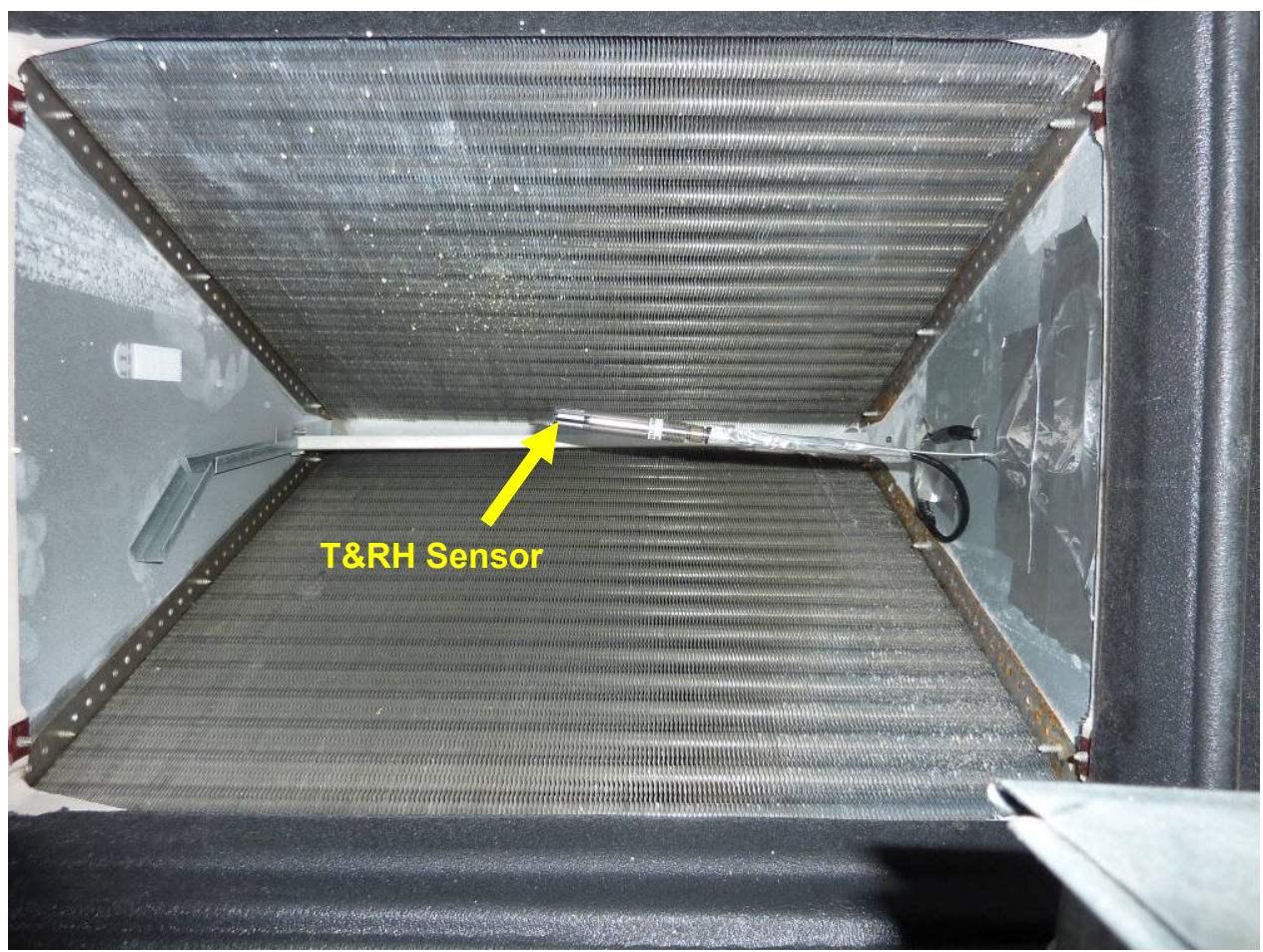

Figure 15. Wired T\&RH sensor installed in the return airstream of the heat pump air handler 
Wireless remote T\&RH sensors (model 3009-02-V4, from Point Six Wireless) were wall mounted in four locations in the house.

- Thermostat

- Master bedroom

- Secondary bedroom

- Unvented cathedralized attic (in the PHA homes only).

The wireless remote sensors were programmed to transmit measurements every 5 minutes to the data logger. The data logger then averaged the measurements every 15 minutes and every hour as well as once a day. An example of an installed wireless T\&RH sensor is shown in Figure 16.

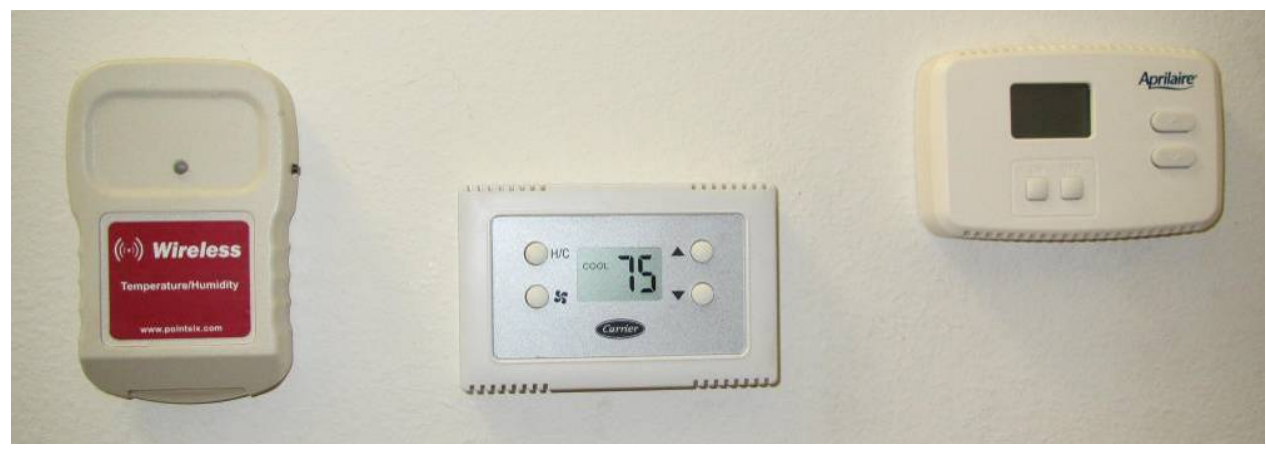

Figure 16. Wireless T\&RH sensor wall mounted near the thermostat and Aprilaire model 70 dehumidistat

\subsubsection{Equipment List}

A summary of the total data logging equipment package installed in these homes is listed in Table 7.

Table 7. Installed Data Logging Equipment

\begin{tabular}{c|c|c|c}
\hline Measurement & Component & Make & Model \\
\hline Electric Energy & Watt meter & $\begin{array}{c}\text { Continental Control } \\
\text { Systems LLC }\end{array}$ & $\begin{array}{c}\text { WattNode Pulse - } \\
\text { WNB-Y-208-P with high } \\
\text { frequency output }\end{array}$ \\
\hline Electric Current & $\begin{array}{c}\text { Current } \\
\text { Transformer } \\
\text { Wired T\&RH } \\
\text { sensor }\end{array}$ & Neilson-Kuljian & SENTRY Series SC100 \\
\hline Space T\&RH & $\begin{array}{c}\text { Wireless T\&RH } \\
\text { sensor }\end{array}$ & Point Six Wireless & HMP50 T\&RH Probe \\
\hline Data Collection & $\begin{array}{c}\text { Data logger } \\
\text { Cell modem }\end{array}$ & $\begin{array}{c}\text { Campbell Scientific } \\
\text { Sierra Wireless }\end{array}$ & 3009-02-V4 \\
\hline Communications & AirLink Raven XTV \\
\hline
\end{tabular}




\subsubsection{Outdoor Weather Data}

The team elected to use data from a local active weather station that was installed by the same NREL/MEP team a few years ago for another house monitoring project. This weather station was still operating and logging data in the same format and manner that would have been compatible with the data logging needs for this project. However, over the course of the study, it was determined that the RH sensor was malfunctioning. Specifically, it was measuring elevated $\% \mathrm{RH}$ readings during high $\% \mathrm{RH}$ events. The team suspects that the sensor may have been damaged during one of the many storms and hurricanes that occurred over the past few years. The team did install two of the wireless T\&RH sensors (model 3009-02-V4, from Point Six Wireless) under the pier foundation, with the hope of acquiring some direct monitored data on the outdoor conditions. However, the measurements from the wireless sensors also appeared to be incorrect. Whether this was due to the location of the sensors in a crawlspace/under pier foundation or whether the fact that the data logger was installed in an outside environment for which it was not designed, these data were abandoned as well. Also, these sensors were only installed in January 2013; therefore, the dataset would have been incomplete. Ultimately, BSC elected to use measured data from the closest National Oceanic and Atmospheric Administration weather station, KMSY (New Orleans International Airport). Hourly dry bulb temperature $\left({ }^{\circ} \mathrm{F}\right)$, $\% \mathrm{RH}$, and DP $\left({ }^{\circ} \mathrm{F}\right)$ were downloaded for the monitoring period and used to provide context for the analysis of the indoor measurements. 


\section{Results and Analysis}

The data that have been collected and analyzed in this report are from October 1, 2012 to November 7, 2013. The data logging equipment was installed in late July 2012; however, a number of problems arose (e.g., hurricane-induced power loss, malfunctioning fan cycling controllers, data logging equipment failure) that jeopardized the integrity of the data before October 1, 2012. Despite these initial problems, however, the project was able to still collect more than a year's worth of data, in accordance with the intent of the study.

\subsection{Comparison of Interior Conditions}

One of the key metrics outlined in the test plan for this project was to compare the humidity levels in conditioned space between the house types. The total amount of hours where the thermostat sensor was measuring more than $60 \%, 65 \%$, and $70 \% \mathrm{RH}$ is summed for each house in Table 8.

The number of hours when the thermostat sensor was measuring more than a $60^{\circ} \mathrm{F} \mathrm{DP}$ was also counted (as the ducted dehumidifier controls sense ${ }^{\circ} \mathrm{F}$ DP rather than $\mathrm{RH}$. The averages of these hours between study houses with and without dehumidification indicate that homes with dehumidifiers operated with fewer hours above $60 \% \mathrm{RH}$ (a reduction of 55\%) compared to homes without dehumidification, which was expected. It should be noted that, as previously stated, the dehumidifier settings were adjusted at PHA 1 and 2 during the course of the study. It is expected that the change in dehumidifier set point would alter the performance of the dehumidification system compared to the intended design.

Contrary to the expected trend indicated by the averaging of hours above $60 \% \mathrm{RH}$ for the three house types, when the binned data are compared on a house by house basis, the data show that there are homes, both with and without dehumidifiers, exhibiting interior humidity levels that were unexpected. PHA 3 experienced more hours above $60 \%$ RH compared to both PHA 5 and 6. The hours above $60 \% \mathrm{RH}$ at PHA 5 and 6 are far below those at PHA 7 and 8 ( $60 \%$ lower).

PHA 4 is the only house with a dehumidifier that exhibited minimal hours above $60 \% \mathrm{RH}(0.1 \%$ of the total study hours). However, it should be noted that the elevated indoor dry bulb temperature that was maintained in the residence $\left(77.8^{\circ} \mathrm{F}\right)$ may also be contributing to the reduced amount of hours above $60 \% \mathrm{RH}$.

The data for each individual house are investigated in more detail in Section 3.2.4. 
Table 8. Hourly Bin Data From October 1, 2012 to November 7, 2013

\begin{tabular}{|c|c|c|c|c|c|c|c|c|c|c|c|}
\hline $\begin{array}{l}\text { Study } \\
\text { House }\end{array}$ & $\begin{array}{c}\text { Dehumidification } \\
\text { System }\end{array}$ & 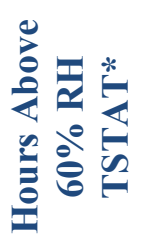 & 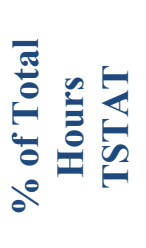 & 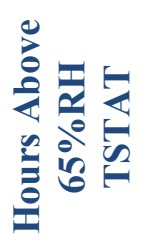 & 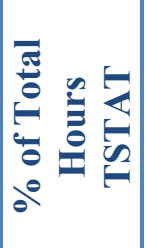 & 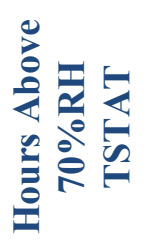 & 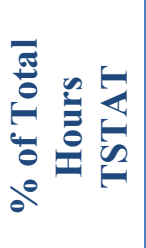 & 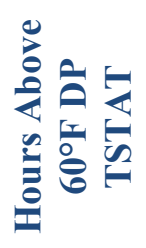 & 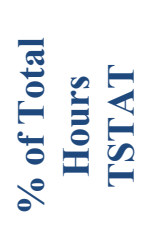 & 离 & 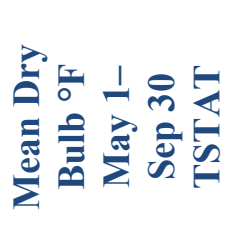 \\
\hline PHA1 $^{6}$ & Ducted dehumidifier & 1566 & $16.4 \%$ & 289 & $3.0 \%$ & 10 & $0.1 \%$ & 691 & $7.3 \%$ & 9531 & 72.3 \\
\hline PHA2 $^{6}$ & Ducted dehumidifier & 2819 & $29.1 \%$ & 456 & $4.7 \%$ & 28 & $0.3 \%$ & 103 & $1.1 \%$ & 9672 & 68.5 \\
\hline PHA3 & Ducted dehumidifier & 2375 & $24.3 \%$ & 411 & $4.2 \%$ & 17 & $0.2 \%$ & 883 & $9.1 \%$ & 9672 & 68.5 \\
\hline PHA4 & Ducted dehumidifier & 12 & $0.1 \%$ & 3 & $0.0 \%$ & 0 & $0.0 \%$ & 611 & $6.3 \%$ & 9672 & 77.8 \\
\hline PHA5 $^{7}$ & None & 1929 & $21.5 \%$ & 396 & $4.4 \%$ & 16 & $0.2 \%$ & 296 & $3.3 \%$ & 8952 & 69.3 \\
\hline РНA6 & None & 1215 & $12.6 \%$ & 220 & $2.3 \%$ & 20 & $0.2 \%$ & 175 & $1.8 \%$ & 9672 & 73.7 \\
\hline PHA7 & None & 4454 & $46.1 \%$ & 2006 & $20.7 \%$ & 361 & $3.7 \%$ & 1920 & $19.9 \%$ & 9672 & 71.6 \\
\hline PHA8 & None & 4356 & $45.0 \%$ & 1398 & $14.5 \%$ & 213 & $2.2 \%$ & 1286 & $13.3 \%$ & 9672 & 73.5 \\
\hline BDC1 $^{8}$ & Standalone dehumidifier & 725 & $10.3 \%$ & 43 & $0.6 \%$ & 0 & $0.0 \%$ & 930 & $13.2 \%$ & 7056 & 73.7 \\
\hline \multirow[t]{3}{*}{$\mathrm{BDC2}^{8}$} & Standalone dehumidifier & 534 & $7.6 \%$ & 88 & $1.2 \%$ & 13 & $0.2 \%$ & 293 & $4.2 \%$ & 7056 & 74.4 \\
\hline & $\begin{array}{c}\text { Mean hours with } \\
\text { dehumidifier }\end{array}$ & 1339 & $14.6 \%$ & 215 & $2.3 \%$ & 11 & $0.1 \%$ & 585 & $6.8 \%$ & 8791 & 72.5 \\
\hline & $\begin{array}{l}\text { Mean hours without } \\
\text { dehumidifier }\end{array}$ & 2989 & $31.3 \%$ & 1005 & $\begin{array}{c}10.5 \\
\%\end{array}$ & 153 & $1.6 \%$ & 919 & $9.6 \%$ & 9492 & 72.0 \\
\hline
\end{tabular}

*Thermostat

\footnotetext{
${ }^{6}$ Data indicate that the dehumidifier settings at PHA 1 and 2 were changed during the course of the study. This was confirmed through correspondence with the homeowners. In addition, the PHA 1 data logger malfunctioned and did not record data from April 3, 2013 to April 9, 2013.

${ }^{7}$ The thermostat sensor at PHA 5 malfunctioned, resulting in data loss. Therefore, data from the master bedroom sensor is used for the hourly bin analysis. In addition, the data logger malfunctioned during the month of October 2012; therefore the dataset is from October 31, 2012 to November 7, 2013.

${ }^{8}$ The date range for the data from BDC1 and 2 is from January 18, 2013 to November 7, 2013.
} 
Figure 17 shows a frequency plot that organizes the hourly RH measurements into eight \%RH range bins and groups the bins with respect to the house type. The blue bars represent PHA homes with dehumidifiers, red bars represent PHA homes with no dehumidifiers, and green bars represent BDC 1 and 2. The house number associated with a specific bar can be counted from left to right. The blue shaded area identifies hours above $60 \% \mathrm{RH}$, the predetermined threshold. The binned dataset for both PHA house types exhibited a normal distribution. However, a "shift" in the concentration of hours can be observed between the two PHA house types. The majority of hours were measured in the $55 \%-60 \%$ RH bin for PHA 5-8, compared to $50 \%-55 \%$ RH for PHA 1-4. The binned hours for the BDC homes do not represent a standard distribution, perhaps due to the very small sample size.

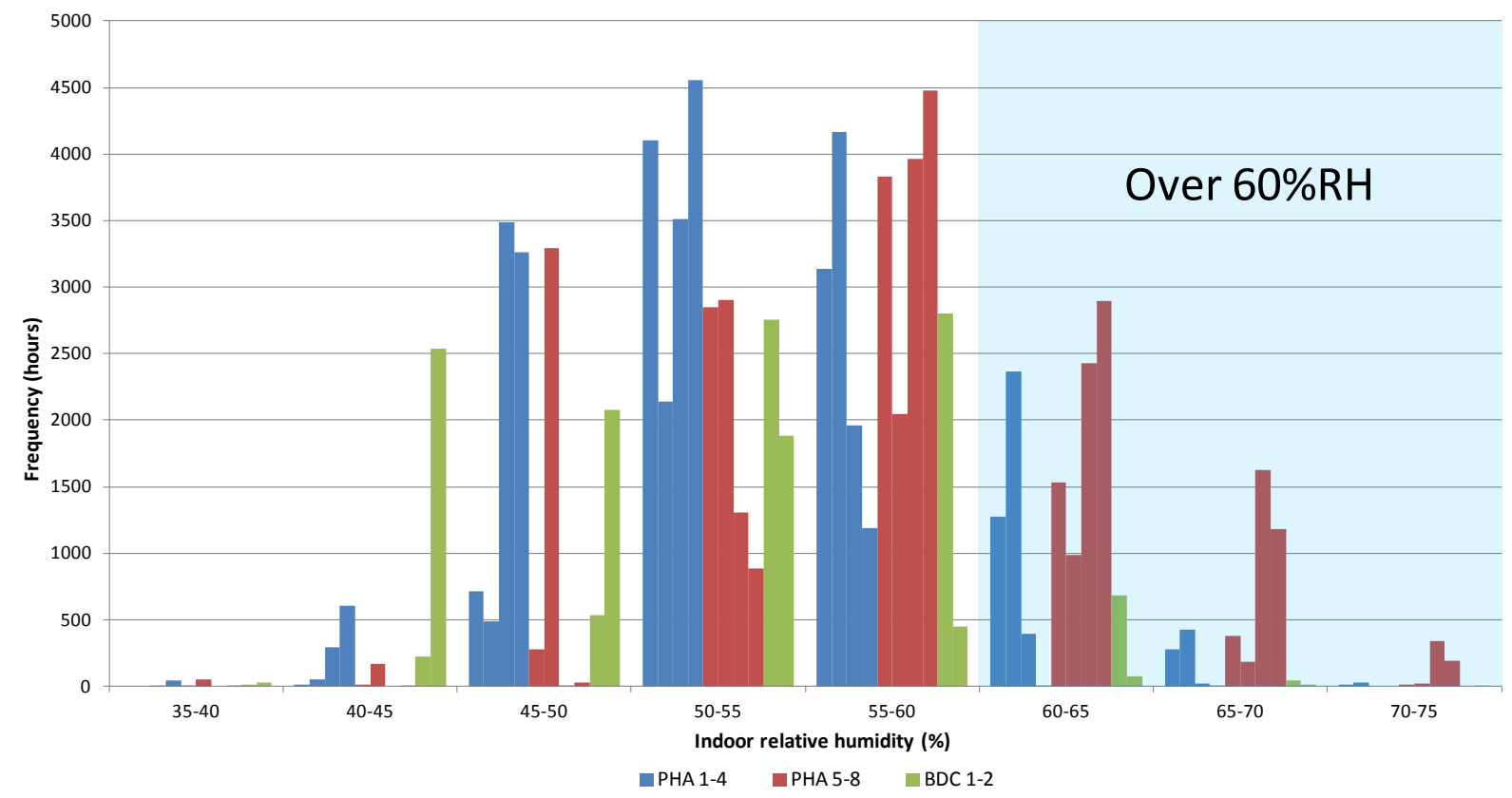

Figure 17. Frequency plot of \%RH hour bin data, grouped into the three study house types

It is important to note, again, that the PHA dehumidifiers operate on a DP set point rather than RH. Therefore, the $60 \% \mathrm{RH}$ threshold could represent a metric that is not applicable to the PHA houses with dehumidifiers. The dehumidistats were set to a $60^{\circ} \mathrm{F}$ DP set point. This would roughly equal a $60 \% \mathrm{RH}$ set point if the indoor dry bulb temperature were $75^{\circ} \mathrm{F}$; however, if the dry bulb set point were lowered below $75^{\circ} \mathrm{F}$, the associated $\% \mathrm{RH}$ set point would increase above $60 \%$ RH.

Figure 18 shows another frequency chart that organized indoor DP $\left({ }^{\circ} \mathrm{F}\right)$ rather than $\mathrm{RH}$, as the dehumidifiers at PHA sense DP not \%RH. A similar "shift" can be observed; however, the difference is not distinct. 


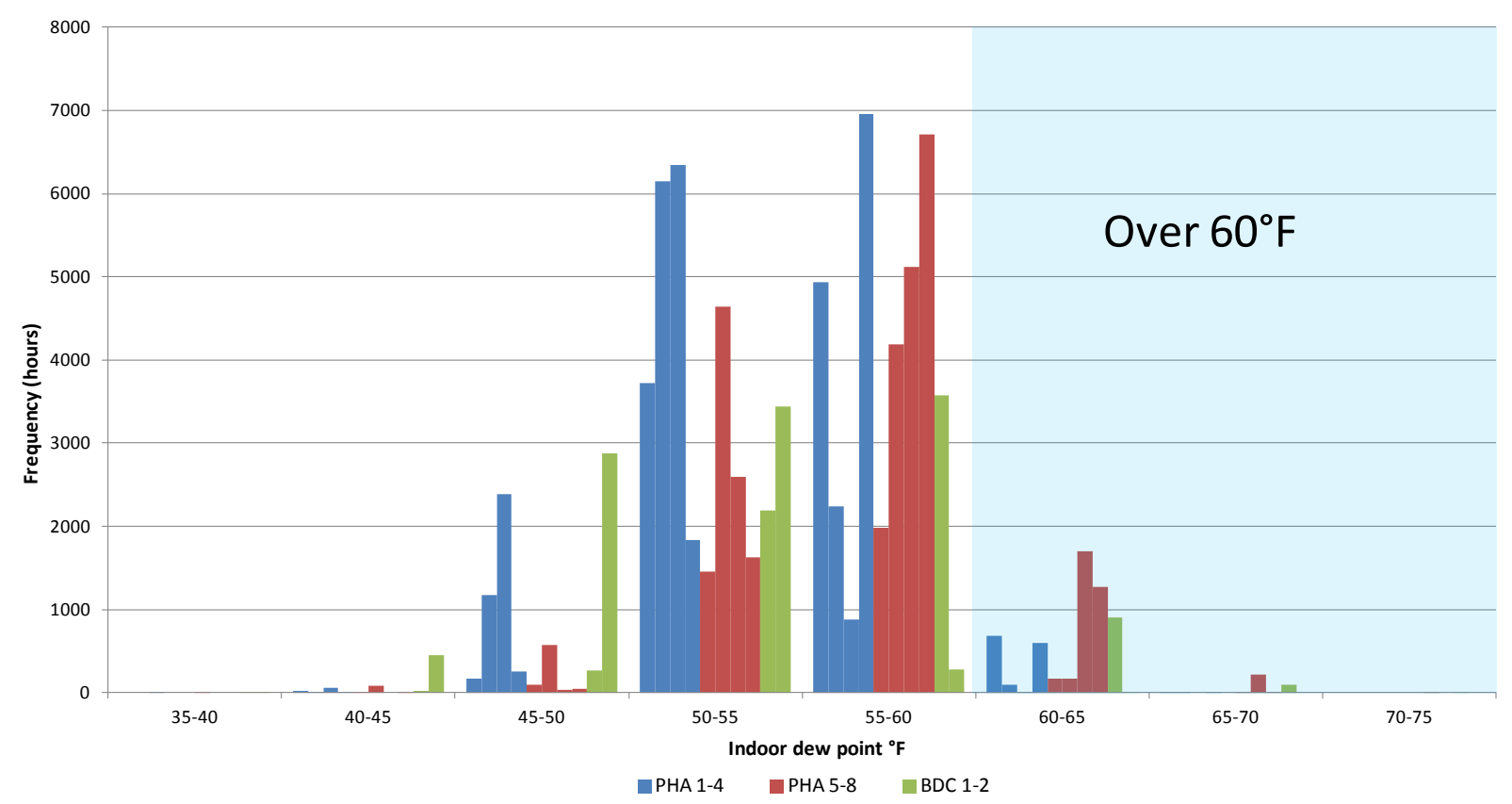

Figure 18. Frequency plot of DP hour bin data, grouped into the three study house types

A number of factors may be contributing to the fact that some of the homes with dehumidification are not strictly below $60 \% \mathrm{RH}$, as was intended with the dehumidifiers being configured as they were.

The amount of hours above $60 \%$ in the homes with dehumidification may be attributed to a higher than intended humidity set point. The Aprilaire 1750 whole-house ducted dehumidifier, installed at PHA 1-4, does not sense \%RH but rather DP. DP can be considered a better indicator of moisture levels in the air than RH, as it is a function of both temperature and humidity (Gatley 2005). However, the observation and analysis of interior RH measurements on dehumidification systems that sense on DP is problematic, as the dry bulb temperature factors in to DP. Therefore, the equivalent \%RH set point may be different throughout PHA 1-4, even with all the dehumidistats configured to the same DP. The dehumidistat at homes that are operating at a lower dry bulb set point will have a higher equivalent \%RH set point versus homes with a higher dry bulb set point. BSC initially configured the humidity set point at the PHA homes to a $60^{\circ} \mathrm{F}$ DP; however, it may have been too high a setting to ensure humidity control in some of the homes to $60 \% \mathrm{RH}$. In PHA 1,3 , and 4 , the $60^{\circ} \mathrm{F}$ DP set point was maintained for most of the study period (the occupants at PHA 2 changed the setting a few times throughout the study, and shut off the unit for much of the monitored period). At this setting, it will limit the $\% \mathrm{RH}$ to $61 \%$ at $75^{\circ} \mathrm{F}$ dry bulb and only $73 \%$ should the occupant choose to operate the house as low as $70^{\circ} \mathrm{F}$. However, it should be noted that accuracy of the DP sensor can vary. For example, at PHA 4, the DP typically rises above $60^{\circ} \mathrm{F}$ DP to a maximum of around $62^{\circ} \mathrm{F}$ DP. This dehumidistat setting was configured at a slightly conservative set point in order to avoid over operation during the summer and subsequently overheating the home. This may explain the hours above $60 \%$ at the dehumidifier homes. In addition, humidity loads in each home typically vary due to occupant behavior (e.g., number of occupants, cooking habits, window operation) and this occupant behavior contributes to higher humidity levels. This is investigated more in Section 3.2.4. 
Alternately, the standalone dehumidifiers at BDC 1 and 2 do sense RH. As with PHA 1-4, there is evidence to suggest that the $\% \mathrm{RH}$ set point was higher than the intended $60 \% \mathrm{RH}$. It is suspected that two variables may have contributed to the higher RH set point.

- The simple potentiometer dial \%RH control was inadvertently set to a higher \%RH set point than intended, as the controls did not allow for the configuration of a specific \%RH set point. As stated previously, the team selected a dial setting based off of observed conditions in the home but the dataset was very small ( $\sim 1$-day time period).

- The operating \%RH sensor dead band may be high, resulting in an actual \%RH set point higher than intended.

Figure 19 and Figure 20 show the hourly indoor DP for the PHA houses with and without dehumidifiers, since the dehumidistat senses on DP.

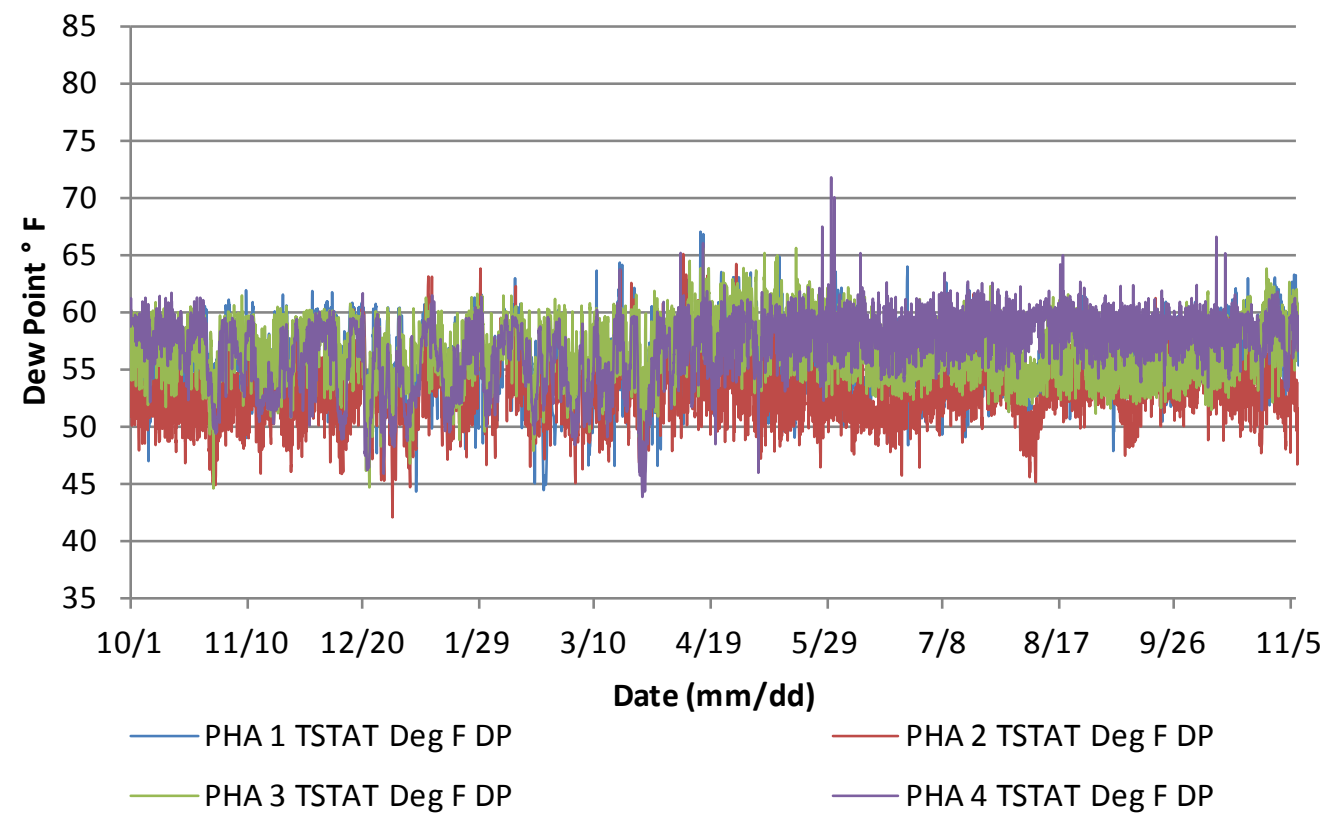

Figure 19. Hourly indoor DP for PHA homes with dehumidifiers 


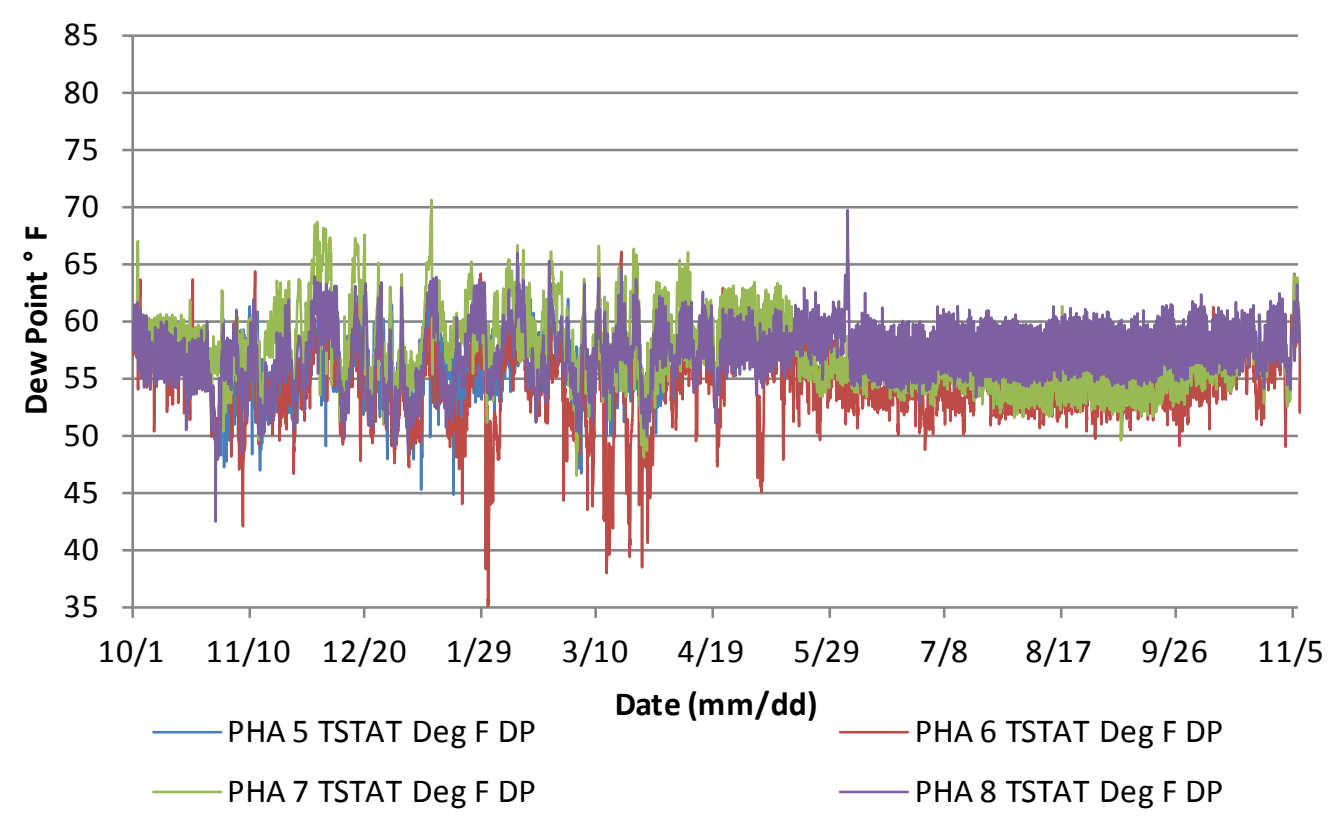

Figure 20. Hourly indoor DP for PHA homes without dehumidifiers

Figure 21 shows the same DP plot for the BDC homes with dehumidifiers. It should be noted here, as previously discussed, that the dehumidifiers at the BDC homes sense \% RH, not DP.

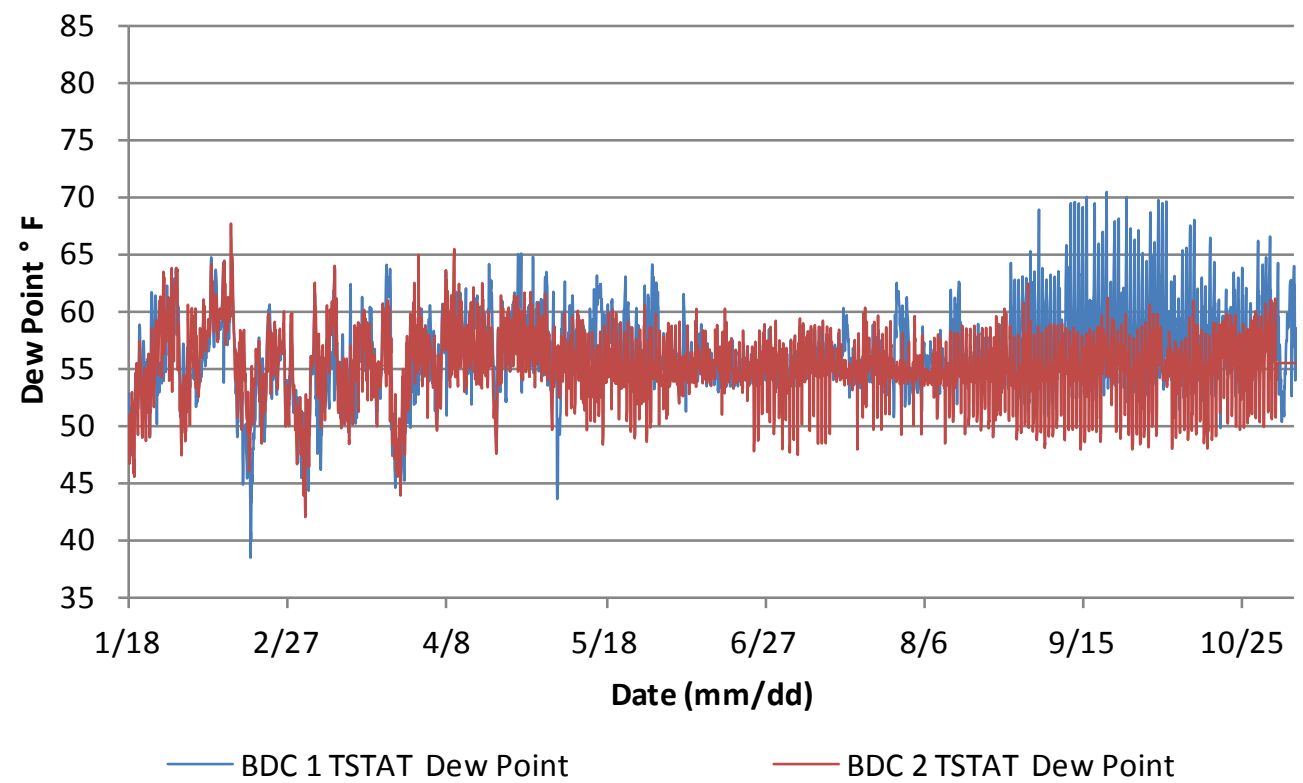

Figure 21. Hourly indoor DP for BDC homes with dehumidifiers

In Section 3.2.4, an analysis seeks to establish a correlation of equipment use on interior humidity levels. 


\subsection{Measured Energy Use Comparison}

Monitored energy use data from all 10 homes are available in a multitude of time-related readings. An analysis of measured hourly kilowatt-hour consumption can help to identify equipment and/or appliances that may be contributing to unexpected measured interior conditions. Monthly averages offer a broader interpretation of the energy use as is related to outdoor conditions (i.e., comparing heating and cooling season performance).

\subsubsection{Hourly End-Use Energy}

In terms of energy use, the dehumidifiers consumed less electricity than most of the monitored end use loads over the course of the study.

Figure 22 shows the PHA total site energy use measured at each monitored end use from October 1, 2012 to November 7, 2013. Compared to the major end uses of the homes, dehumidifier energy use represented a very small percentage of the total site energy use, ranging from $1.3 \%$ to $7.6 \%$.

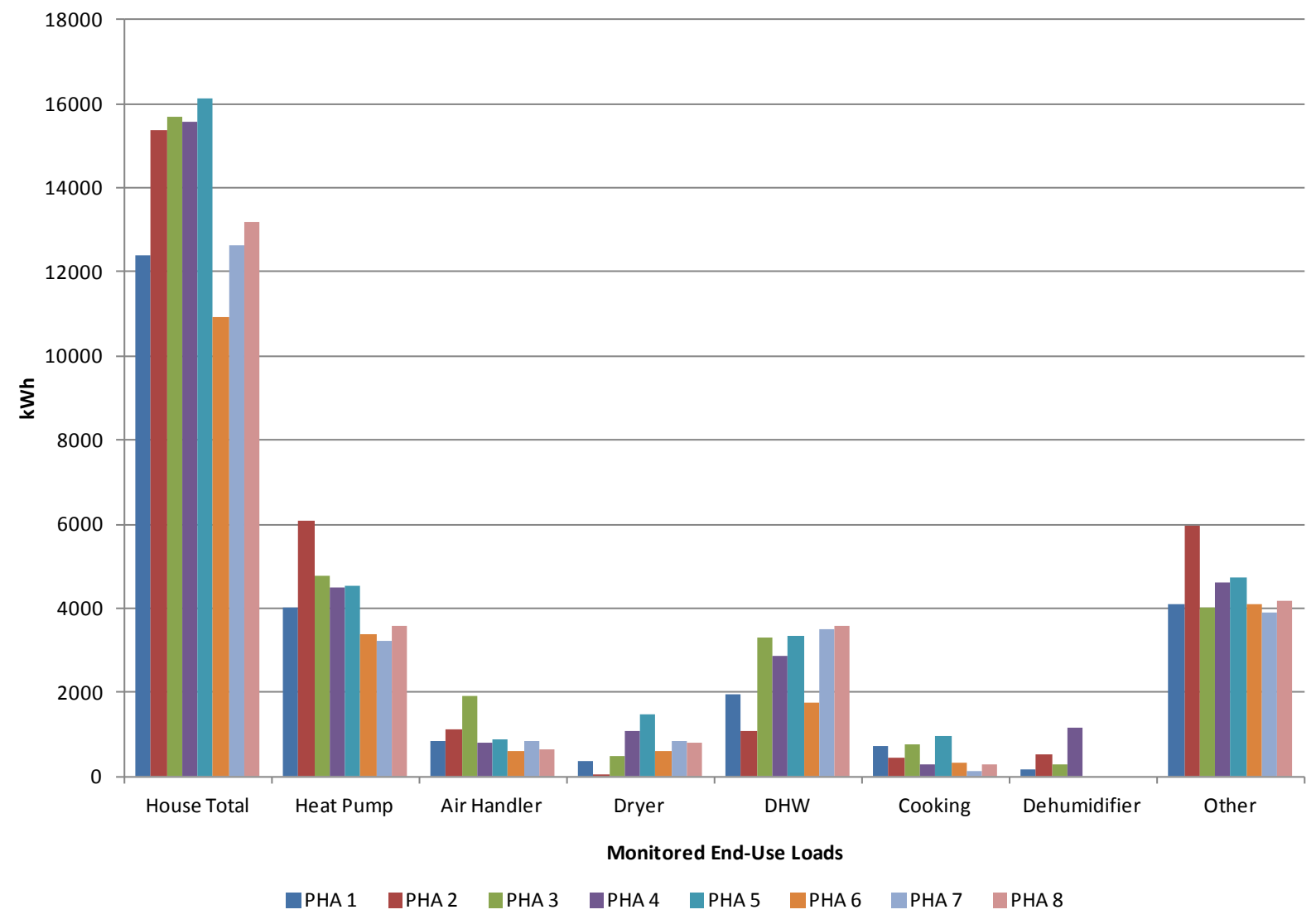

Figure 22. Measured site energy use per end use at PHA homes

Figure 23 shows the BDC total site energy that was measured at each monitored end use from January 18, 2013 to November 7, 2013. Compared to the major end uses of the homes, dehumidifier energy use also represented a very small percentage of the total site energy use, ranging from $1.9 \%$ to $6.5 \%$. 


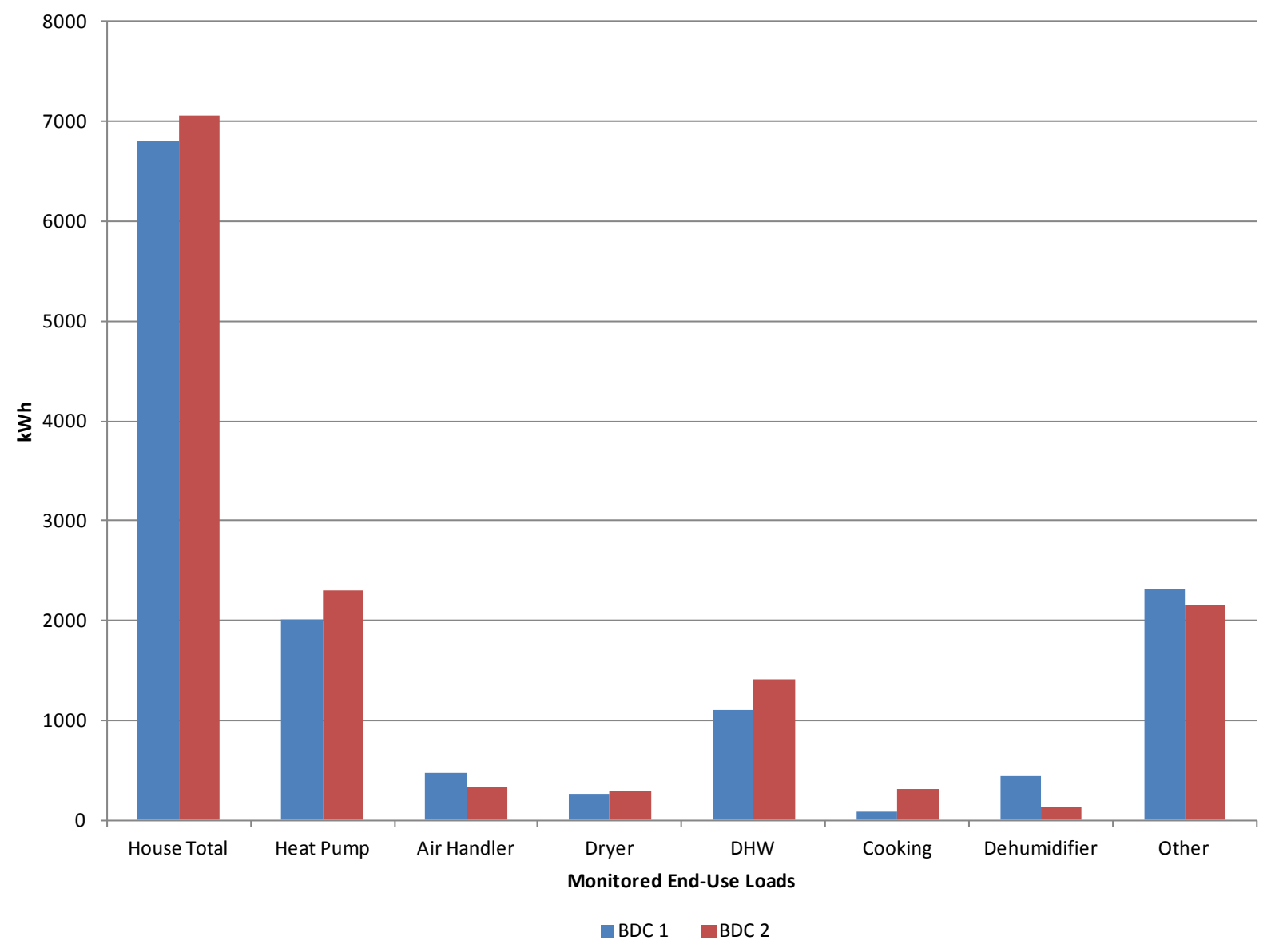

Figure 23. Measured energy use per end use at BDC homes

\subsubsection{Monthly End-Use Energy}

Presenting the end-use energy consumption data as monthly averages can identify trends in the performance that may be related to outdoor conditions.

Figure 24 indicates a correlation between monthly heat pump energy use (outdoor heat pump only) with an elevated monthly average outdoor DP $\left({ }^{\circ} \mathrm{F}\right)$. 


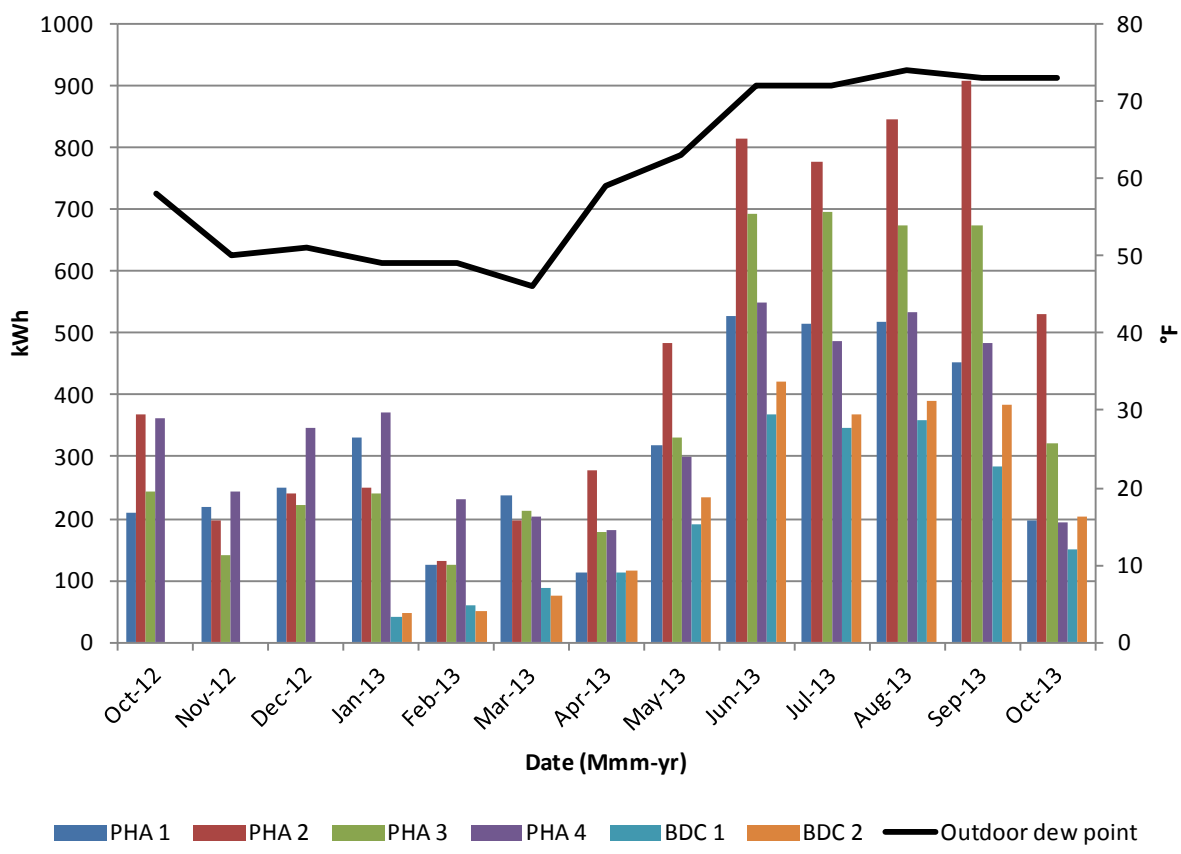

Figure 24. Monthly heat pump energy use versus average outdoor DP for homes with dehumidifiers

Figure 25 shows a similar relationship for homes without dehumidifiers.

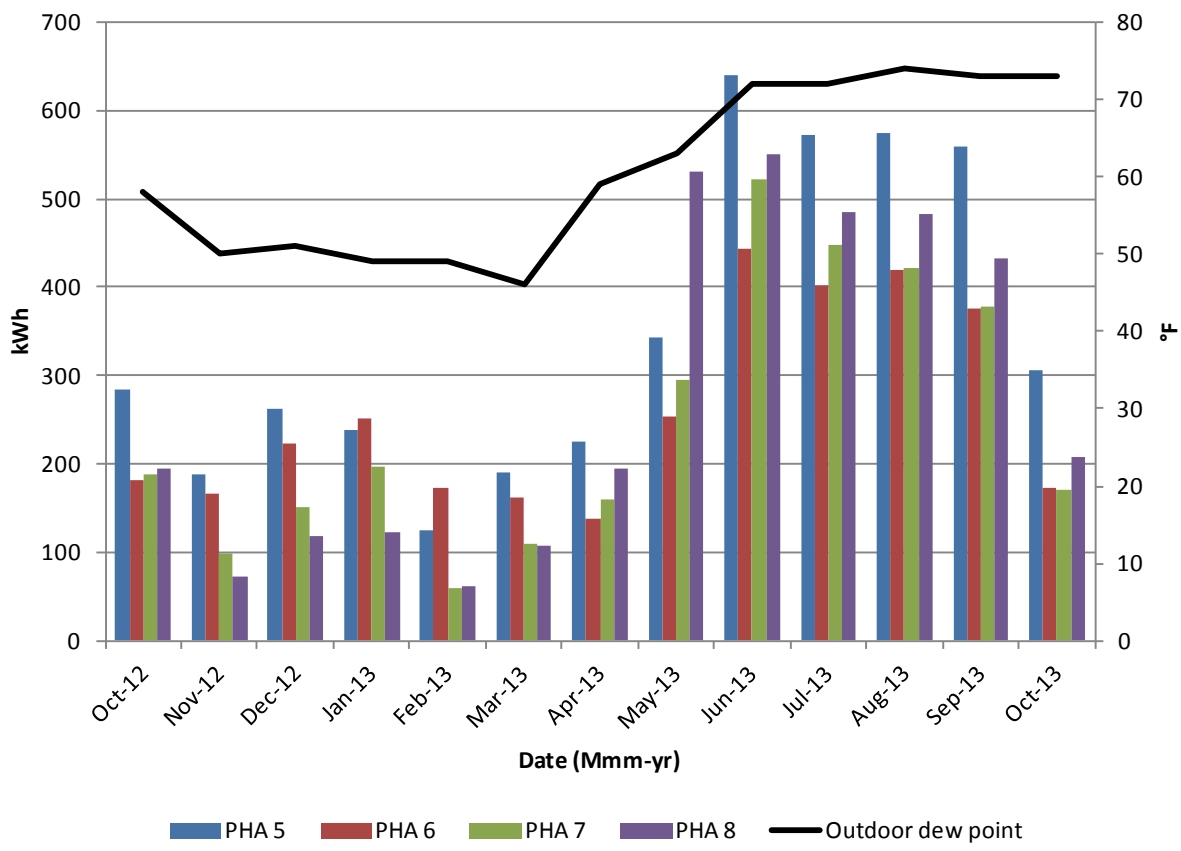

Figure 25. Monthly heat pump energy use versus average outdoor DP for homes without dehumidifiers 
Figure 26 shows air handler energy use versus outdoor DP. There is little to no correlation between the monthly air handler energy use and outdoor conditions. This is most likely due to the consistent energy used by the air handler during fan cycling, which all air handlers were programmed for a 33\% duty cycle for the entire study. The plot does indicate an elevated amount of air handler operation for PHA 3. This is due to excessive electric heat operation from November 2012 to March 2013.

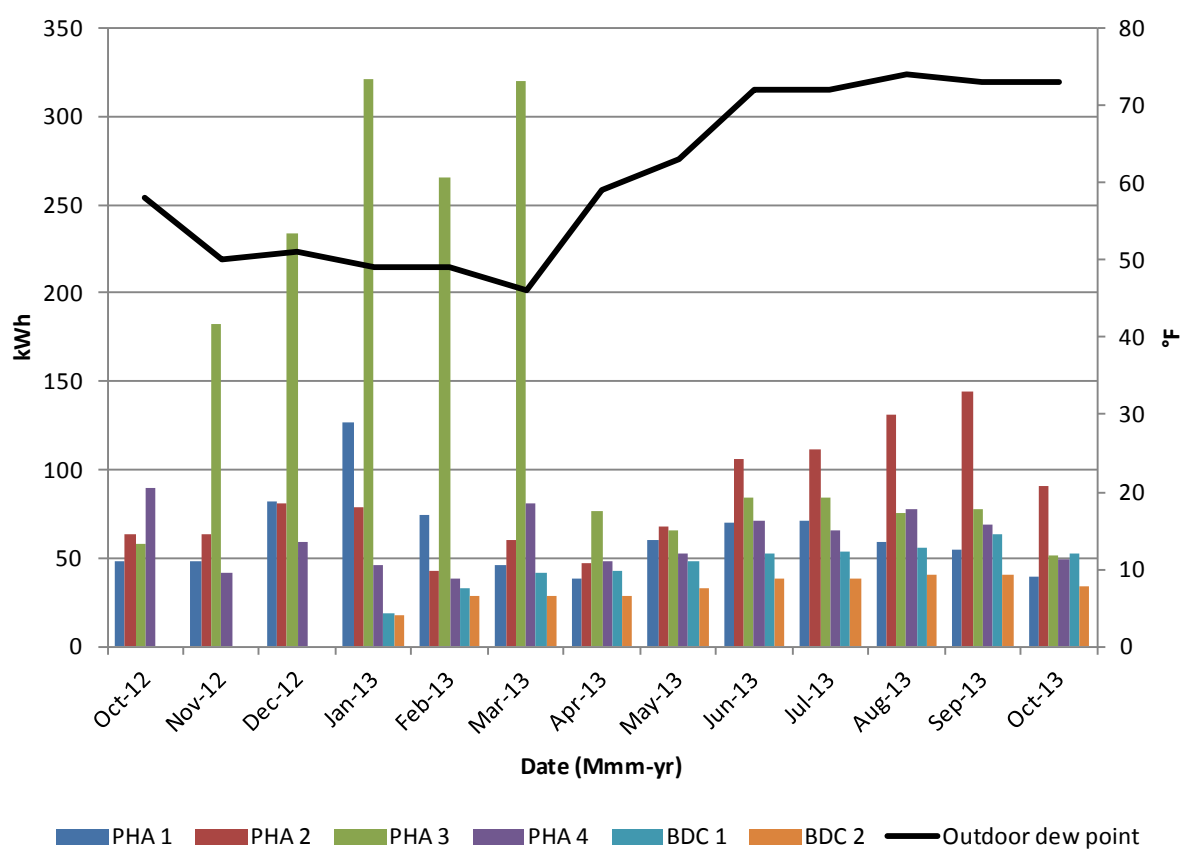

Figure 26. Monthly air handler energy use versus average outdoor DP for homes with dehumidifiers

Figure 27 also does not indicate a correlation; however elevated air handler energy use can be observed at PHA 5 and PHA 7 during the months of January 2013 and March 2013, respectively. 


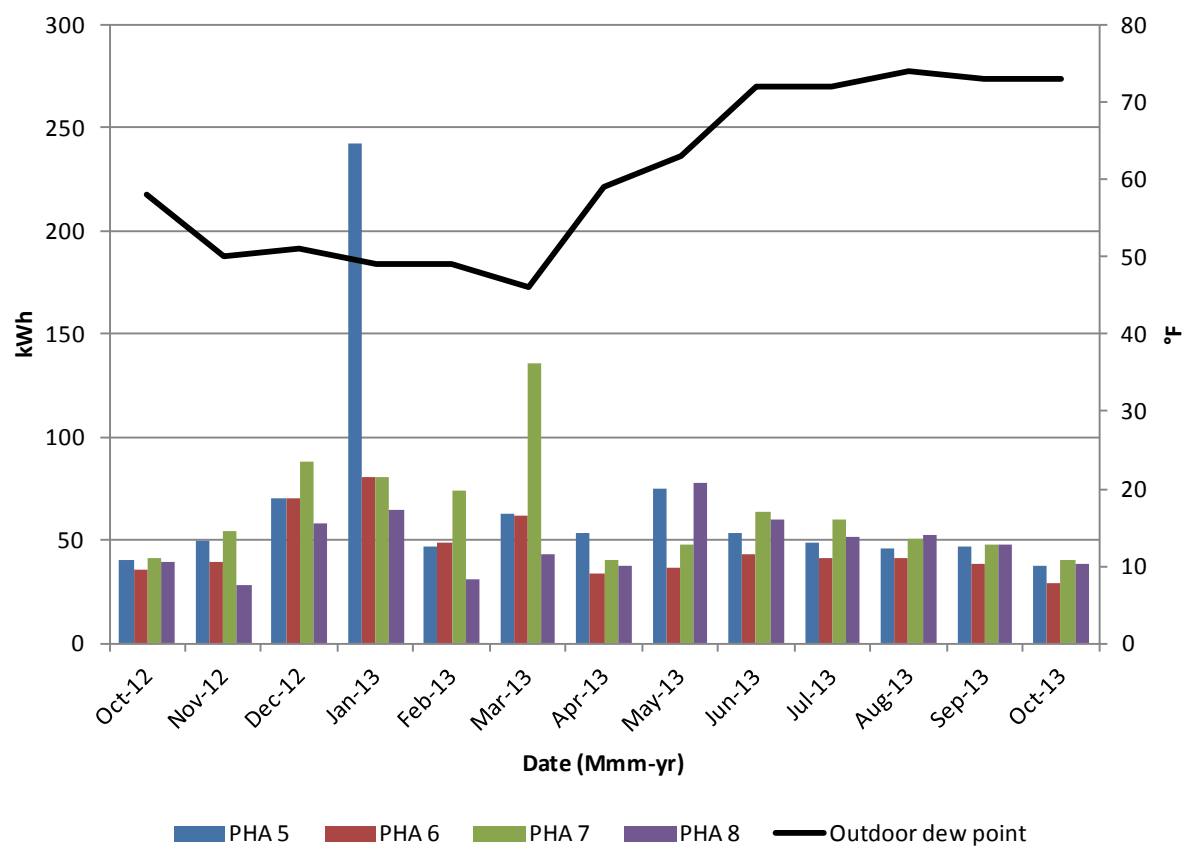

Figure 27. Monthly air handler energy use versus average outdoor DP for homes without dehumidifiers

Figure 28 does show a correlation between monthly dehumidifier energy use versus the monthly average outdoor DP. However, changes in the dehumidistat set points at PHA 1 and 2 most likely have affected the monthly dehumidifier use. For example, it appears that the dehumidistat at PHA 2 was changed to a lower DP setting at around August 2013.

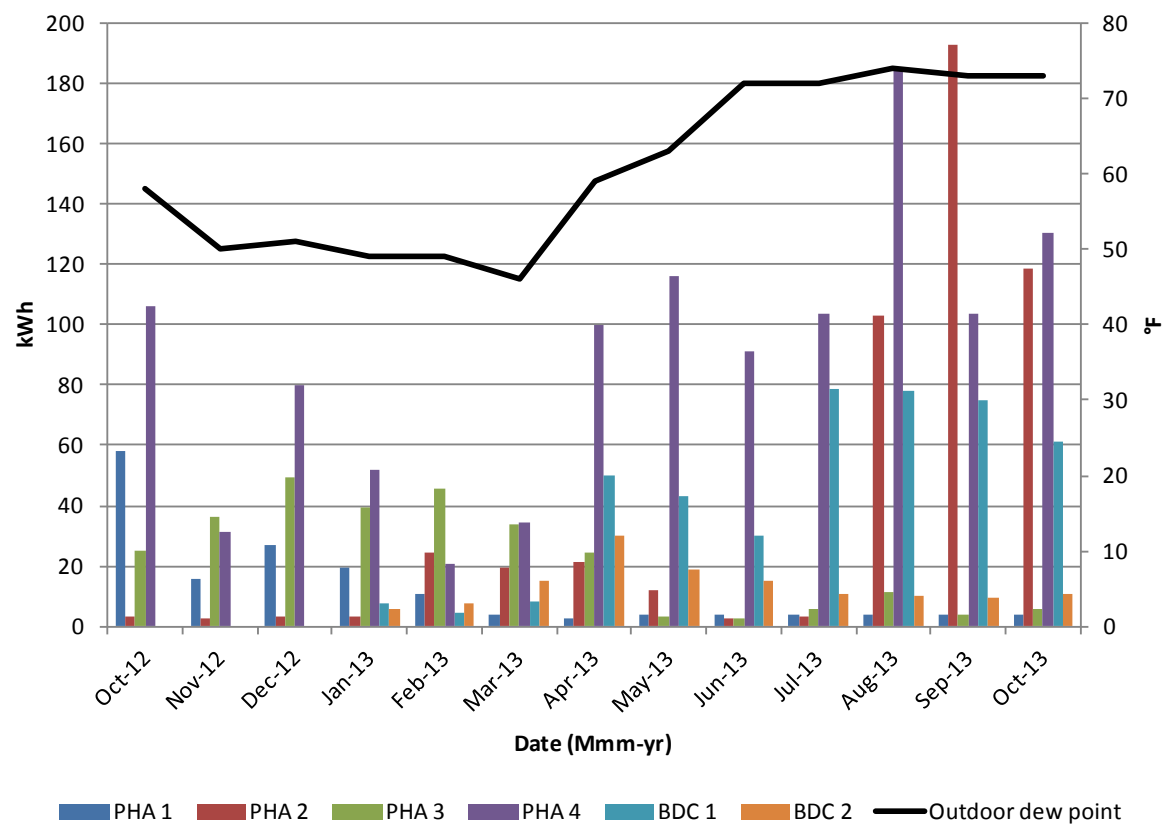

Figure 28. Monthly dehumidifier energy use plotted against average outdoor DP 


\subsubsection{Comparison to Predicted Performance}

The monitored data were compared to the predicted performance from the energy model (BEopt + ). The monitored dehumidifier performance was also compared to the predicted performance based on previous research, which was detailed in Section 1.6.

\subsubsection{Electricity Rate}

The electricity rate used in the calculation of end use energy costs in this study is $\$ 0.11 / \mathrm{kWh}$. This rate includes the following charges (note that rates can fluctuate; therefore, the figures below are approximations) but does not include service charges or other flat monthly fees.

Table 9. Electricity Rate-Individual Component Charges

\begin{tabular}{c|c}
\hline Charge & Rate* \\
\hline Electricity Base Rate Charge & $\sim \$ 0.07 / \mathrm{kWh}($ rate NE_RS1) \\
\hline Formula Rate Plan Credit (Discount) & $\sim 10 \%$ of the calculated electricity base rate \\
charge
\end{tabular}

*Information on the electricity rate from Entergy New Orleans can be found on its website: www.entergyneworleans.com/your_home/tariffs.aspx.

\subsubsection{Dehumidifier Energy Use}

It was not possible to extract the dehumidifier energy use from the hourly output of the BEopt + energy models; therefore, the dehumidifier energy use is compared to the calculated $\mathrm{kWh}$ following a $10 \%$ operation rule of thumb that was detailed in Section 1.6. Table 10 shows the comparison between the actual and predicted dehumidifier site energy use throughout the study. The cost to operate the dehumidifiers was one of the lowest of the monitored end uses.

Table 10. Comparison of Predicted Versus Actual Dehumidifier Energy Use and Estimated Utility Cost

\begin{tabular}{l|c|c|c|c}
\hline House & $\begin{array}{c}\text { Actual } \\
\mathbf{k W h}\end{array}$ & $\begin{array}{c}\text { Predicted } \\
\mathbf{k W h}\end{array}$ & $\begin{array}{c}\text { \% of } \\
\text { Predicted }\end{array}$ & $\begin{array}{c}\text { Estimated } \\
\text { Utility Cost }\end{array}$ \\
\hline PHA 1 & 160.7 & 1077 & $15 \%$ & $\$ 18$ \\
PHA 2 & 536.8 & 1077 & $50 \%$ & $\$ 59$ \\
PHA 3 & 289.1 & 1077 & $27 \%$ & $\$ 32$ \\
PHA 4 & 1176.7 & 1077 & $109 \%$ & $\$ 129$ \\
BDC 1 & 444.3 & 404 & $110 \%$ & $\$ 49$ \\
BDC 2 & 137.3 & 404 & $34 \%$ & $\$ 15$ \\
\hline
\end{tabular}




\subsubsection{Whole-House and End-Use Energy Use}

BEopt+ was used to generate an hourly output of energy use and interior conditions. BSC was able to select predicted hourly performance for the date range of the study. Again, the study period for the PHA homes was October 1, 2012 to November 7, 2013, and the study period BDC was from January 18, 2013 to November 7, 2013.

Figure 29 through Figure 31 show the actual energy use for the three house types compared to their respective BEopt + predicted energy use. The cyan bars indicate monitored energy use for a specific end use. A cyan bar can be associated with a specific house number by applying the numbers listed in the legend left to right. For example, in Figure 29, the leftmost cyan bar is PHA 1, then the next is PHA 2, etc. The yellow bar represents the BEopt+ predicted end-use site energy consumption. It should be noted that the BEopt + models were run with the Building America specified set points of $71^{\circ} \mathrm{F}$ heating and $76^{\circ} \mathrm{F}$ cooling. The varying set points at each of the homes will impact the HVAC energy use compared to the BEopt + model.

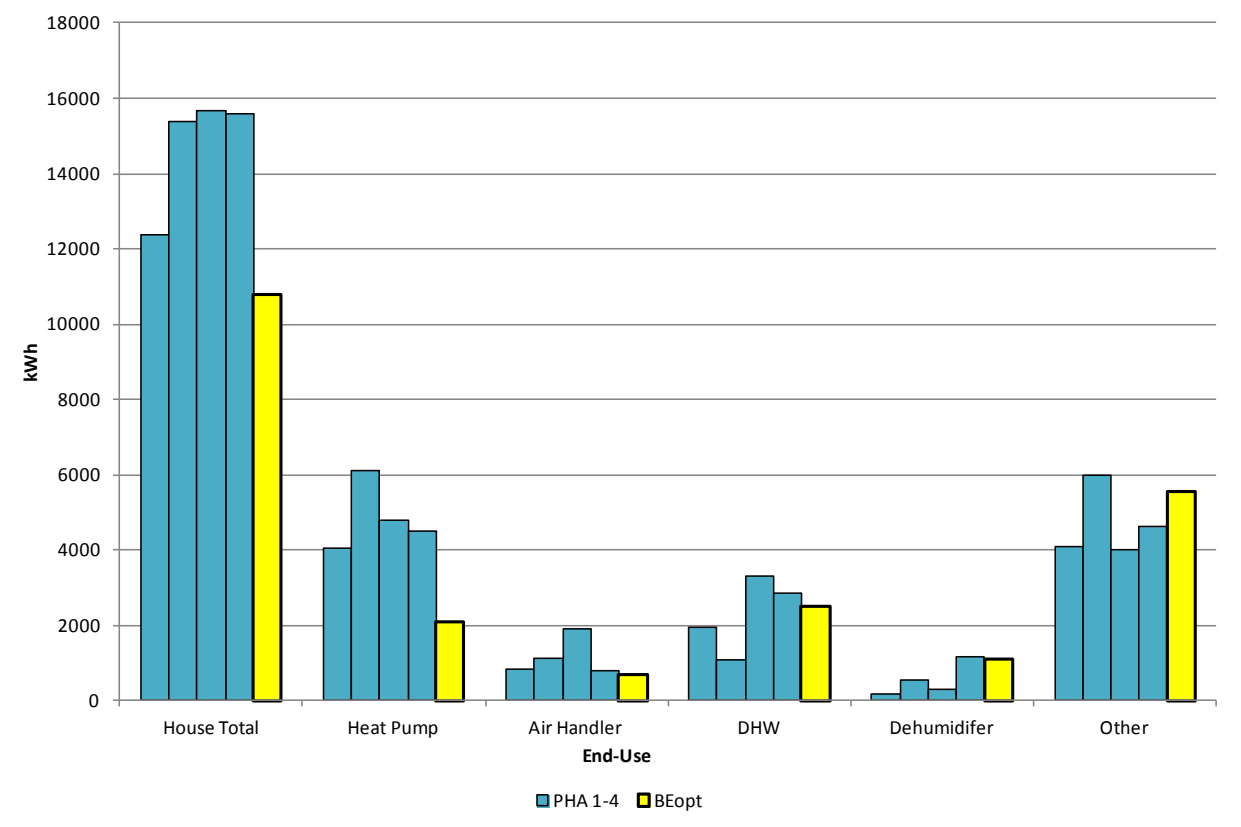

Figure 29. Actual versus BEopt+ predicted energy use for various end uses in PHA homes with dehumidifiers (PHA 1-4) 


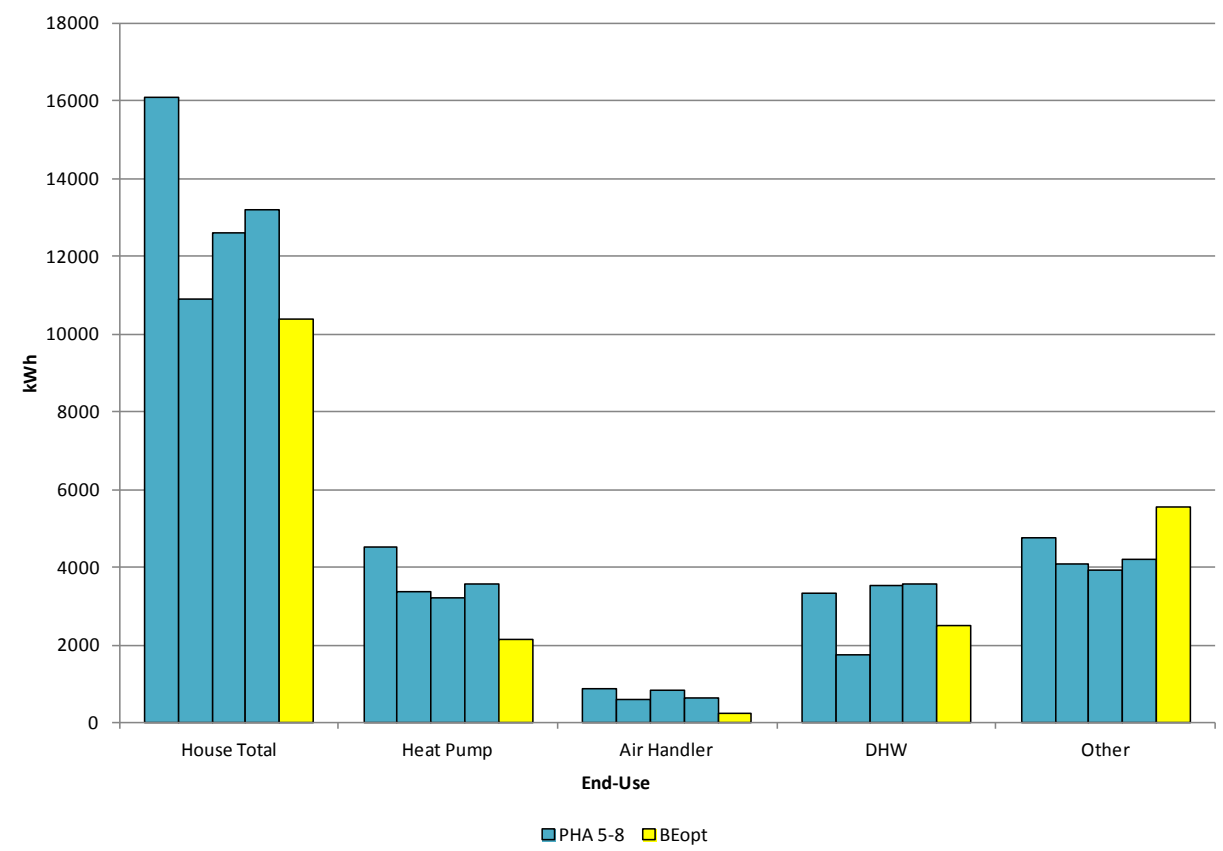

Figure 30. Actual versus BEopt+ predicted energy use for various end uses in PHA homes without dehumidifiers (PHA 5-8)

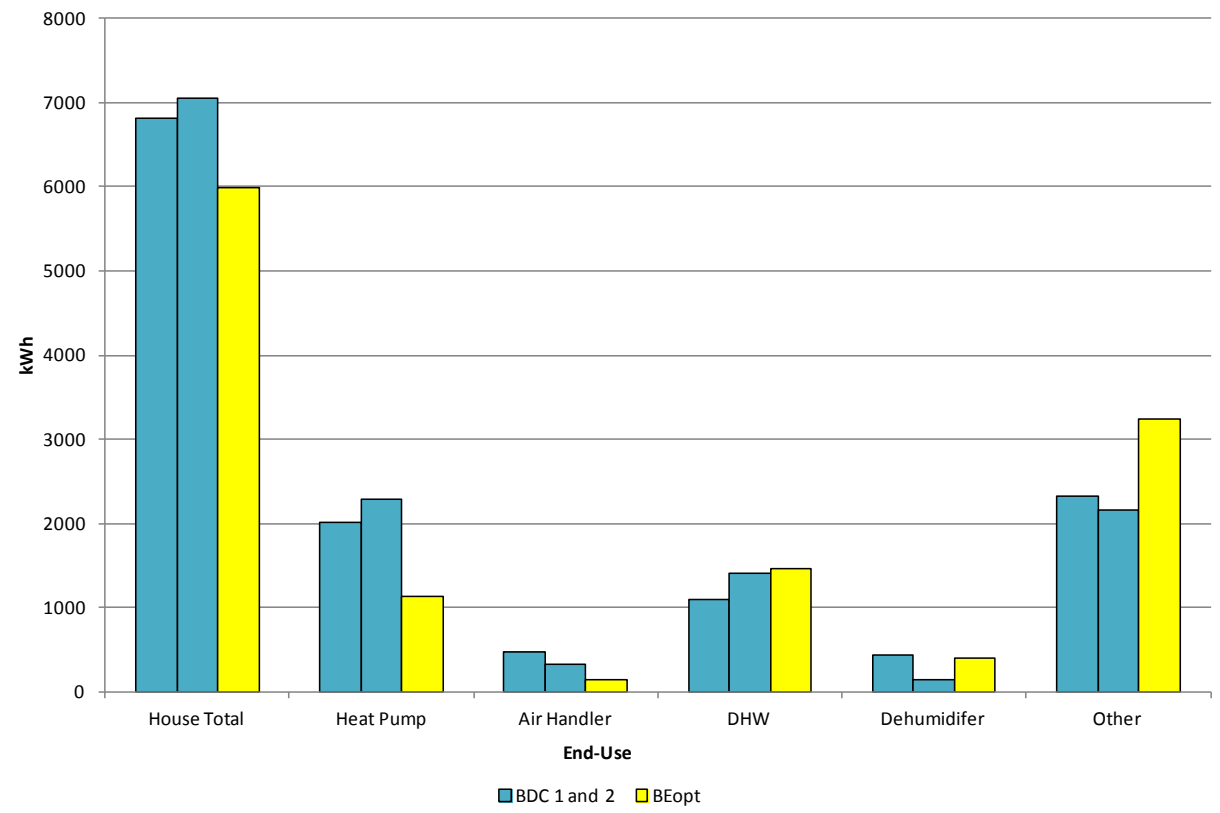

Figure 31. Actual versus BEopt+ predicted energy use for various end uses in BDC homes with dehumidifiers (BDC 1 and 2) 


\subsubsection{Equipment Operation and Impact on Humidity Control}

It was expected that the indoor RH levels would vary from house to house due to occupant effects. The monitoring installation was specifically broadened in scope, through the direct assistance of NREL and MEP, to monitor the performance of some of the end uses, in addition to the HVAC system. These measurements were seen as potential additional explanatory variables for house-to-house variations in the indoor humidity. The measurements added to the scope for this purpose were:

1. Outdoor air damper actuator current: This was measured primarily to ensure that the sample of homes received equivalent moisture loading due to ventilation air.

2. Master and secondary bathroom exhaust fan current: Bath exhaust fans can contribute to indoor humidity by inducing increased air leakage into the home or reduce indoor humidity loading by removing humid air during bathing. As stated in Section 2.4.1, a range hood, ducted to the outside, was installed in the kitchen, but the team was unable to install a current transducer for the range hood. Some information on range hood operation was obtained through homeowner interviews.

\section{End-use electric energy consumption for:}
a. Clothes dryer
b. Domestic hot water (DHW) heater
c. Cooking range.

Use of the cooking range has the potential to introduce humidity into the space. It can also increase the sensible internal gains leading to increased heat pump use. The increased heat pump use could then reduce humidity. The DHW consumption provides an indicator of shower and bath use that may introduce humidity. The clothes dryer exhausts air from the house, thereby inducing increased infiltration that may increase humidity loading.

4. Whole-house electric energy consumption: If the indoor humidity varies with the net electricity consumption after subtracting the monitored end uses, it may indicate that an end use that was not measured is contributing to indoor humidity. High whole-house energy use may also result in high sensible internal gains that could increase heat pump use, thereby lowering humidity.

\subsubsection{Homes Without Dehumidifiers-Project Home Again 5-8}

The monthly hours above $60 \% \mathrm{RH}$ are shown in Figure 32 for the PHA homes without dehumidification. The number of hours above $60 \% \mathrm{RH}$ was low over the summertime months, which was expected due to cooling operation. All homes had a significant number of hours above $60 \% \mathrm{RH}$ for the remainder of the year, indicating the lack of humidity control that is separate from cooling.

Theoretically, if all occupant effects were equal, one would expect the homes to have similar indoor humidity. However, two of the homes exhibited increased number of hours above $60 \%$ RH than the other two. PHA 7 and PHA 8 had nearly three times as many hours above $60 \%$ RH than PHA 5 and PHA 6. This provides an interesting test case of the use of the explanatory variables to understand humidity differences without the complication of dehumidification. 


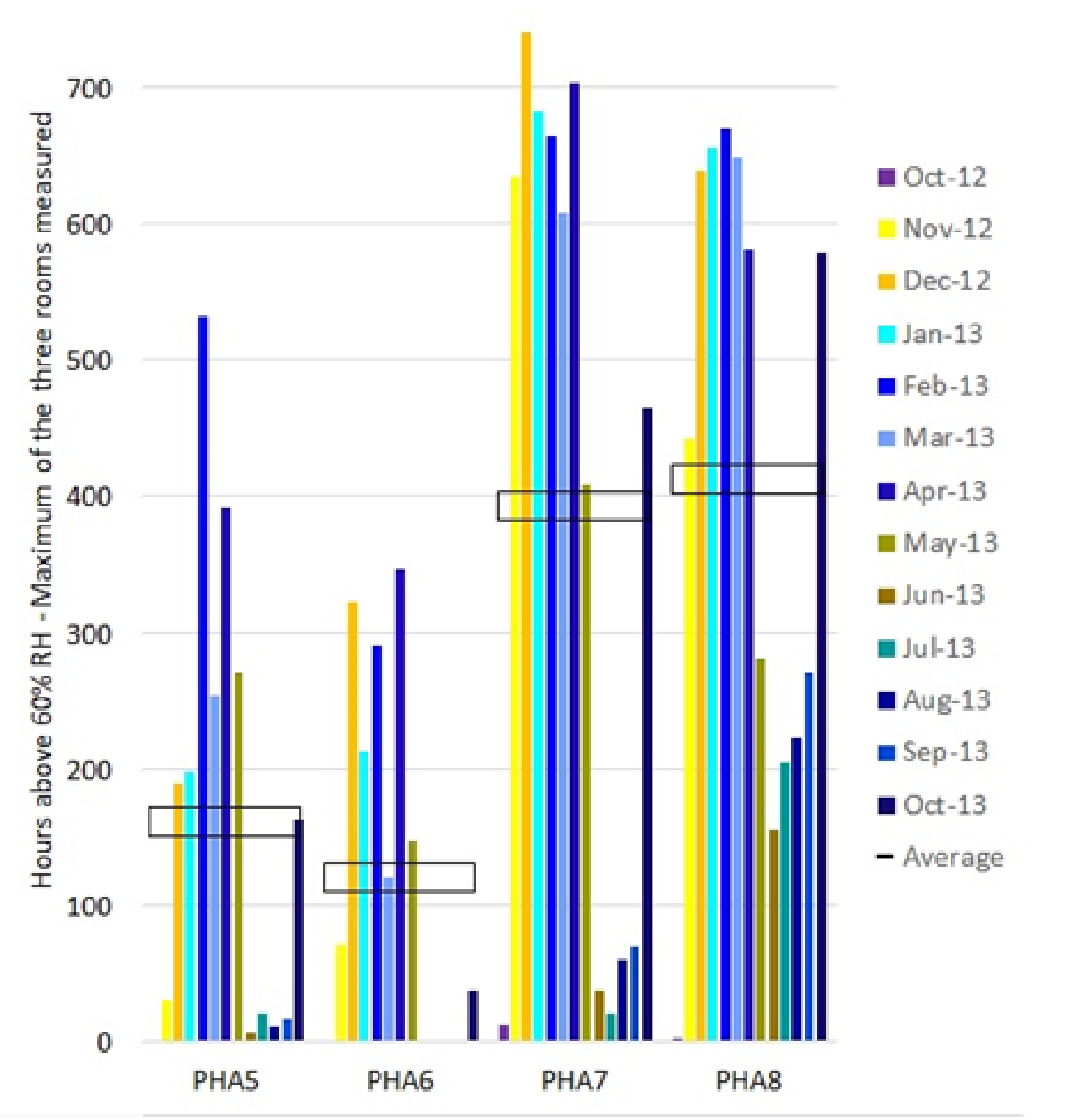

Figure 32. Monthly hours above $60 \%$ RH for PHA homes without dehumidifiers. The open box indicates the average value for the test period.

As $\mathrm{RH}$ is a function of dry bulb temperature, differences in $\% \mathrm{RH}$ can still occur if the homes exhibit the same humidity ratio (HR) but maintain different indoor set points. A higher indoor temperature leads to a lower \%RH for the same HR. For the conditions in these homes, a reduction in dry bulb temperature of $1.8^{\circ} \mathrm{F}$ corresponds to a three to four percentage points increase in $\% \mathrm{RH}$. Therefore, if the $\% \mathrm{RH}$ happens to be just close to $60 \%$, small indoor dry bulb temperature differences could lead to substantial difference in the number of hours above $60 \% \mathrm{RH}$.

The average indoor dry bulb temperature for the four homes over the test period was $70^{\circ} \mathrm{F}$. Figure 33 shows the average dry bulb temperature variations from that mean. The $\mathrm{x}$-axis is the difference between average dry bulb temperature for the rooms indicated and the average dry bulb temperature throughout all four homes for the entire test period. PHA 6 operated as the warmed house on average; this may help to explain why its hours above $60 \% \mathrm{RH}$ were relatively low. However, PHA 5 temperatures were the lowest but it also has the lowest hours above $60 \%$ 
RH. This is opposite to what we would expect if the indoor temperature were responsible for the differences in $\% \mathrm{RH}$ between the homes. The indoor temperatures do not provide a consistent explanation for the differences in hours above $60 \% \mathrm{RH}$ for the homes.

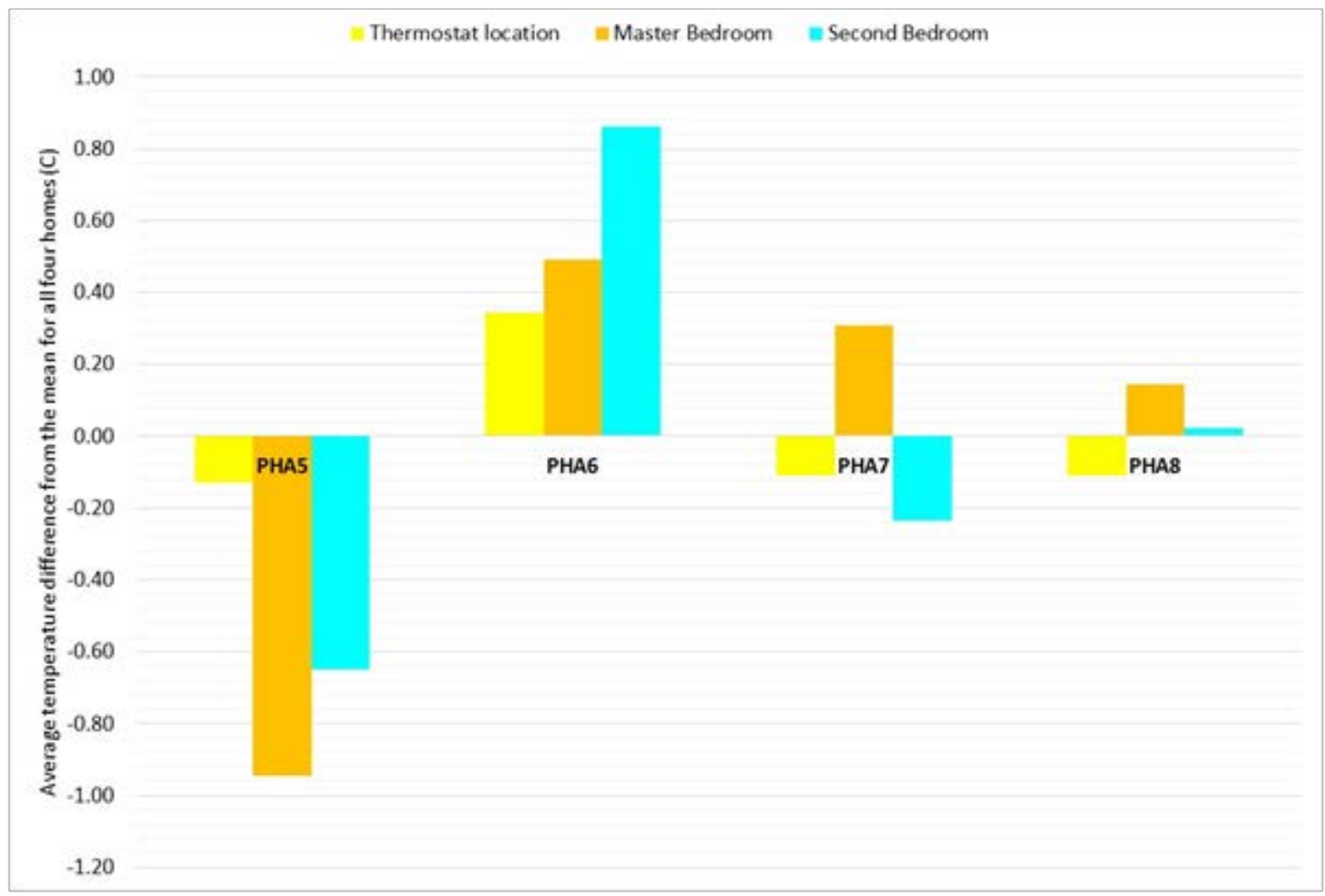

Figure 33. Average space dry bulb temperature variations for homes without dehumidification

The house-to-house variation in other potentially explanatory variables was also investigated in search of a pattern similar to the house-to-house variation in humidity. The variations around the mean of each of the variables investigated are shown in Figure 34. Each variable was normalized so that their variations around the mean for the four homes could be visualized in one chart. The intended observation of Figure 34 is not the absolute values of the variables in each house, but the relative difference from home to home. The square symbols represent the variation in hours above $60 \% \% \mathrm{RH}$ for the test period. The variables for each house are distilled in Table 11. Each of the variables is labeled with one of three categories: Low, Average and High, with increasingly darker shading coloring. Each of the variables may have a different impact on the humidity, both in magnitude and direction. These impact differences are not captured in Figure 34 and Table 11; only the differences in the magnitudes of the variables themselves.

The absolute humidity, represented by the HR, follows the same pattern as the hours above $60 \%$ RH-low in PHA 5 and 6, high in PHA 7 and 8. The fact that the both the HR and the hours above $60 \% \mathrm{RH}$ are similar for PHA 5 and 6 is puzzling in the light of the average indoor temperature difference between the homes. 


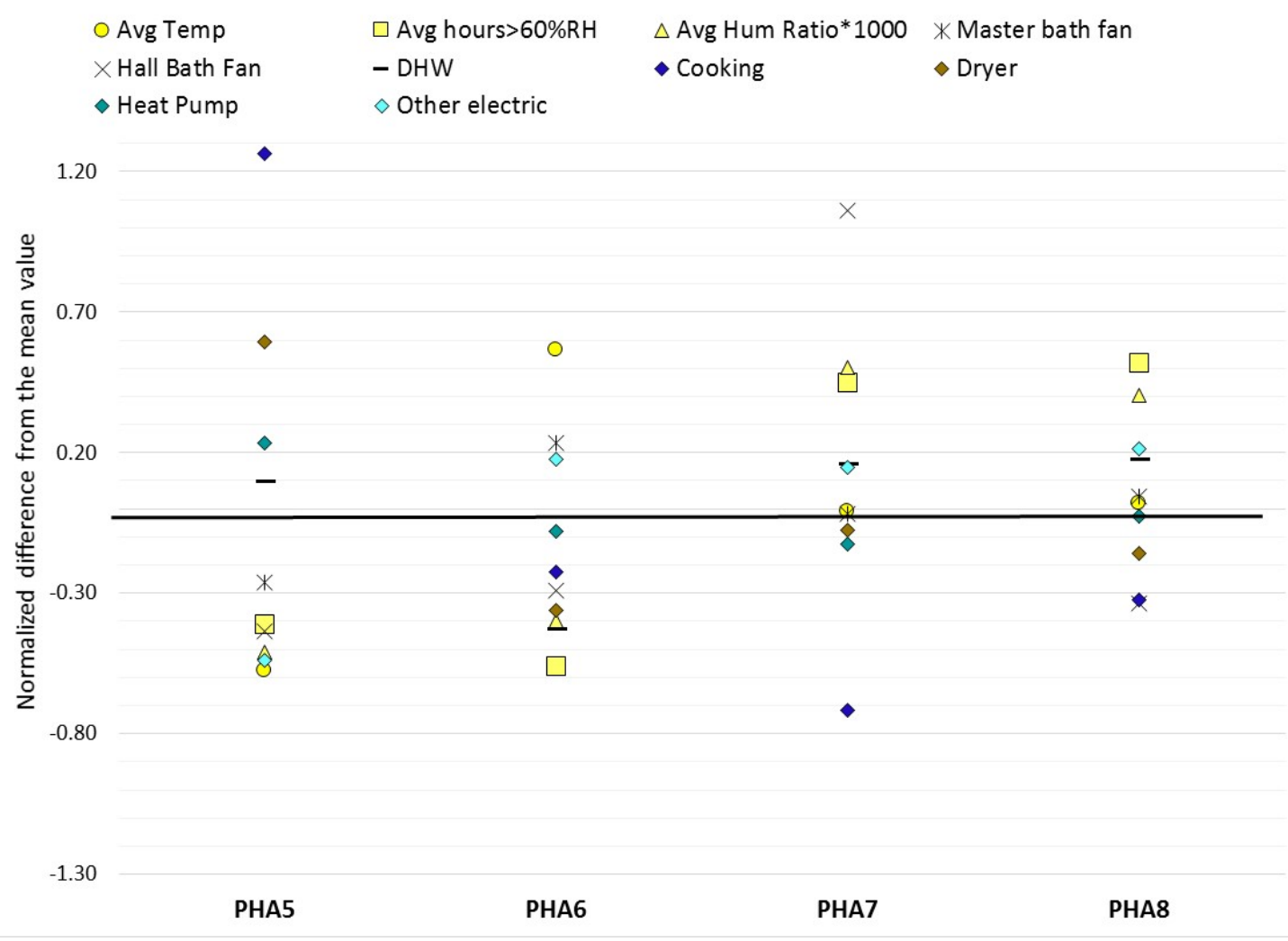

Figure 34. Variations in equipment energy use and interior conditions for PHA homes without dehumidification

Table 11. Classification of Variations in Measurements From the Mean Values for the PHA Homes Without Dehumidification

\begin{tabular}{l|c|c|c|c|}
\hline \multicolumn{2}{c}{ PHA5 } & PHA6 & PHA7 & PHA8 \\
\hline Occupancy (\# of People) & 3 & 2 & 2 & 2 \\
\cline { 2 - 5 } Hours above 60\% RH & Low & Low & High & High \\
\cline { 2 - 5 } HR & Low & Low & High & High \\
\cline { 2 - 5 } Indoor Temperature & Low & High & Average & Average \\
\cline { 2 - 5 } Mall Bath Fan & Low & High & Average & Average \\
\cline { 2 - 5 } Heat Pump Electricity & Low & Low & High & Low \\
\hline DHW Electricity & High & Average & Average & Average \\
\hline Cooking Electricity & High & Low & High & High \\
\hline Clothes Dryer Electricity & High & Low & Low & Low \\
\hline
\end{tabular}

PHA 5 maintained a somewhat lower set point dry bulb temperature than the other homes and subsequently had the highest heat pump electricity use. Cooking energy use in this home was much higher than the others. The high internal gains from cooking may also be contributing to the high heat pump use. The combination of low temperature and high heat pump use has the 
potential to push $\% \mathrm{RH}$ in either direction - a lower temperature tends to increase $\% \mathrm{RH}$ but the heat pump removes humidity as it runs, thereby reducing humidity. The clothes drying energy was also high. This has the potential to increase \% RH through induced infiltration. In addition, the DHW electricity was high but bath fan use was low; another combination we would expect to increase humidity. The fact that the humidity was actually low in this house may indicate that the higher use of the heat pump has a larger effect than the other variables.

In PHA 6, the high indoor temperature, the combination of low DHW and high master bath fan use, and low cooking and drying electricity all are expected to contribute to lower $\% \mathrm{RH}$. The higher indoor temperature stands out as a significant difference in this home.

PHA 7 and PHA 8 maintained indoor temperatures and exhibited heat pump use close to the sample mean. DHW electricity use in both homes was somewhat higher than average, but similar to PHA 5. Elevated operation of the hall bath fan use and small cooking energy consumption stand out in PHA 7; otherwise, the measured values are all fairly close to the mean in these two homes. Unlike PHA 5 and 6, the humidity in these homes was higher than that in the homes with dehumidifiers. A larger sample size would be required to ascertain how representative these homes are to the larger population with respect to indoor humidity.

\subsubsection{Homes With Dehumidifiers_Project Home Again 1-4 and Broadmoor Development Corporation 1-2}

It is clear from the above discussion that there is substantial home-to-home variability in humidity in homes without dehumidification. This underlying variability makes evaluating the effectiveness of the dehumidifiers in homes challenging.

A bar chart showing monthly hours above $60 \% \mathrm{RH}$ is in Figure 35 . As previous stated, PHA 4 was the only house with dehumidification that exhibited few hours over $60 \% \mathrm{RH}$. The hours above $60 \% \mathrm{RH}$ in the other three homes with dehumidifiers were similar to, or higher than, PHA 5 and 6. 


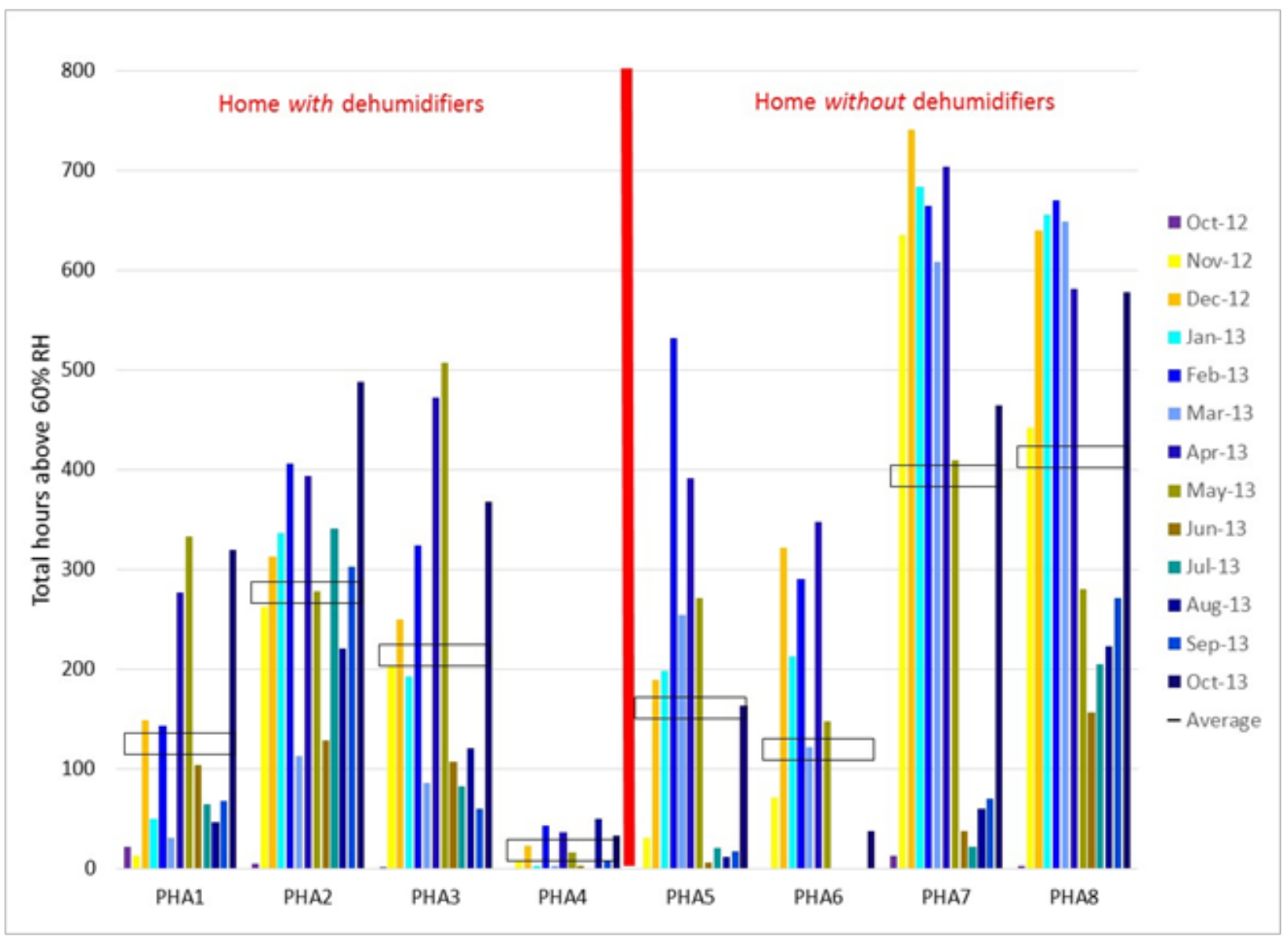

Figure 35. Monthly hours above $60 \%$ RH for all PHA homes

Figure 36 shows the total monthly dehumidifier site energy used in each PHA home with supplemental dehumidification systems. The dehumidifiers at PHA 1-3 consumed a very small amount of electricity during many of the months. Interviews with the homeowners confirmed that the dehumidistat settings were changed at PHA 1 and 2 at points during the study; however, the homeowners were unable to provide details on the control changes. The data do suggest that the dehumidistat was adjusted to a lower DP set point sometime later in the summer of 2013. It also appears that the dehumidistat was adjusted to a higher DP set point sometime in early February 2013, and it remained set at that set point for the remainder of the study. 


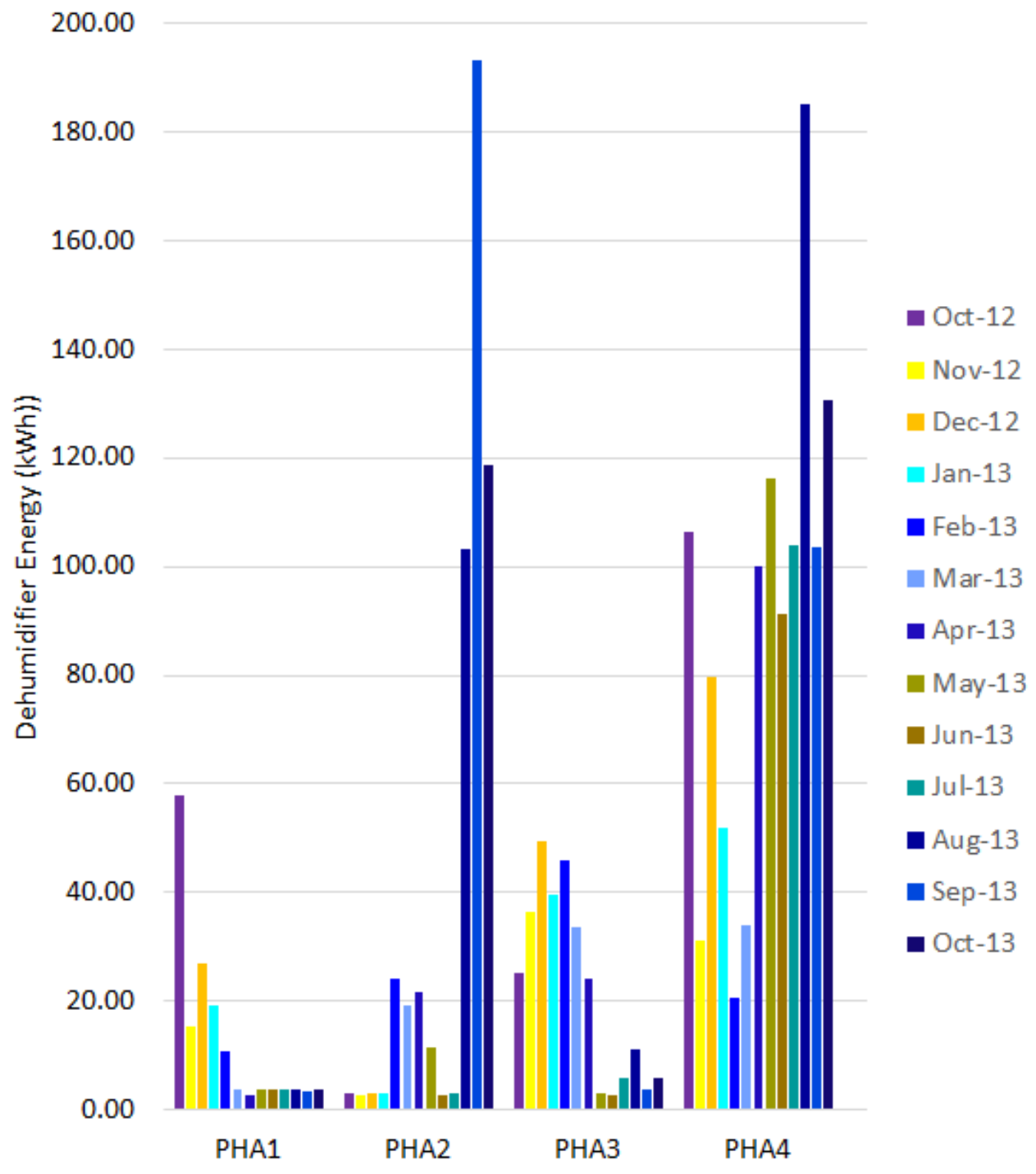

Figure 36. Monthly dehumidifier site energy use for PHA 1-4

The team examined the patterns of potentially explanatory variables in the whole sample of homes, with and without dehumidifiers. Once again varying dry bulb set point impacts the resulting RH. Figure 37 shows the indoor temperature, normalized \%RH and HR as variation from the mean of all homes. PHA 2 maintained the lowest average temperature of the sample and PHA 4 the highest. The lower dry bulb temperature in PHA 2 is associated with a lower than average $\mathrm{HR}$, due to dehumidification from the increased cooling operation, but a higher than average $\%$ RH. The reverse pattern can clearly be seen for PHA 4 . 


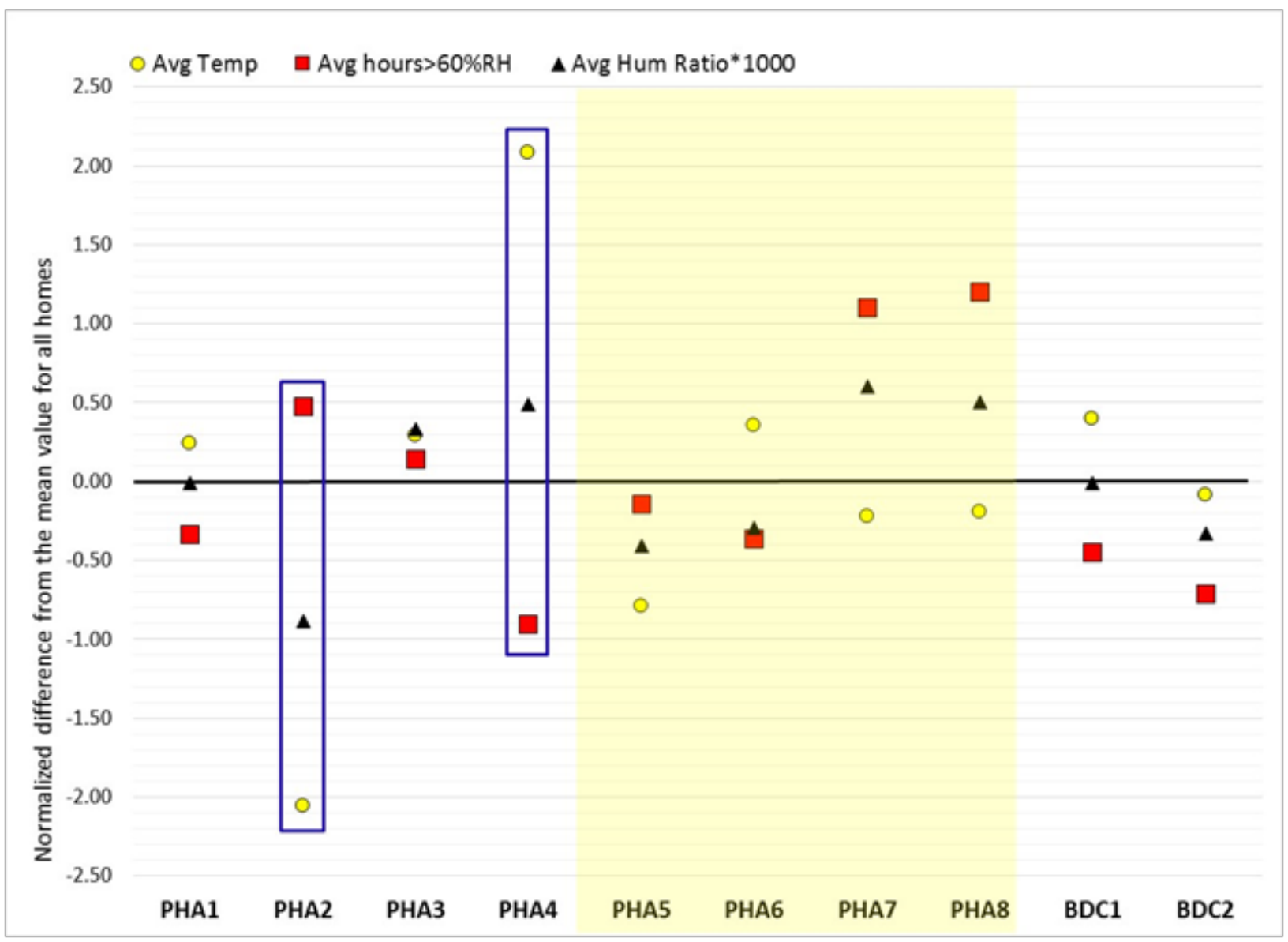

Figure 37. Variations in interior conditions from the mean values for all homes

A comparison of all the measured variables is shown in Figure 38. PHA 4 appears to have achieved consistently low \% RH through a combination of relatively high dehumidifier use, high use of both bath fans, and high indoor temperature. It is interesting to note that while PHA 4 had the lowest hours above $60 \% \mathrm{RH}$; it had the highest average $\mathrm{HR}$ - a measure of absolute humidity. The dehumidifiers are designed to control the absolute humidity by using DP for the humidity set point. This again indicates that the high indoor temperature in PHA 4 probably contributed significantly to its low hours above $60 \%$ RH.

On average the HR is actually higher in homes with higher bath fan use. PHA 4, which had the highest bath fan use, also exhibited the highest HR. However, there is quite a bit of scatter in the measured HR for homes with low fan use. DHW energy use also does not correlate well with HR. Bath exhaust fan use also does not correlate well with the DHW energy use. This may be due to differences in shower length and temperature between homes. 


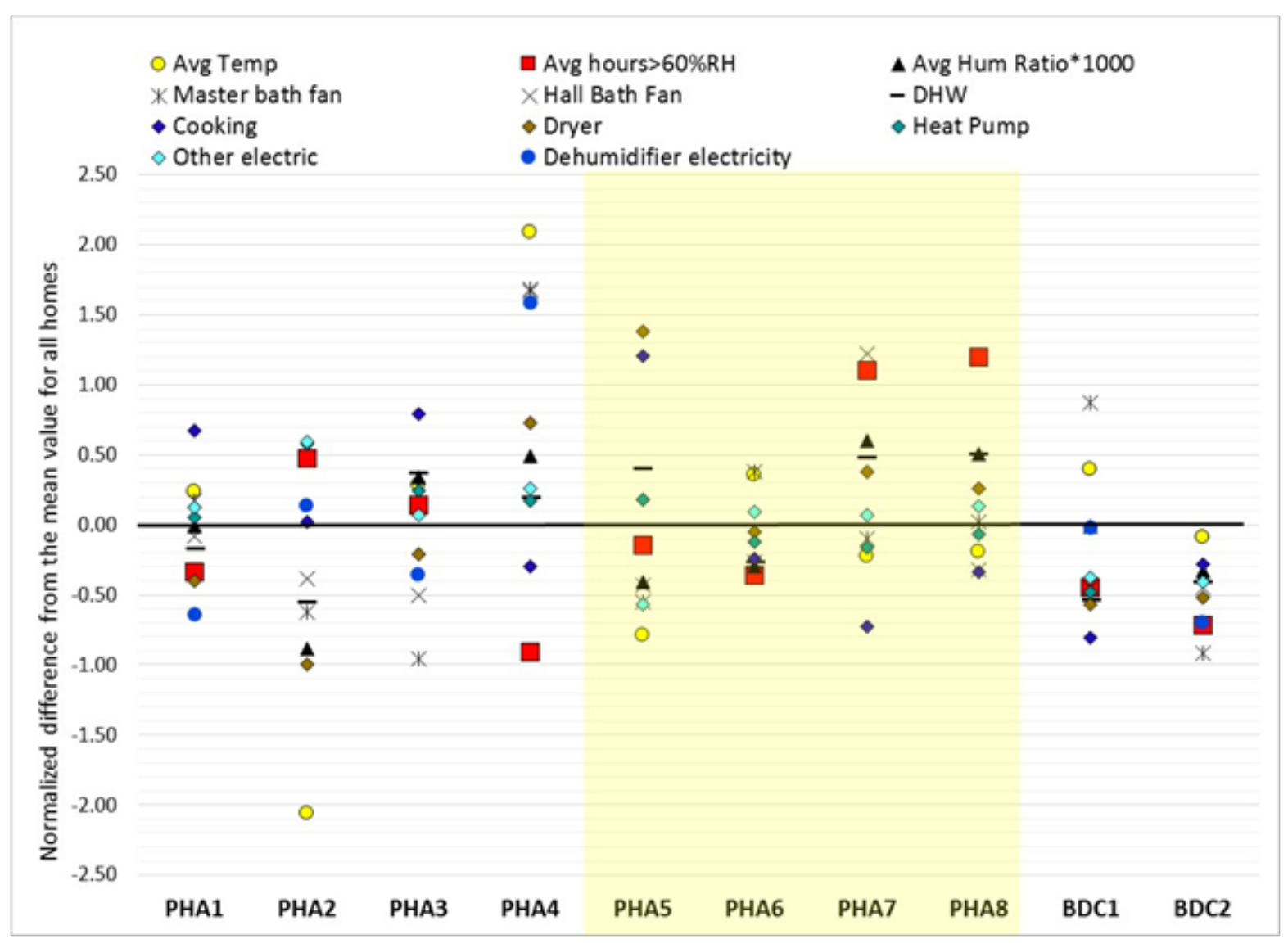

Figure 38. Variations in interior conditions and equipment operation from the mean values for all homes

A correlation also cannot be observed between dehumidifier energy use and the HR, as shown in Figure 39. 


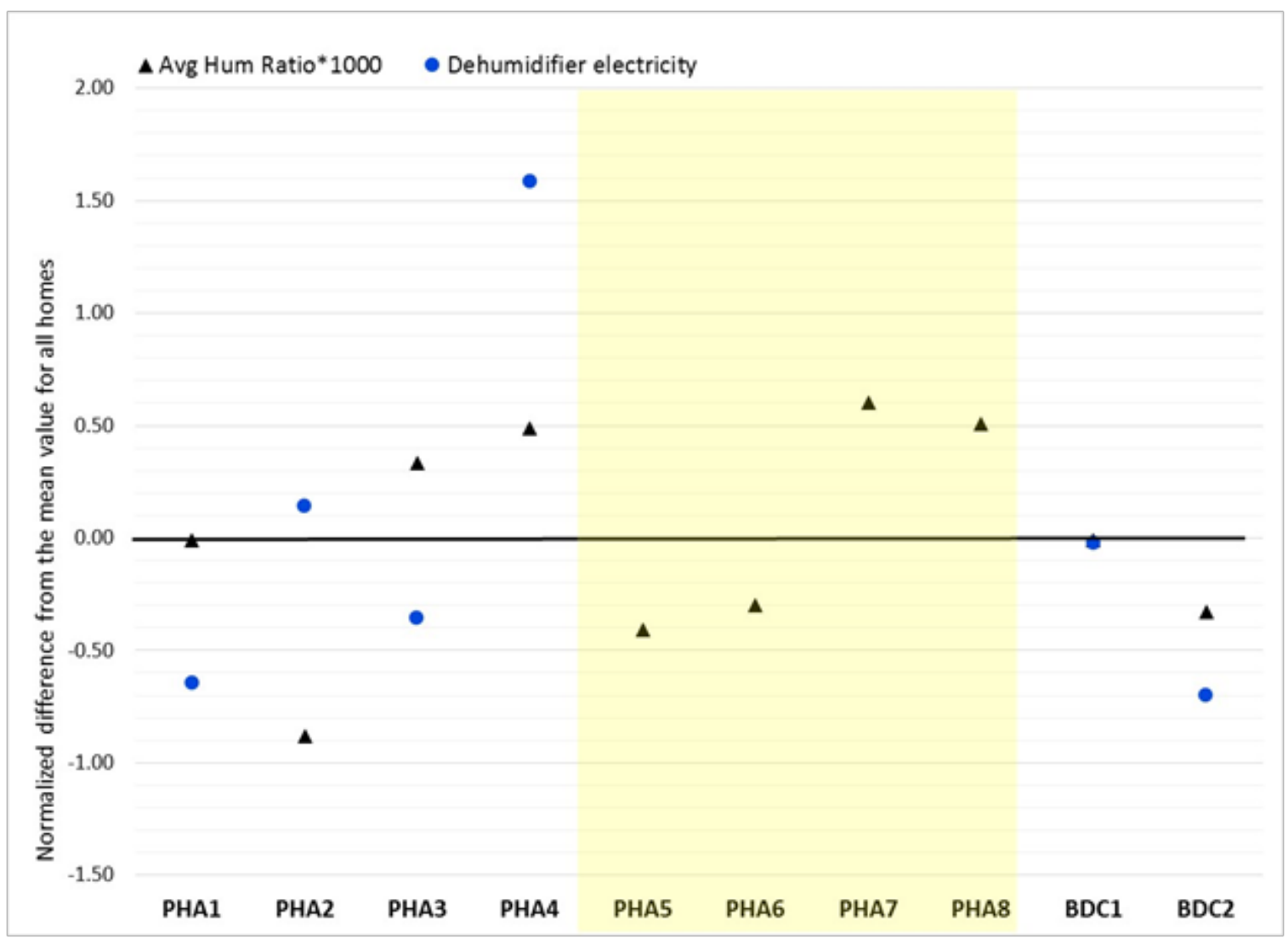

Figure 39. Variations in dehumidifier site energy use and HR from the mean values for all homes

Table 12 distills the variations in measurements into three categories, as was previously presented for the PHA homes without dehumidifiers.

Table 12. Classification of Variations in Measurements From the Mean Values for the PHA and BDC Homes With Dehumidification

\begin{tabular}{|c|c|c|c|c|c|c|}
\hline & \multicolumn{1}{c}{ PHA1 } & \multicolumn{1}{c}{ PHA2 } & \multicolumn{1}{c}{ PHA3 } & \multicolumn{1}{c}{ PHA4 } & \multicolumn{1}{c}{ BDC1 } & \multicolumn{1}{c}{ BDC2 } \\
\hline Occupancy (\# of People) & $1^{\mathrm{a}}$ & 1 or $2^{\mathrm{b}}$ & 4 & 4 & 1 & 1 \\
\cline { 2 - 7 } Hours Above 60\% RH & Average & High & High & Low & Low & Low \\
\hline HR & Average & Low & High & High & Average & Low \\
\hline Indoor Temperature & Average & Low & Average & High & High & Low \\
\cline { 2 - 7 } Master Bath Fan & Average & Low & Low & High & High & Low \\
\hline Hall Bath Fan & Average & Low & Low & High & Low & Low \\
\hline $\begin{array}{c}\text { Dehumidifier Electricity } \\
\text { Heat Pump Electricity }\end{array}$ & Low & High & Low & High & Average & Low \\
\hline DHW Electricity & Average & High & High & High & Low & Low \\
\hline Cooking Electricity & High & Average & High & Low & Low & Low \\
\hline Clothes Dryer Electricity & Average & Low & High & High & Low & Low \\
\hline
\end{tabular}

${ }^{a}$ Homeowner indicated that guests frequently stayed at the house

${ }^{b}$ Two occupants at the house until April 2013, then one for remainder of study 
In general, no single explanatory variable appears to provide a consistent understanding of the humidity control in each house. Indoor humidity is likely due to all of the factors we have examined, their interactions, and the specifics of how they are used by each occupant. The magnitude of this variability and the difficulty encountered in finding explanatory variables are important findings with implications for future research.

\subsection{Individual Data Results}

A discussion regarding the performance of each individual house can be instrumental in understanding and explain unexpected data results. The data presented for each house consist of:

- Scatter plot of hourly RH measurements $(\% \mathrm{RH})$ from the thermostat sensor.

- Frequency plot organizing a binned dataset of the number of hours the thermostat sensor was measured to have RH readings in specific ranges.

- Observations on occupant behavior, whether through interviews or direct observation during the installation and removal of the data logging equipment.

\subsubsection{Project Home Again 1: House With Dehumidifier}

The homeowner at PHA 1 initially indicated, during the equipment installation, that three people were living full time in the house: two adults and one child. The homeowner also noted that the house is often empty during the weekend. The occupancy profile did change throughout the study. At the end of the study, the homeowner indicated that only one person (the homeowner) lived in the house full time, but that guests are often staying at the house during weekends and holidays.

Figure 40 shows a plot of the interior \% $\mathrm{RH}$ along with the thermostat dry bulb. The data indicated an average dry bulb temperature of $72.3^{\circ} \mathrm{F}$ during the cooling season (May 1 to September 30).

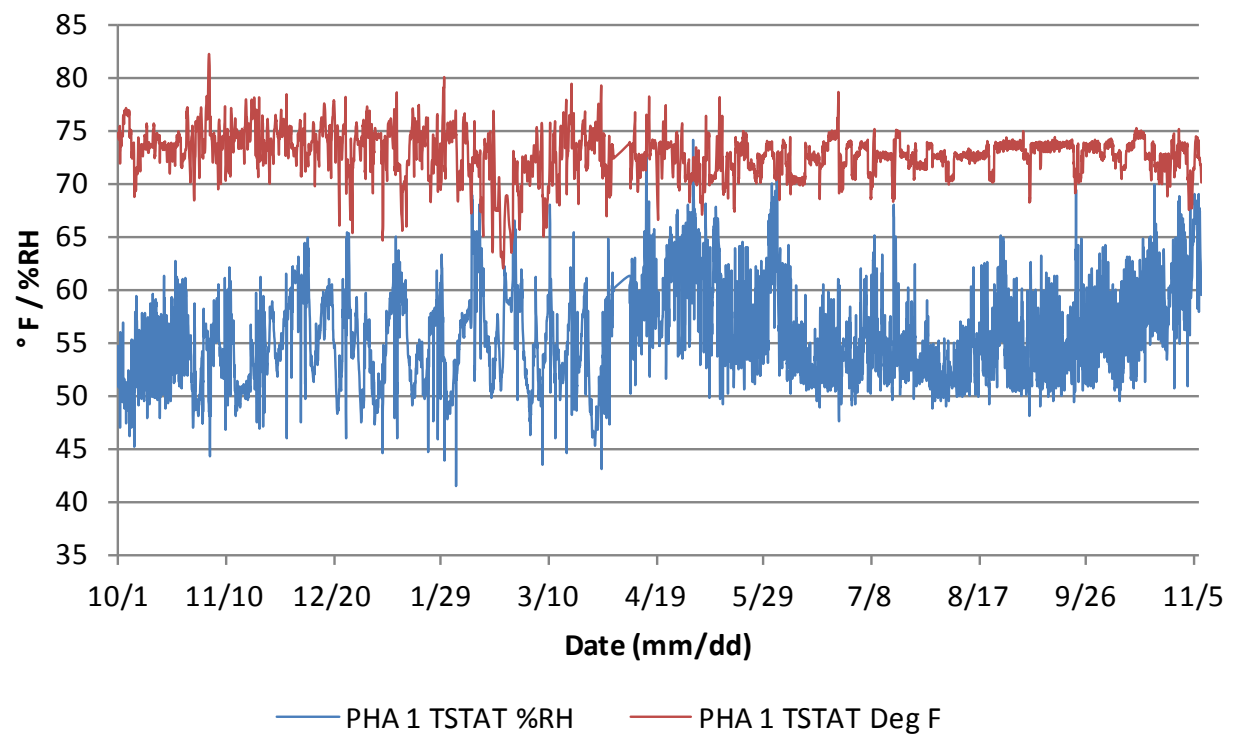

Figure 40. PHA 1 hourly interior temperature and \%RH plot 
Both bath fans appear to operate on an every other day basis, according to the monitored data. The occupant indicated in the interview that the kitchen range hood is operated during cooking. It was also indicated that the occupants rarely open the windows during the year. The dehumidistat was observed, during the removal of the equipment, to have been changed from the intended 2 bars $\left(60^{\circ} \mathrm{F} \mathrm{DP}\right)$ to 1 bar $\left(65^{\circ} \mathrm{F} \mathrm{DP}\right)$.

Figure 41 shows a plot of the hourly dehumidifier site energy use and the hourly average measured $\% \mathrm{RH}$ at the thermostat. The hourly data suggest that the dehumidistat set point change occurred on or around February 12, 2013. The dehumidifier only consumed $34.5 \mathrm{kWh}$ for the remainder of the study period.

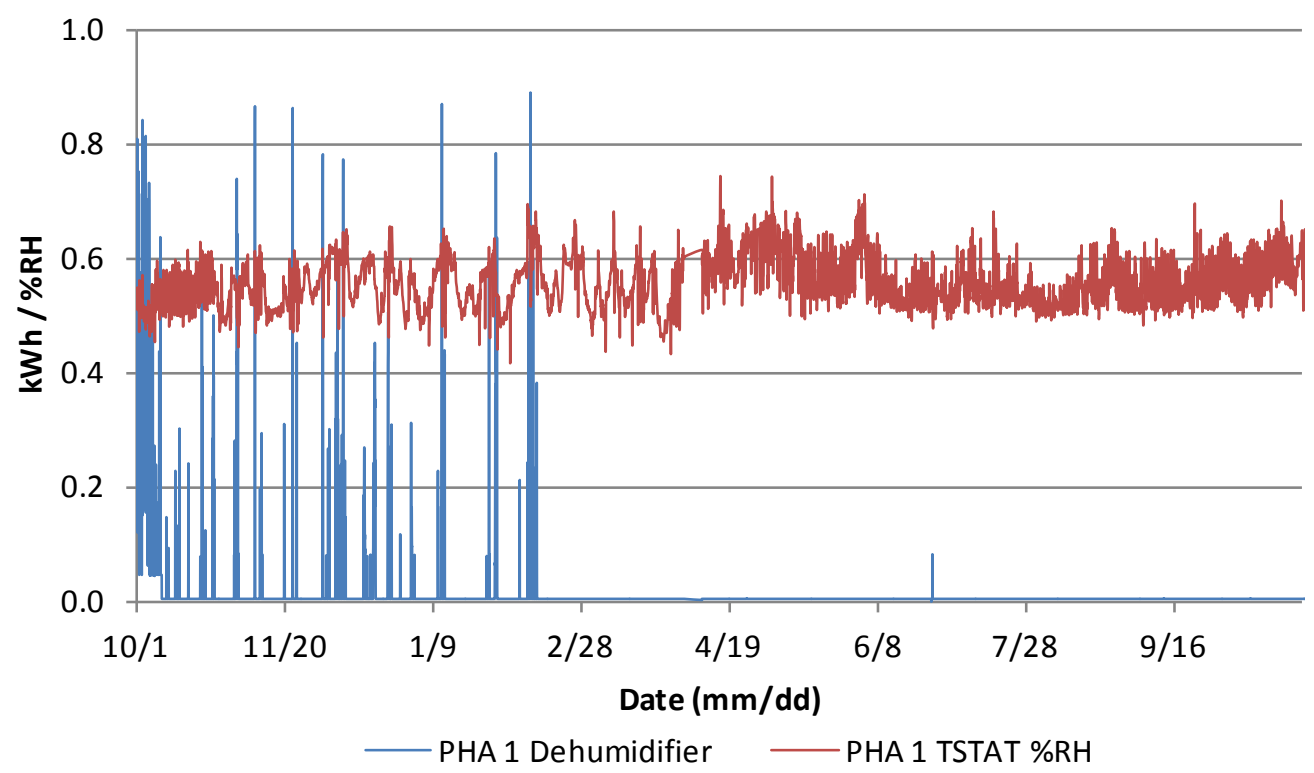

Figure 41. Hourly dehumidifier site energy use versus TSTAT \%RH for PHA 1

The summed hours above $60 \% \mathrm{RH}$ were parsed into two categories, to differentiate performance at the different set points:

- Hours when the dehumidistat was set to the intended two bars (October 1, 2012 to February 12, 2013

- Hours when the dehumidistat was changed to one bar (February 13, 2013 to November 7, 2013).

The number of hours above $60 \%$ RH drops from 1,566 hours for the whole year (16.4\%) to 269 hours while the dehumidistat was configured as intended (2.6\%). 1,297 of the hours above 60\% $\mathrm{RH}(82.8 \%$ of the total hours above $60 \% \mathrm{RH})$ were measured after the dehumidistat setting had been changed.

Figure 42 shows the hourly TSTAT \%RH frequency plot for PHA 1. Most hours are in the 50\%$55 \%$ range. 
PHA 1: $10 / 01 / 2012$ to $11 / 07 / 2013$

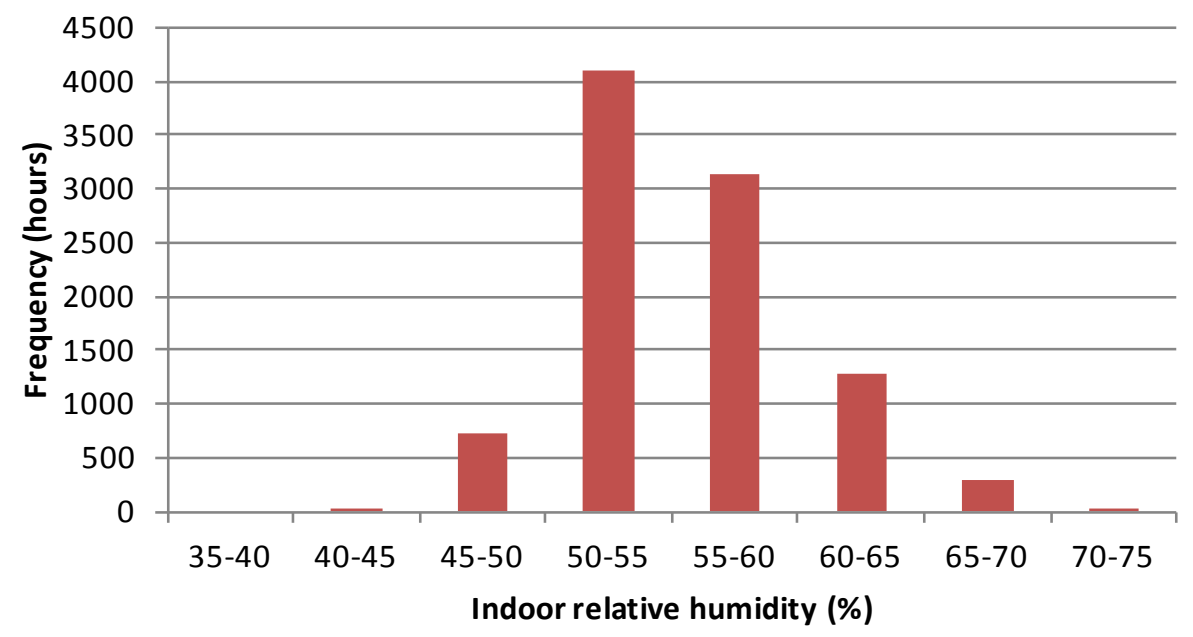

Figure 42. PHA 1 hourly \%RH frequency chart

Figure 43 shows the same frequency plot, for only for the hours from October 12, 2012 to February 12, 2013, when the data suggest that the dehumidistat was changed. There is a slight shift in the distribution of hours, as a higher percentage of hours are in the $50 \%-60 \% \mathrm{RH}$ range.

PHA 1: $10 / 01 / 2012$ to $02 / 12 / 2013$

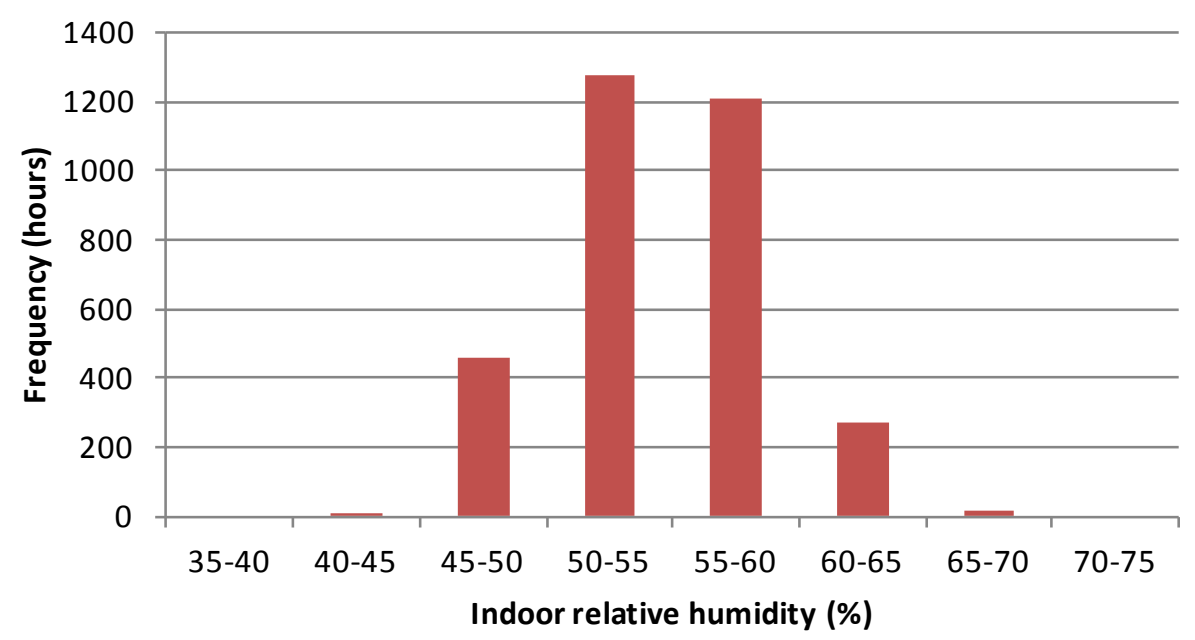

Figure 43. PHA 1 hourly \%RH frequency chart-hours with intended dehumidifier set point

\subsubsection{Project Home Again 2: House With Dehumidifier}

PHA 2 initially had two adult occupants, and two dogs, living full time in the residence and one of the occupants is home some of the weekdays. The number of occupants was reduced to one (the homeowner) in April 2013. The homeowner initially changed the dehumidistat setting from the intended two bars $\left(60^{\circ} \mathrm{F} \mathrm{DP}\right)$ to one bar $\left(65^{\circ} \mathrm{F} \mathrm{DP}\right)$, citing a perceived benefit in health at a 
higher RH. However, the data suggest that the set point was altered a number of times throughout the study. The dehumidistat setting was observed to be set to three bars $\left(56^{\circ} \mathrm{F} \mathrm{DP}\right)$ and the onboard display was indicating a measured $\mathrm{RH}$ in the space of $50 \% \mathrm{RH}$, during the equipment removal.

Figure 40 shows a plot of the interior \% RH along with the thermostat dry bulb. The data indicated an average dry bulb temperature of $68.5^{\circ} \mathrm{F}$ during the cooling season (May 1 to September 30). Thus, with the thermostat being set to around $70^{\circ} \mathrm{F}$, the dehumidifier will only maintain $\%$ RH below around $80 \%$.

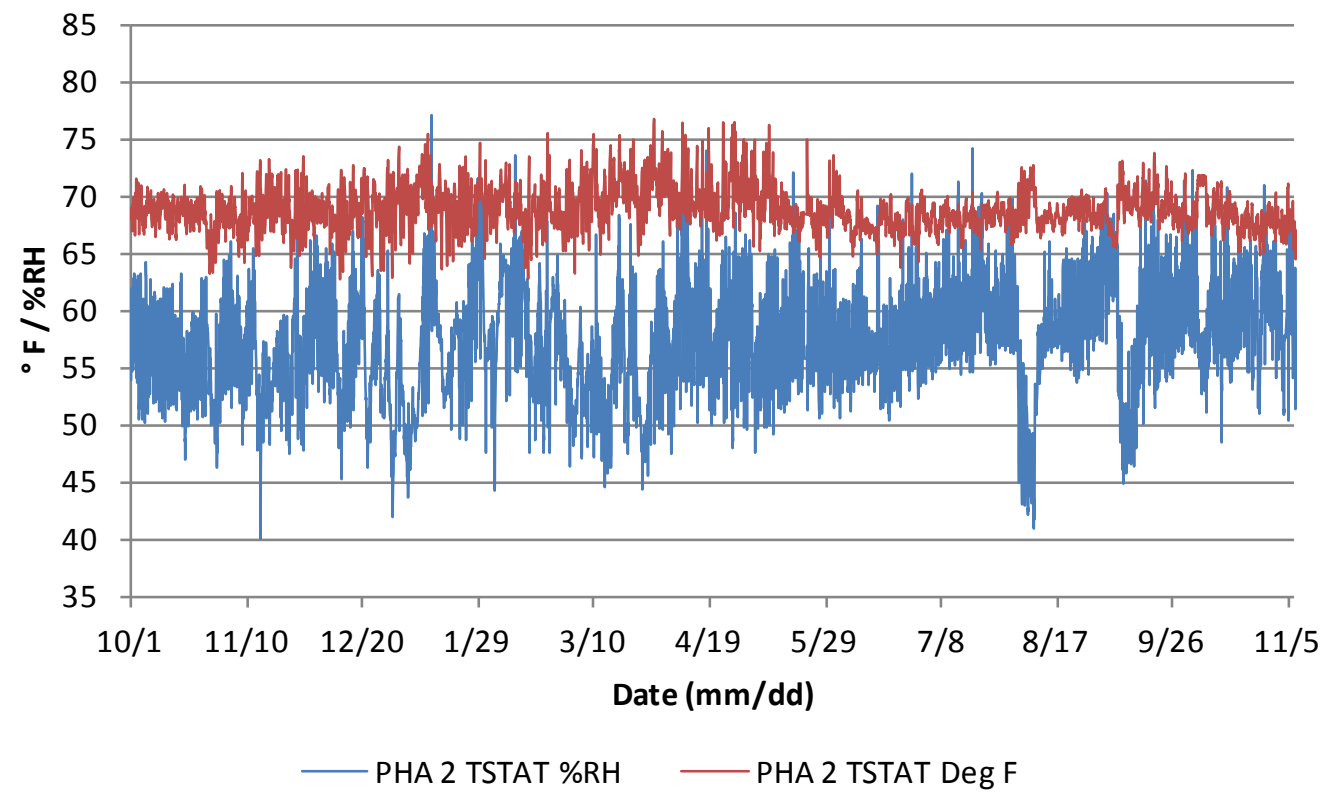

Figure 44. PHA 2 hourly interior temperature and \%RH plot

The master bathroom fan is operated about every other day, and the secondary bath fan is rarely turned on. The range/oven combination is being used on a daily basis according to the monitored data, but the homeowner reports only occasionally turning on the kitchen fan to control smoke.

Figure 45 shows the hourly TSTAT \%RH frequency plot for PHA 2. Most hours are in the 50\%$55 \%$ range, with around 800 hours in the $55 \%-60 \%$ bin. 
PHA 2: $10 / 1 / 2012$ to $11 / 07 / 2013$

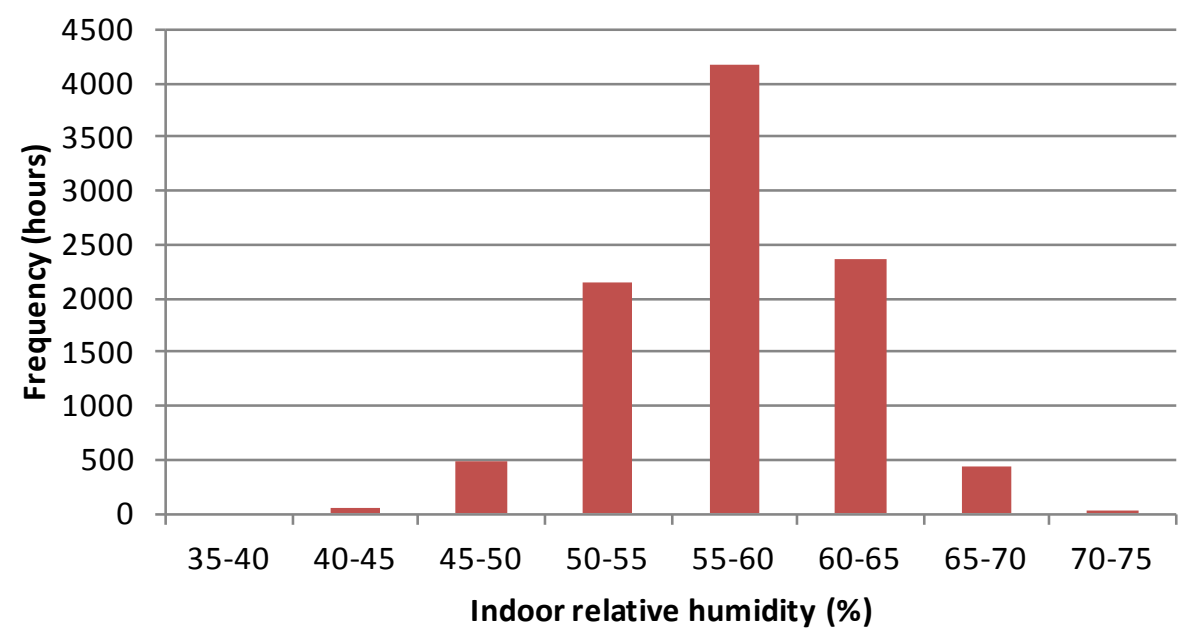

Figure 45. PHA 2 hourly \%RH frequency chart

Figure 46 shows daily dehumidifier kilowatt-hour consumption. It is difficult to confirm with the existing dataset, but there appear to be four episodes of operation: February, April, July, and September/October. The impact on RH was observed during dehumidifier operation in July and September/October.

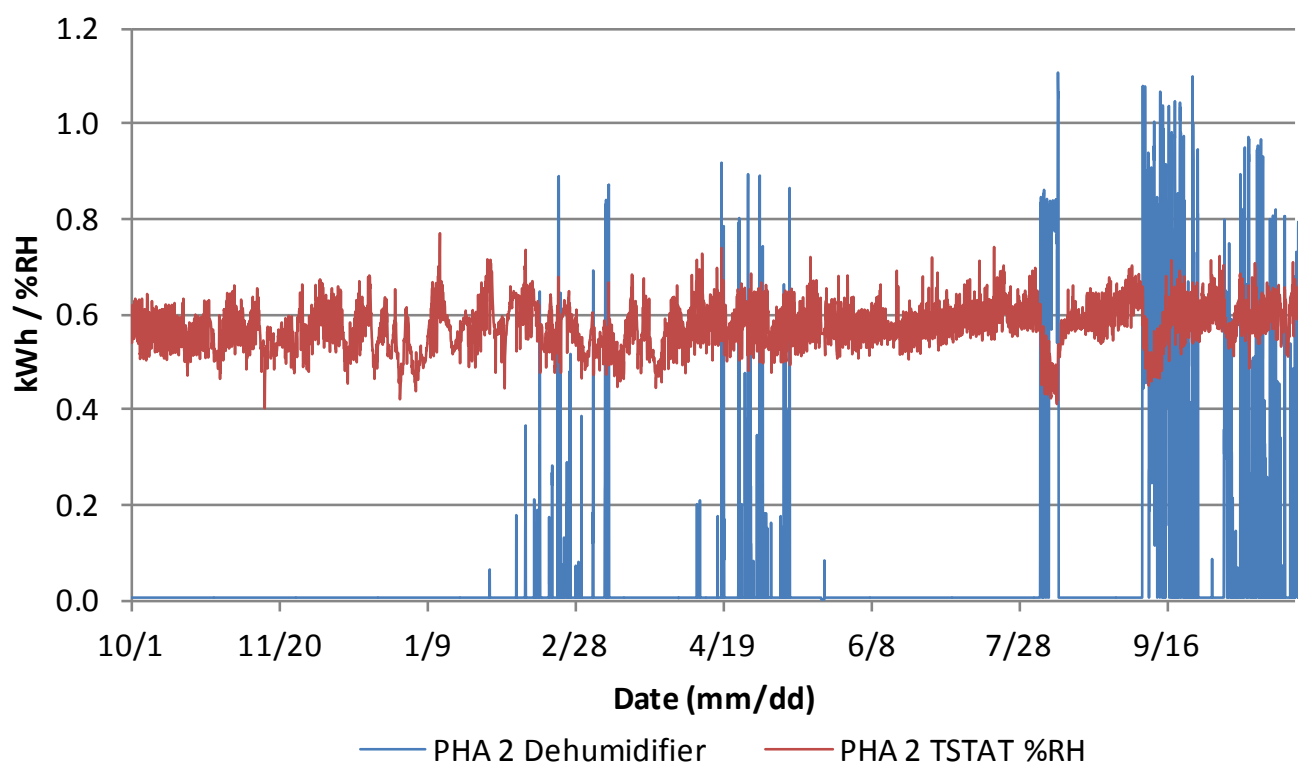

Figure 46. Hourly dehumidifier site energy use versus TSTAT \%RH for PHA 2 


\subsubsection{Project Home Again 3: House With Dehumidifier}

PHA 3 has four occupants: two adults and two children, living full time in the residence. One of the occupants is home some of the weekdays. Figure 47 shows a plot of the interior \%RH along with the thermostat dry bulb. The data indicated an average dry bulb temperature of $68.5^{\circ} \mathrm{F}$ during the cooling season (May 1 to September 30).

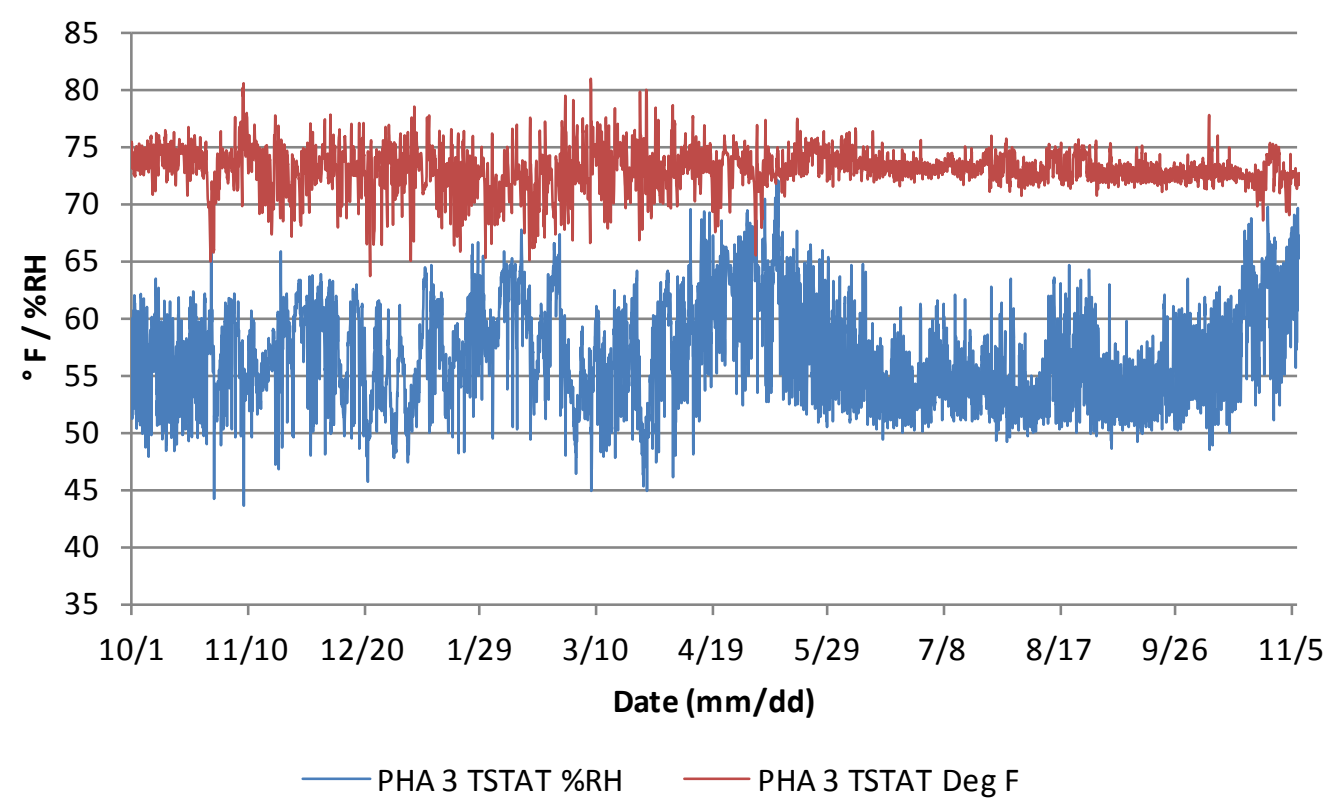

Figure 47. PHA 3 hourly interior temperature and \% RH plot

The monitored data indicated that both the master bathroom fan and the second bath fan were not operated at all during the study. The sensors did detect a few instances of fan use, suggesting that the sensors were functioning properly. The homeowners indicated that they do not cook or use the kitchen range hood on a daily basis. However, according to the data, the amount of site energy consumed by the oven/range is the second highest out of all 8 PHA homes $(780 \mathrm{kWh}$, which is $37 \%$ higher than the average figure)

Figure 48 shows the hourly TSTAT \%RH frequency plot for PHA 3. Most hours are in the 50\%$55 \%$ range, with around 700 hours in the $55 \%-60 \%$ bin. 
PHA3: $10 / 01 / 2012$ to $11 / 07 / 2013$

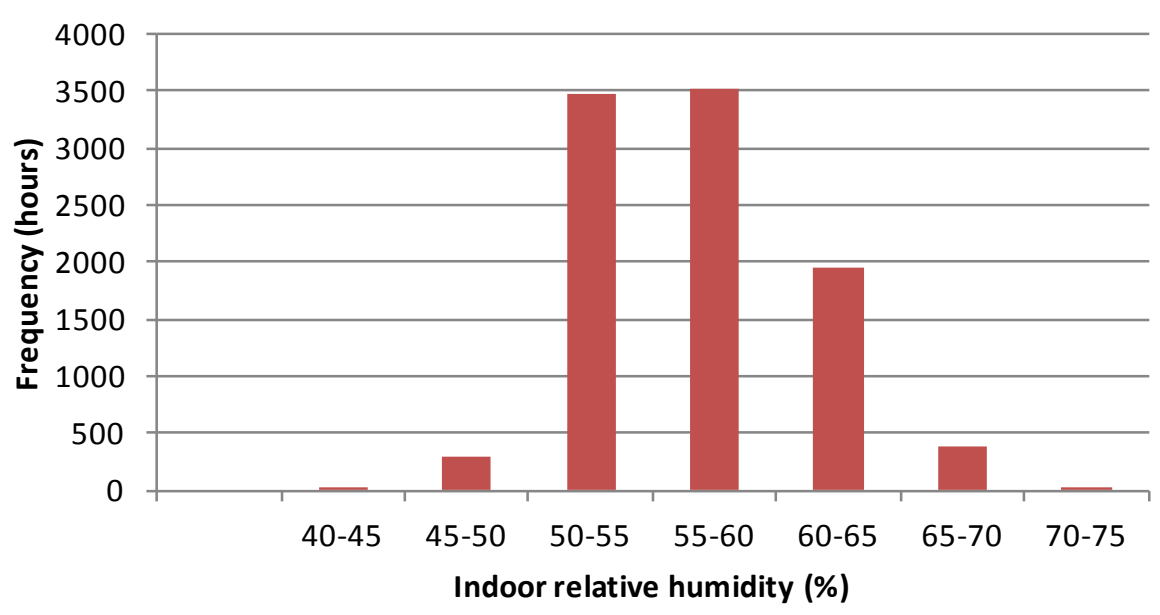

Figure 48. PHA 3 hourly \%RH frequency chart

Figure 49 shows daily dehumidifier kilowatt-hour consumption. A change in the performance of the dehumidifier occurred on around April 12, 2013. The occupant claims to not have adjusted the dehumidistat setting, and it was observed to be set to the intended two bars during the equipment removal.

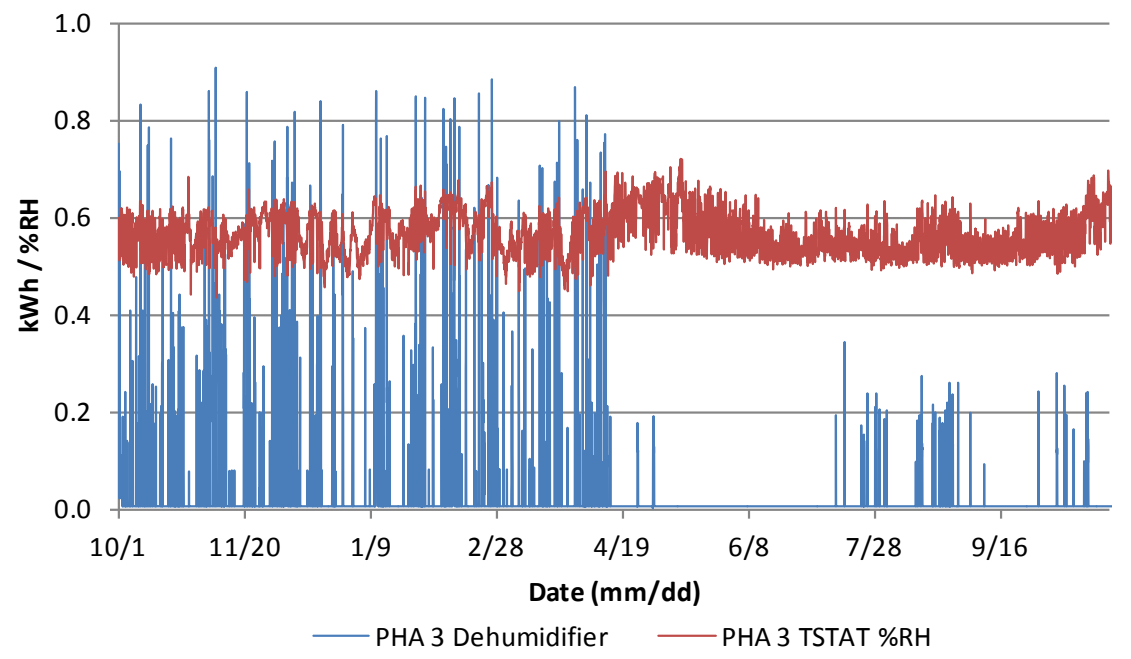

Figure 49. Hourly dehumidifier site energy use versus TSTAT \%RH for PHA 3

As discussed in Section 3.2.2, electric backup heat was operating excessively from November 2012 to March 2013. Figure 50 below shows an example of the 1-minute data for PHA 3 during the month of January 2013. The air handler electricity use and the dry bulb temperature in the supply plenum of the HVAC system are plotted. The large spikes in both air handler kilowatthours and supply plenum dry bulb temperatures suggest electric backup heat operation. 


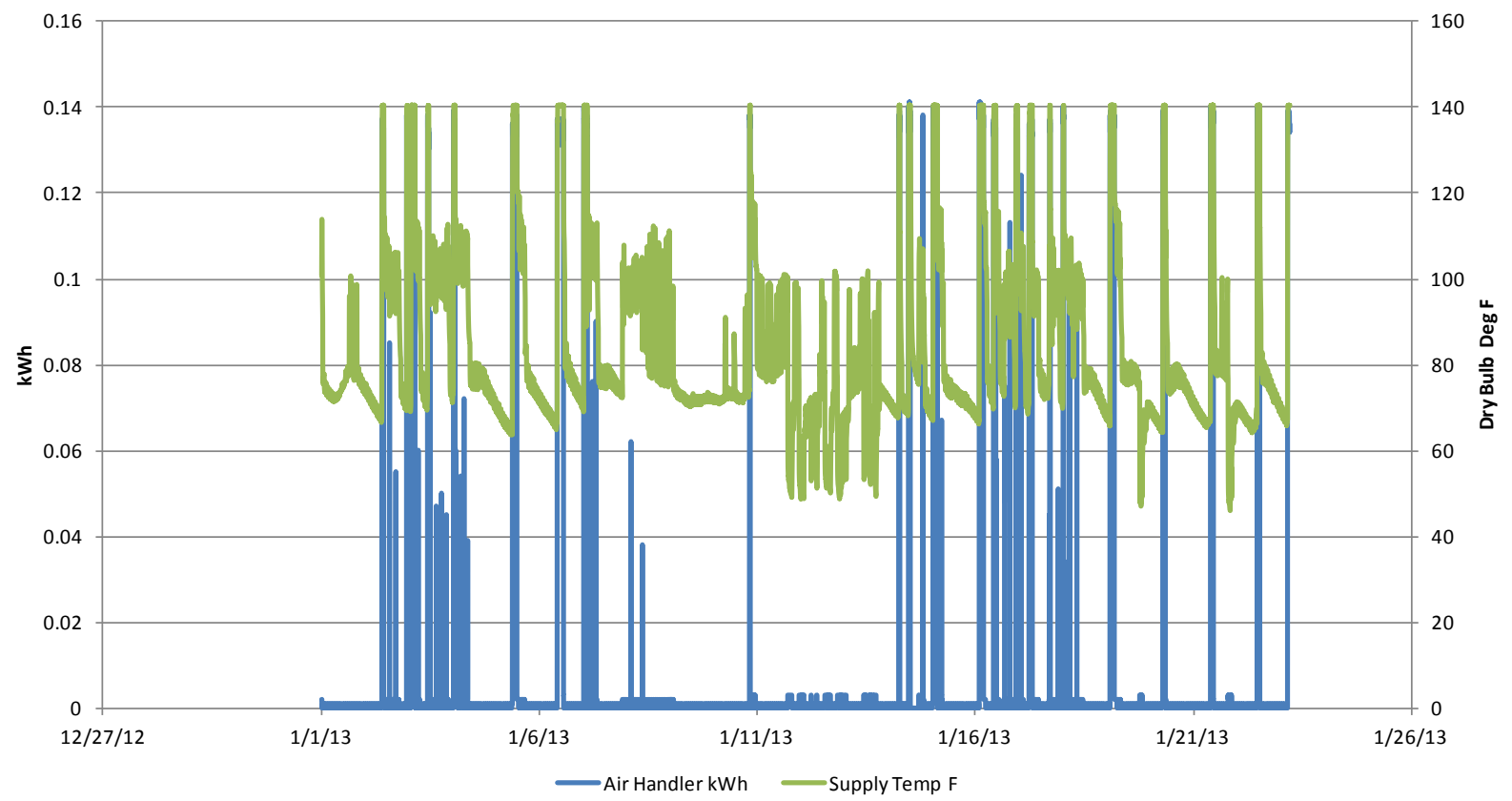

Figure 50. PHA 3 air handler and supply plenum air temperature-1-min plot for January 2013

\subsubsection{Project Home Again 4: House With Dehumidifier}

PHA 4 has four occupants: two adults and two children, living full time in the residence. The house is unoccupied during the weekdays. Figure 51 shows a plot of the interior $\% \mathrm{RH}$ along with the thermostat dry bulb. The data indicated an average dry bulb temperature of $77.8^{\circ} \mathrm{F}$ during the cooling season (May 1 to September 30).

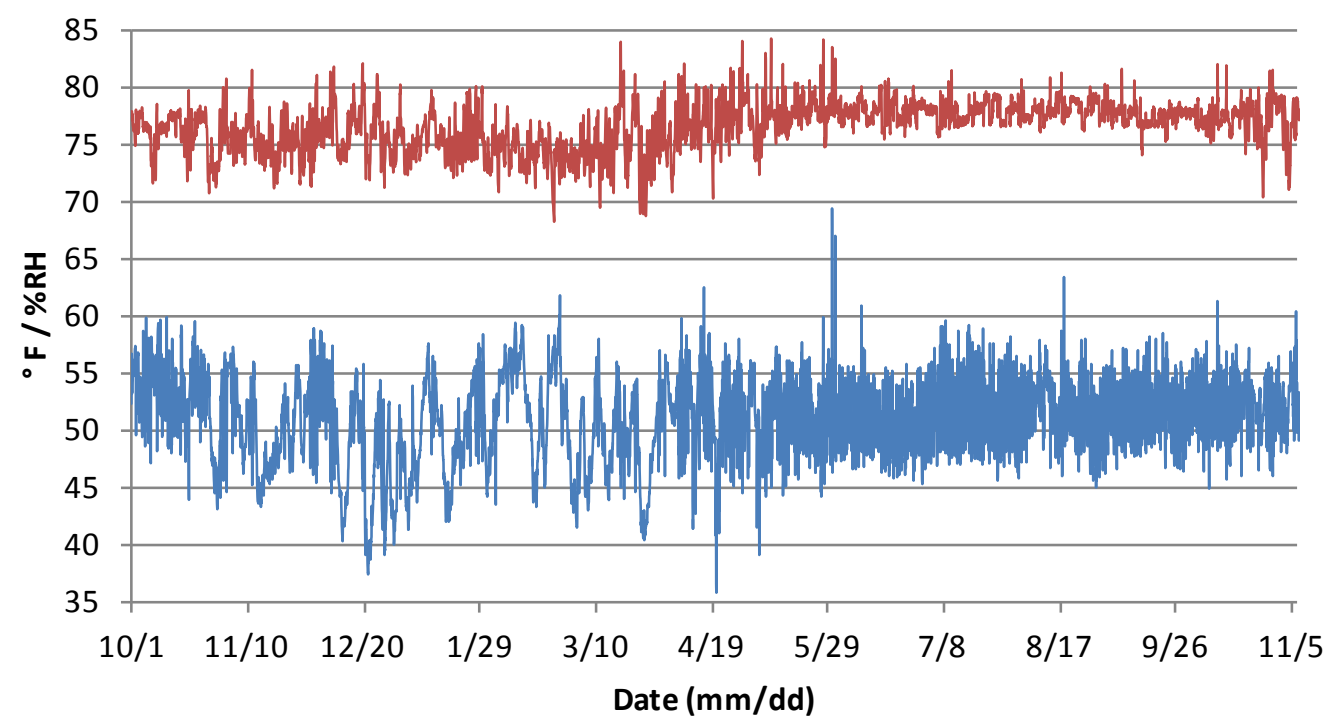

— PHA 4 TSTAT \%RH — PHA 4 TSTAT Deg F

Figure 51. PHA 4 hourly interior temperature and \%RH plot 
The master bathroom fan is operated daily, and the secondary bath fan is operated most days. Details on the operation of the kitchen exhaust were not determined.

Figure 52 shows the hourly TSTAT \%RH frequency plot for PHA 4. Most hours are in the 50\%$55 \%$ range, with around 400 hours in the $55 \%-60 \%$ bin. The number of hours above $60 \%$ RH was 12 hours. It should be noted that the elevated indoor dry bulb temperature that was maintained in the residence $\left(77.8^{\circ} \mathrm{F}\right)$ may also be contributing to the reduced amount of hours above $60 \% \mathrm{RH}$.

PHA 4 is the sole house with supplemental dehumidification that controlled humidity levels in the living space throughout the study, limiting the hours above $60 \%$ RH to 12 hours out of 9,672 total hours ( $0.1 \%$ of hours). The Aprilaire 1750 whole house, ducted, dehumidifier operated around 1400 hours throughout the study period $(14.5 \%$ versus the $10 \%$ runtime that was predicted). The dehumidifier consumed 1,177 $\mathrm{kWh}$ of site energy, equivalent to around $\$ 129$ in utility costs. It should be noted that the predicted site energy use $(1,077 \mathrm{kWh})$ is only $9 \%$ less than the measured kilowatt-hours, which suggests that the estimated 1400 hours of operation may be higher than the actual runtime, but it was not possible to calculate it with the dataset as is.

PHA4: $10 / 01 / 2012$ to $11 / 07 / 2013$

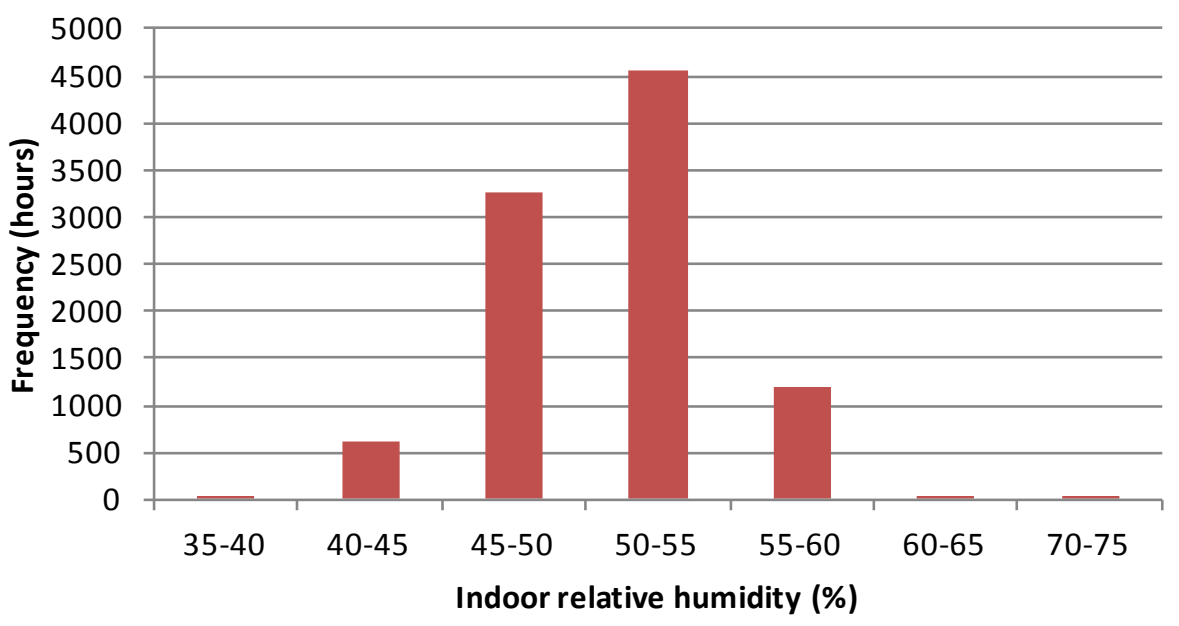

Figure 52. PHA 4 hourly \%RH frequency chart

Figure 53 shows daily dehumidifier kilowatt-hour consumption. The dehumidifier operated consistently throughout the year, with a reduction in operation during the winter months (as expected). 


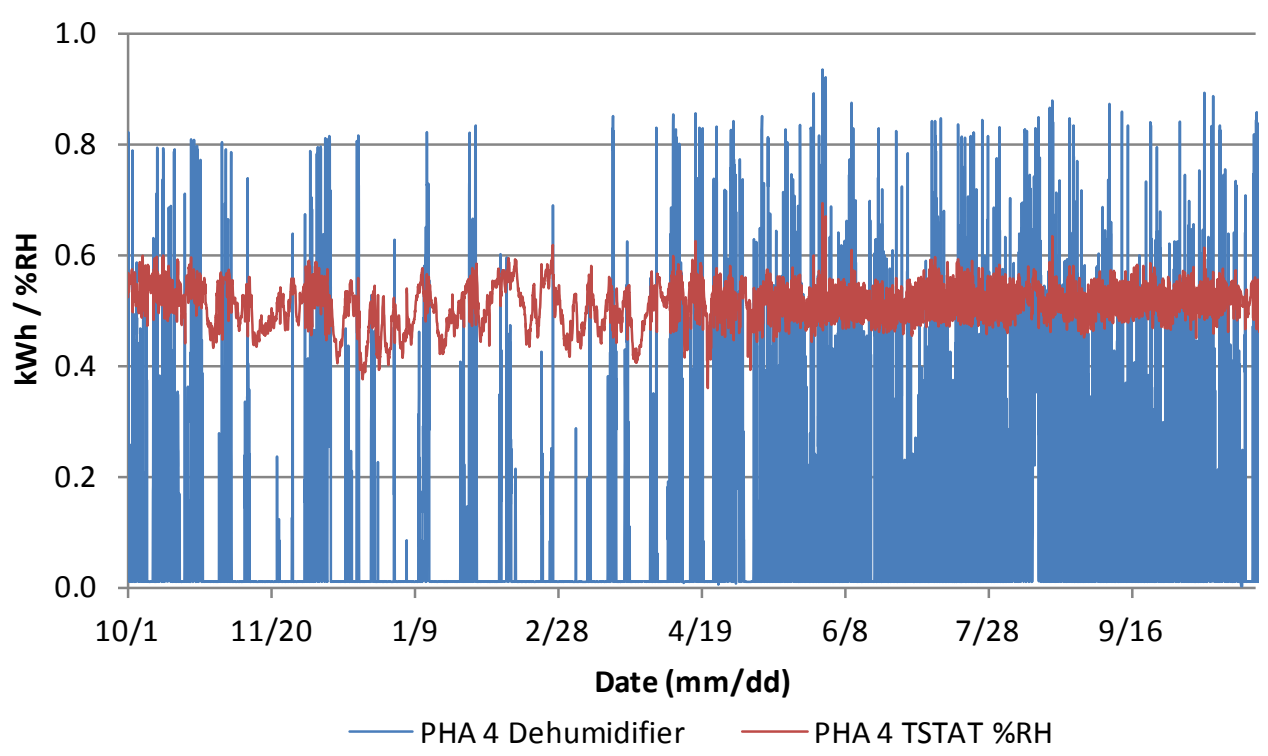

Figure 53. Hourly dehumidifier site energy use versus TSTAT \%RH for PHA 3

\subsubsection{Project Home Again 5: House Without Dehumidifier}

The homeowner at PHA 5 initially indicated, during the equipment installation, that four people were living full time in the house: three adults and one child. At the end of the study, the homeowner indicated that only three people were living in the house full time, two adults and one child. Figure 54 shows a plot of the interior $\% \mathrm{RH}$ along with the dry bulb temperature in the master bedroom (the thermostat sensor malfunctioned, as stated earlier in the report). The data indicated an average dry bulb temperature of $69.3^{\circ} \mathrm{F}$ during the cooling season (May 1 to September 30).

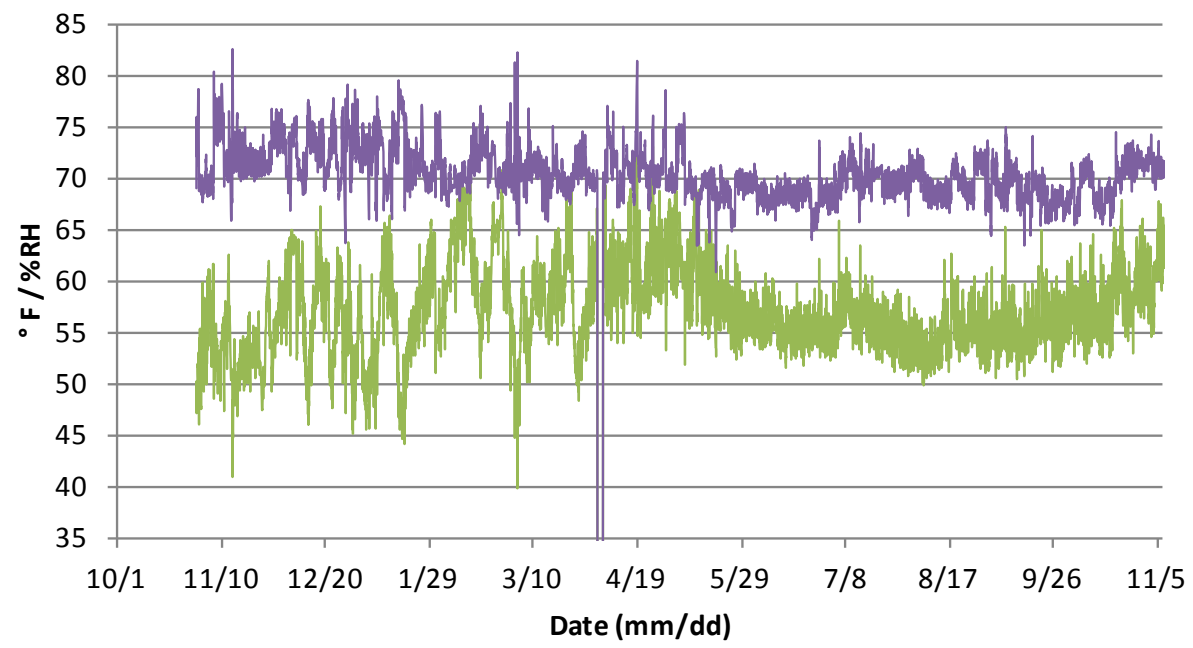

— PHA 5 M Bed \%RH — PHA 5 M Bed Deg F

Figure 54. PHA 5 hourly interior temperature and \%RH plot 
The bath exhaust fans were operated intermittently throughout the study. Details on the operation of the kitchen exhaust were not determined.

Figure 55 shows the hourly TSTAT \%RH frequency plot for PHA 5. The vast majority of the hours are in the $45 \%-55 \%$ range.

PHA 5: $10 / 31 / 2012$ to $11 / 07 / 2013$

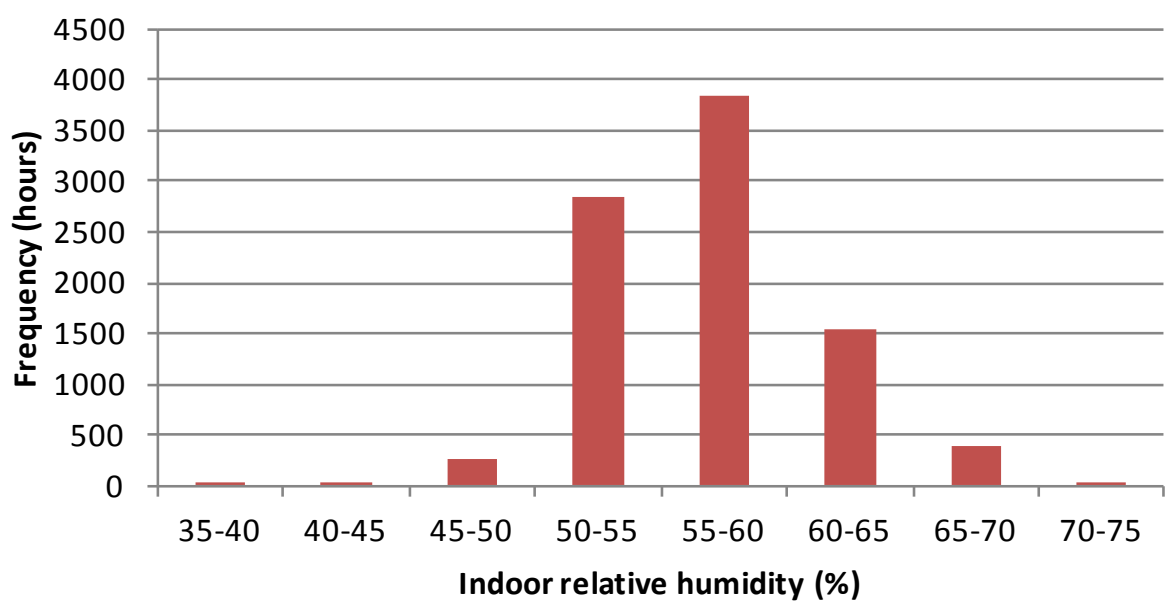

Figure 55. PHA 5 hourly \%RH frequency chart

PHA 5 registered very few hours above $60 \% \mathrm{RH}$, despite not having a dehumidifier. As mentioned in Section 3.2.4, one contributing factor may be that the cooking and dryer use at PHA 5 is among the highest in the entire study group. Additional sensible gain from these appliances may be increasing the sensible gain to the space, which may be contributing to the higher than average HVAC energy use. The extended runtimes will result in better humidity control.

\subsubsection{Project Home Again 6: House Without Dehumidifier}

PHA 6 has one occupant and two dogs and the house is unoccupied during the weekdays. Figure 56 shows a plot of the interior $\% \mathrm{RH}$ along with the thermostat dry bulb. The data indicated an average dry bulb temperature of $73.7^{\circ} \mathrm{F}$ during the cooling season (May 1 to September 30 ).

The interior conditions appear to follow an expected $\% \mathrm{RH}$ pattern, with humidity control being provided by the cooling system during the summer and levels beginning to rise in the fall.

The bath exhaust fans are operated daily, according to the measured data. The total energy use was the lowest out of the eight PHA homes. The master bath fan is used every day, and the hall bath fan appears to be used when occupied, which was confirmed by the occupant. Range/oven use is limited compared to the other residences, and the occupant confirms that the kitchen exhaust is used during occasional cooking. A reduced sensible gain in the house due to low occupancy, and the proper use of point source exhaust fans, are contributing to the low humidity levels in the space. 


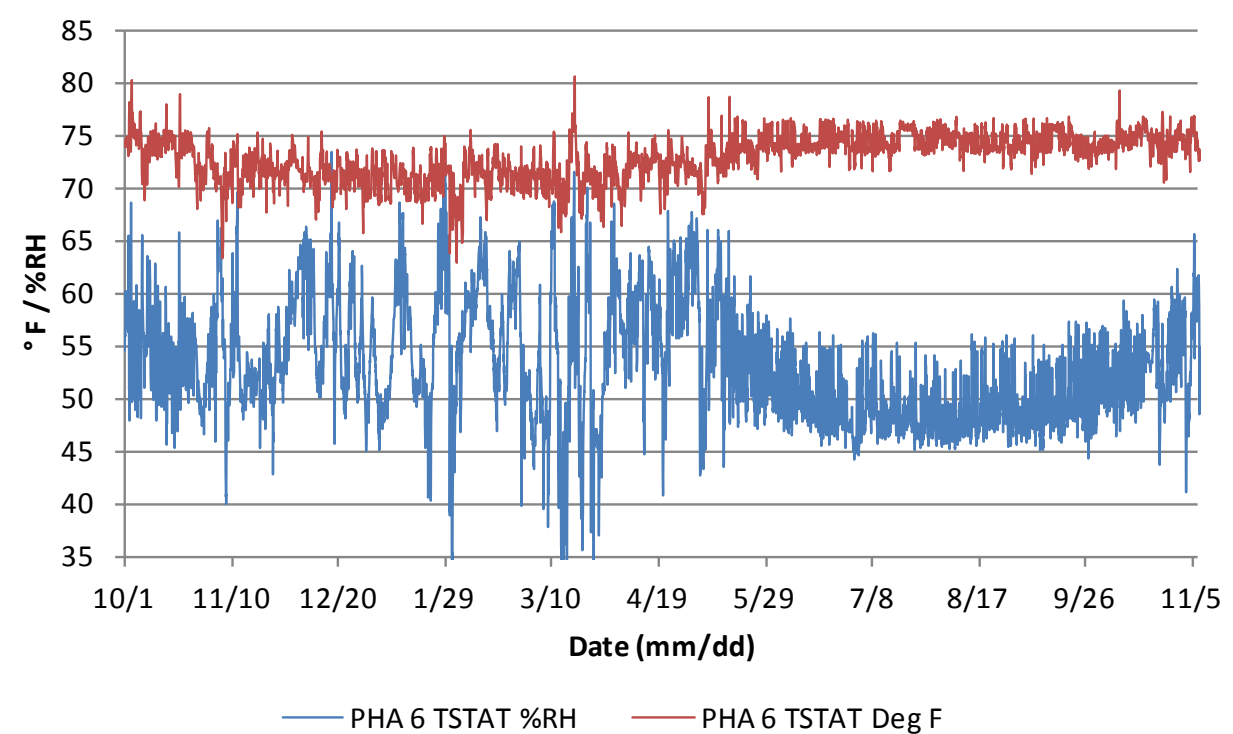

Figure 56. PHA 6 hourly interior temperature and \%RH plot

Figure 57 shows the hourly master bedroom \%RH frequency plot for PHA 6. Most hours are in the $45 \%-50 \%$ range.

PHA6: $10 / 01 / 2012$ to $11 / 07 / 2013$

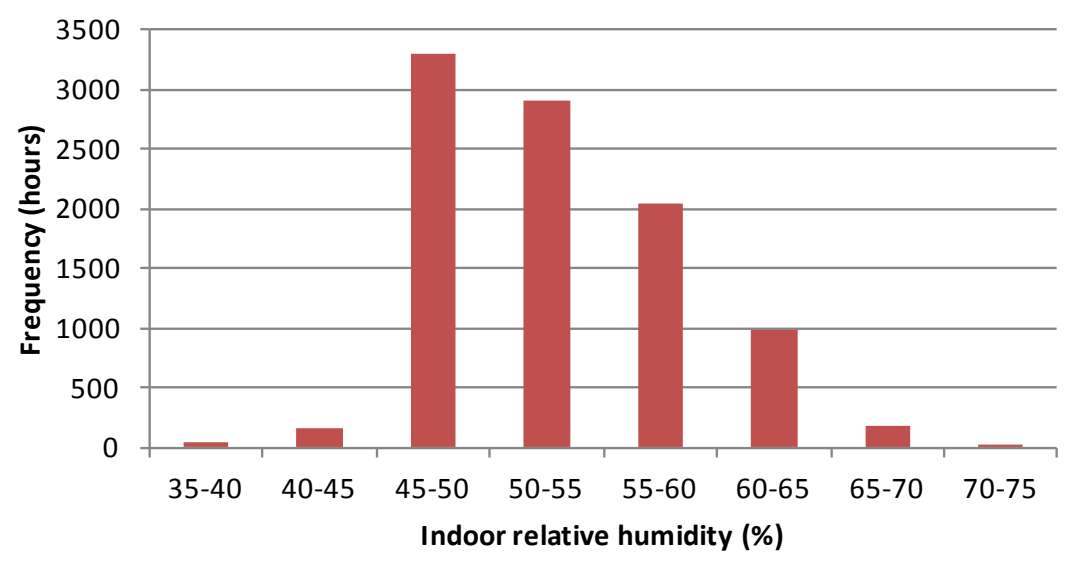

Figure 57. PHA 6 hourly \%RH frequency chart

\subsubsection{Project Home Again 7: House Without Dehumidifier}

The homeowner at PHA 7 initially indicated, during the equipment installation, that four people were living full time in the house: one adult and three adolescents. At the end of the study, the homeowner indicated that only two people were living in the house full time. Figure 56 shows a plot of the interior \%RH along with the thermostat dry bulb. The data indicated an average dry bulb temperature of $71.6^{\circ} \mathrm{F}$ during the cooling season (May 1 to September 30). PHA 7 is also 
following an expected \%RH pattern, with humidity control being provided by the cooling system during the summer and levels beginning to rise in mid-September.

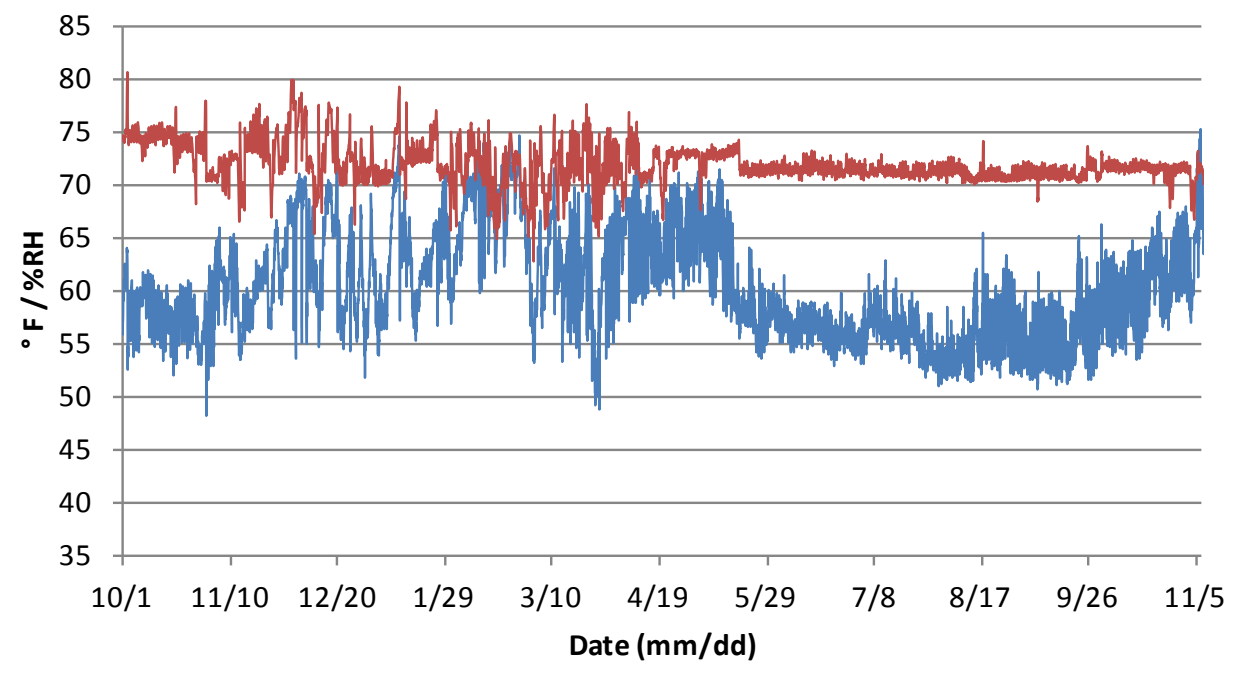

- PHA 7 TSTAT \%RH — PHA 7 TSTAT Deg F

Figure 58. PHA 7 hourly interior temperature and \%RH plot

The bath exhaust fans are operated daily, according to the measured data. Details on the operation of the kitchen exhaust were not determined.

The hot water energy use at PHA 7 was the second highest out of the eight PHA homes.

Figure 59 shows the hourly TSTAT \%RH frequency plot for PHA 7. Most hours are in the 50\%$55 \%$ range.

PHA 7: $10 / 01 / 2012$ to $11 / 07 / 2013$

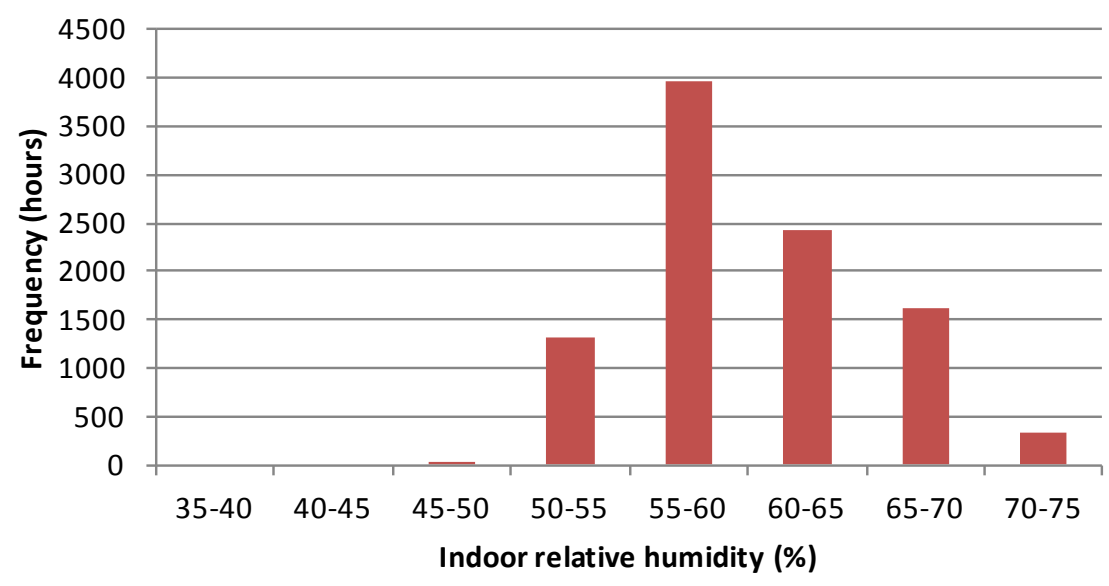

Figure 59. PHA 7 hourly \%RH frequency chart 


\subsubsection{Project Home Again 8: House Without Dehumidifier}

PHA 8 has two occupants and three dogs living full time in the house. One of the occupants is present during the weekdays. Figure 60 does show a rise in interior humidity levels from midNovember 2012 to February 2013. The data indicated an average dry bulb temperature of $74.4^{\circ} \mathrm{F}$ during the cooling season (May 1 to September 30).

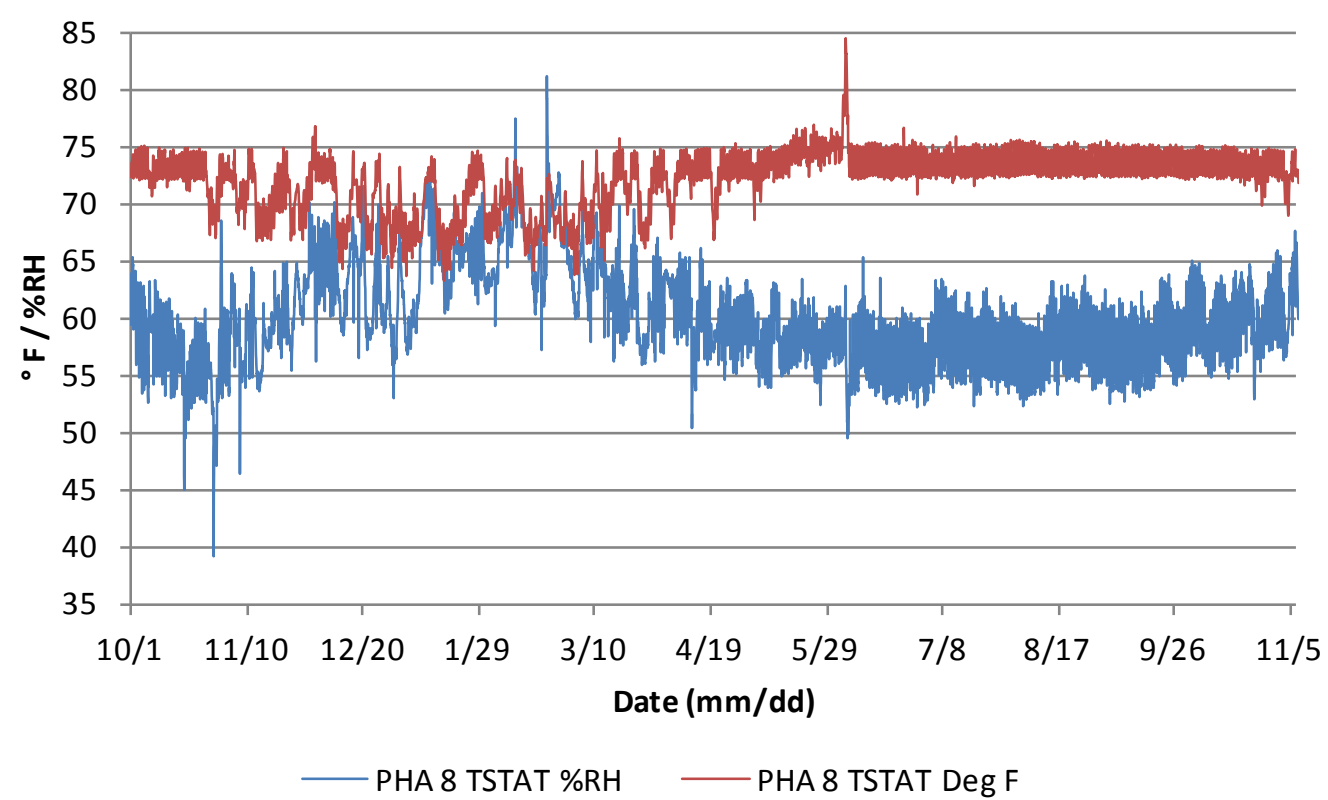

Figure 60. PHA 8 hourly interior temperature and \%RH plot

As indicated in Section 3.1, there are significant periods when the \%RH is above $60 \%$. The homeowner did not notice the elevated humidity levels in the space, and was not aware of the continuously operating air handler until contacted by the team.

The bath exhaust fans are operated daily, according to the measured data. The homeowner indicated that the range hood fan is turned on during cooking.

Figure 61 shows the hourly TSTAT \%RH frequency plot for PHA 8. Most hours are in the 55\%$60 \%$ range, along with 612 hours above $60 \% \mathrm{RH}$. 
PHA 8: $10 / 01 / 2012$ to $11 / 07 / 2013$

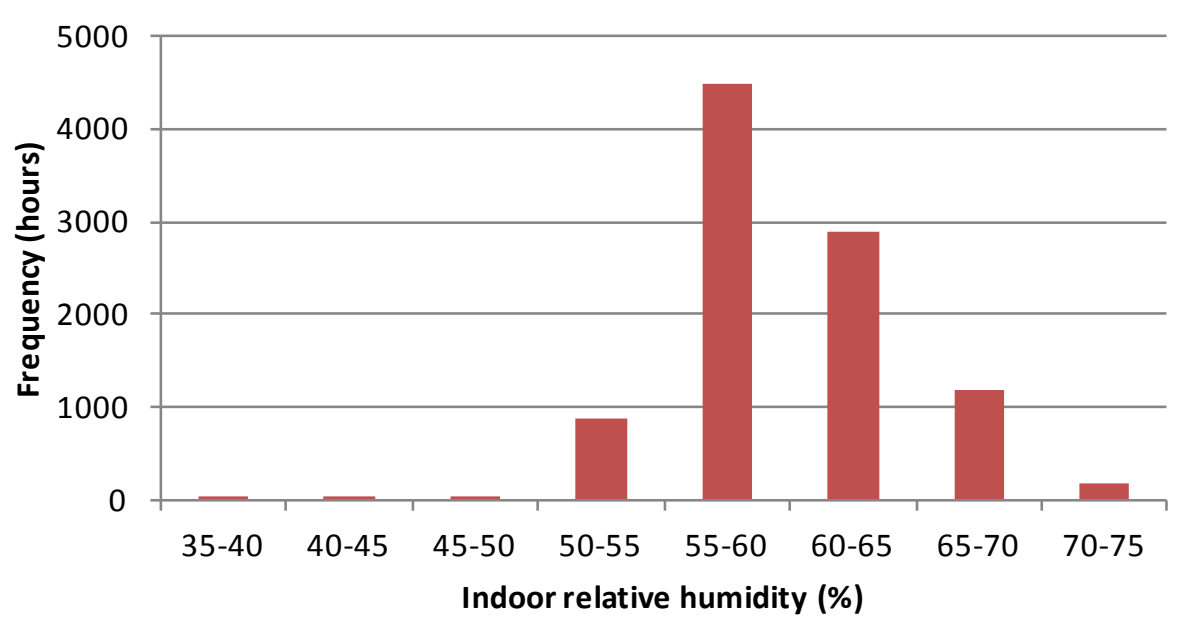

Figure 61. PHA 8 hourly \%RH frequency chart

\subsubsection{Broadmoor Development Corporation 1: House With Dehumidifier}

BDC 1 has one occupant, plus one cat and one dog, living full time in the residence. Figure 62 shows a plot of the interior $\% \mathrm{RH}$ along with the thermostat dry bulb. The data indicated an average dry bulb temperature of $73.7^{\circ} \mathrm{F}$ during the cooling season (May 1 to September 30 ).

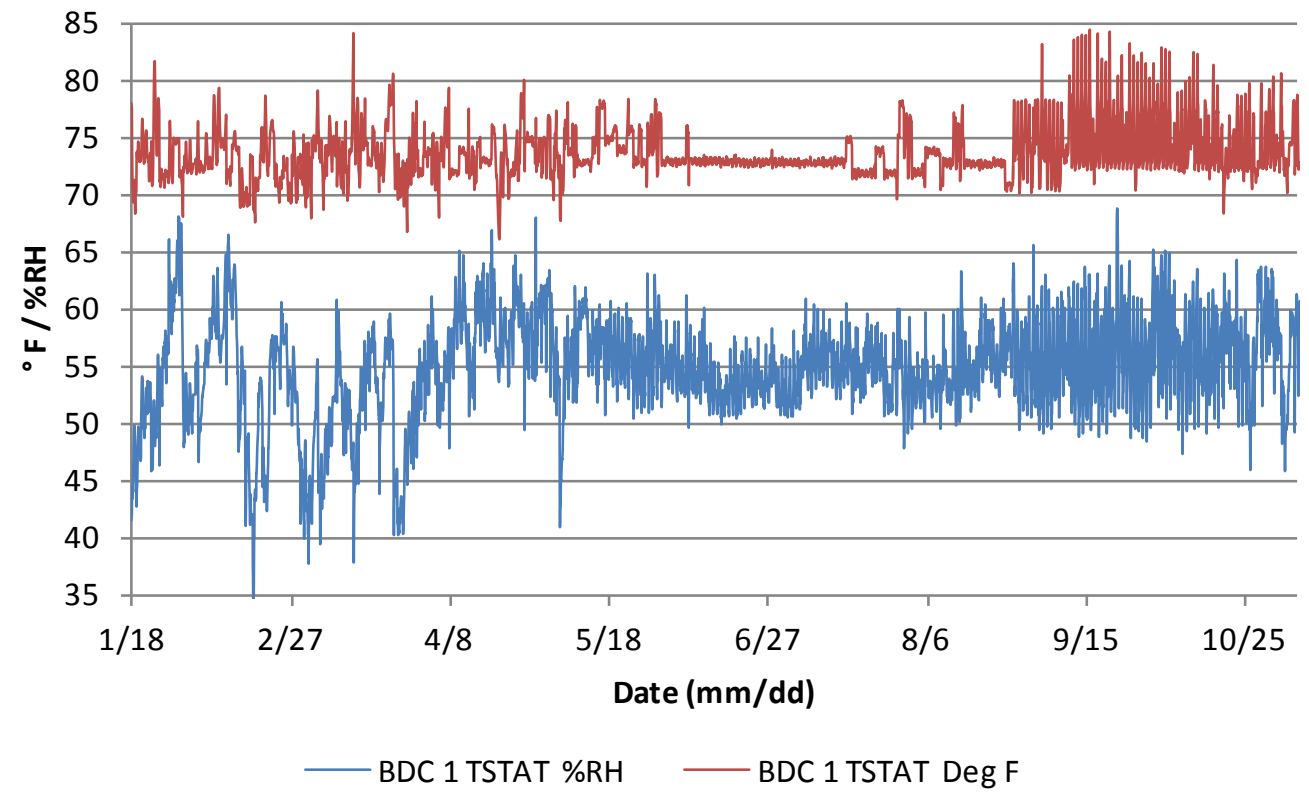

Figure 62. BDC 1 hourly interior temperature and \%RH plot

Figure 63 shows the hourly TSTAT \%RH frequency plot for the BDC 1 . Most hours are in the $50 \%-60 \%$ range. 
BDC 1: $01 / 18 / 2013$ to $11 / 07 / 2013$

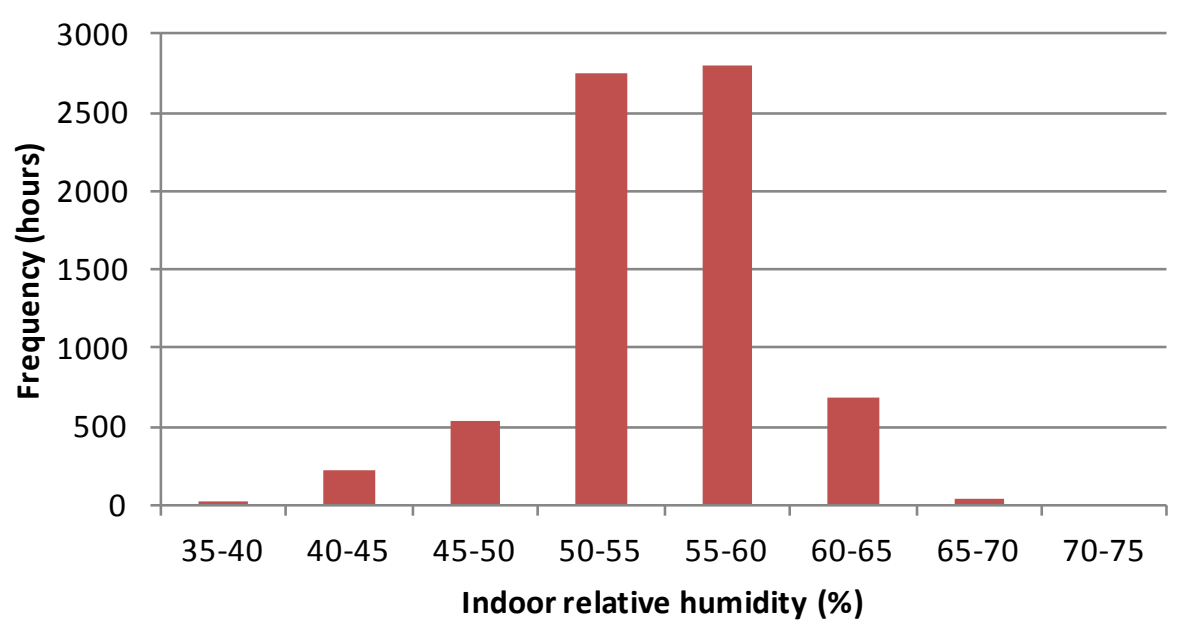

Figure 63. BDC 1 hourly \%RH frequency chart

Figure 64 shows daily dehumidifier kilowatt-hour consumption. The dehumidifier consumed the most energy during the summer and early fall months. The reduced latent removal capacity of the HVAC system, due to the oversized air handler, may have forced the dehumidifier to operate more to compensate.

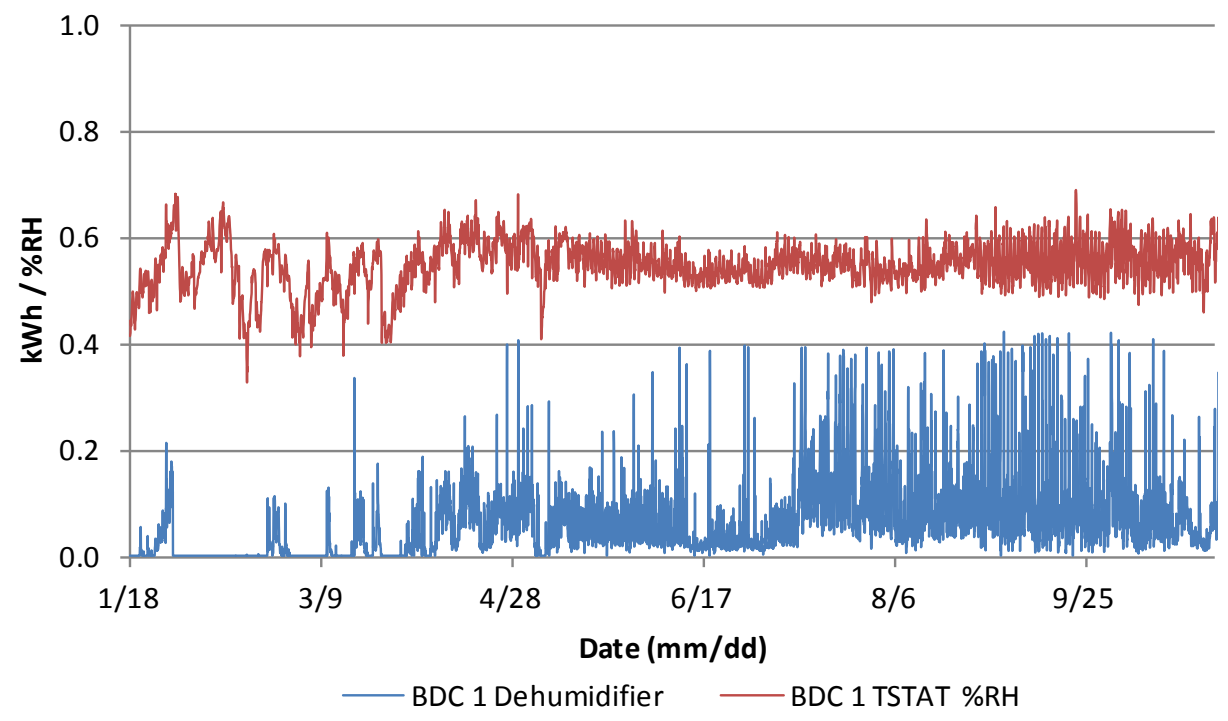

Figure 64. Hourly dehumidifier site energy use versus TSTAT \%RH for BDC 1

\subsubsection{Broadmoor Development Corporation 2: House With Dehumidifier}

BDC 2 has 1 occupant living full time in the residence. Figure 65 does show a rise in interior humidity levels from February to May. The data indicated an average dry bulb temperature of $74.4^{\circ} \mathrm{F}$ during the cooling season (May 1 to September 30 ). 


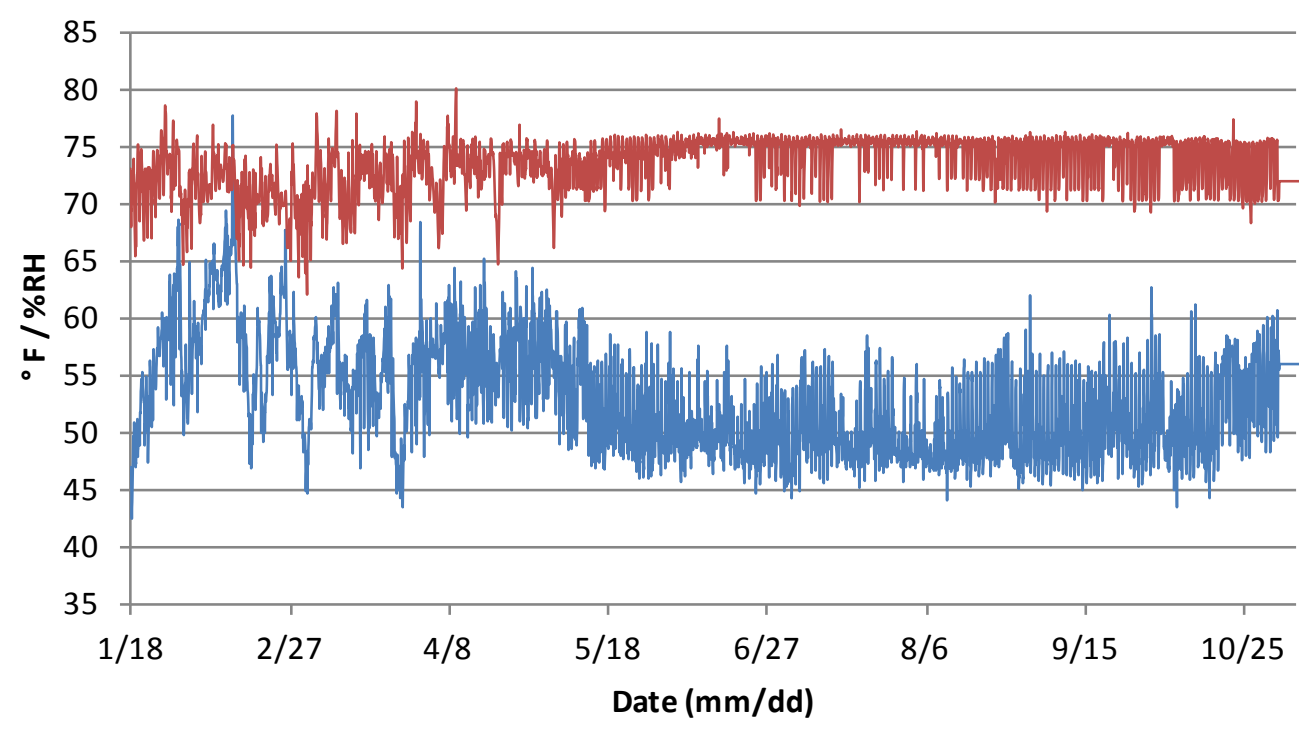

BDC 2 TSTAT \%RH - BDC 2 TSTAT Deg F

Figure 65. BDC 2 hourly interior temperature and \%RH plot

Figure 66 shows the hourly TSTAT \%RH frequency plot for the BDC 2.

BDC 2: $1 / 18 / 2013$ to $11 / 07 / 2013$

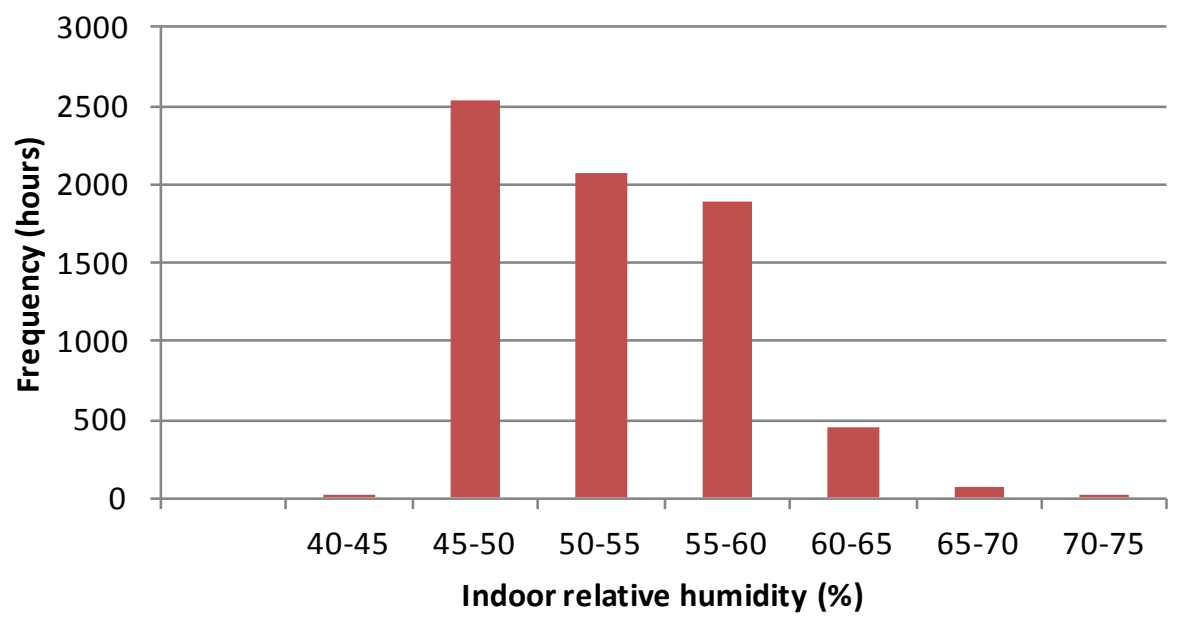

Figure 66. BDC 2 Hourly \%RH Frequency Chart

Figure 67 shows daily dehumidifier kilowatt-hour consumption. The dehumidifier consumed the most energy during the summer and early fall months. The reduced latent removal capacity of the HVAC system, due to the oversized air handler, may have forced the dehumidifier to operate more to compensate. 


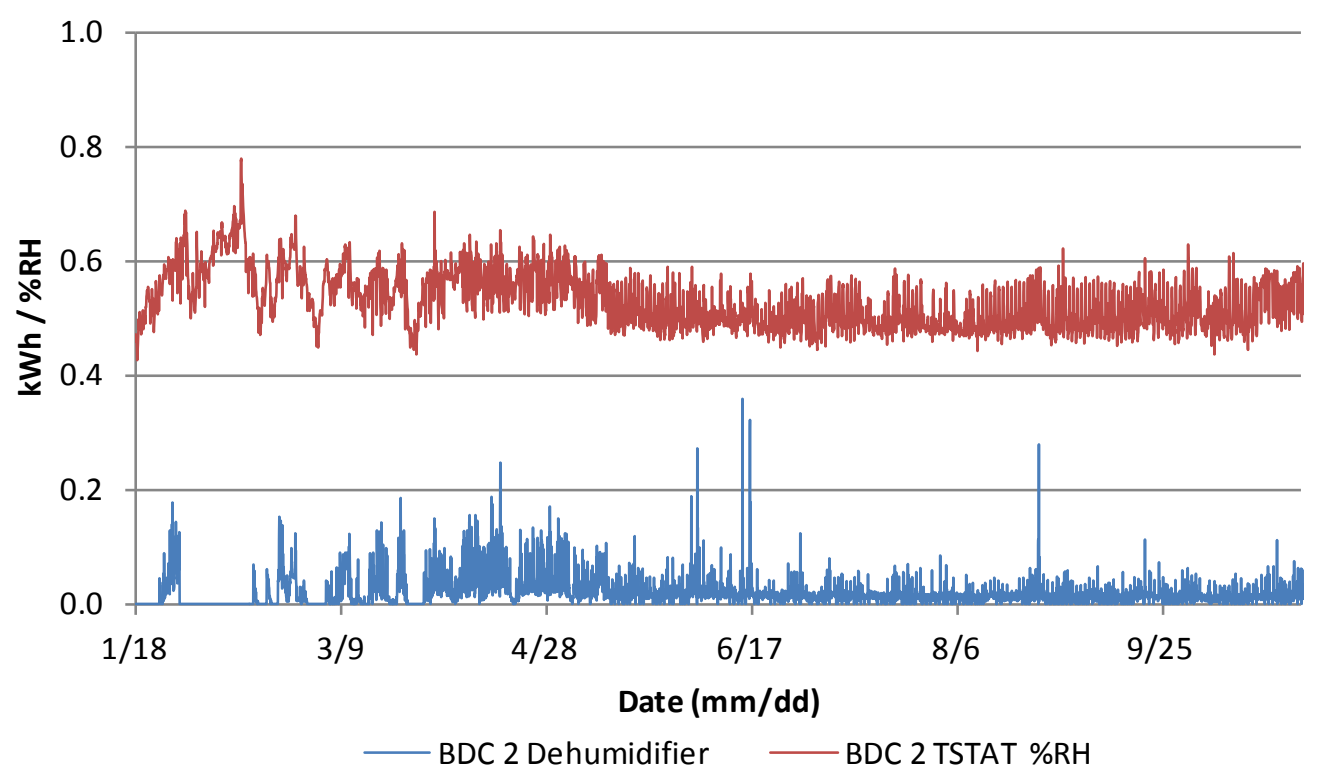

Figure 67. Hourly dehumidifier site energy use versus TSTAT \%RH for BDC 2 


\section{Conclusion}

\subsection{Research Questions}

BSC sought to address the following research questions through this research project:

Quantify whether, and the extent to which, indoor humidity levels are elevated in homes without supplemental dehumidification compared to homes with supplemental dehumidification?

On average, the homes without dehumidification operated above $60 \%$ RH for $31.3 \%$ of the total hours of the study. Conversely, the homes with dehumidification operated above $60 \% \mathrm{RH}$ for only $14.7 \%$ of the total hours.

However, a closer inspection showed some inconsistencies. The performance of the homes without dehumidification in this study (PHA 5-8) is split. PHA 7 and 8 are exhibiting far more hours above $60 \%$ RH ( $\sim 5 \%$ of the total study hours) than any of the other homes, which was to be expected. However, the hours above $60 \%$ RH at PHA 5 and 6 are well below that $(\sim 17 \%)$, and even lower than two of the homes with dehumidifiers (PHA 2 and 3). It has been noted that the dehumidifier settings were altered multiple times at PHA 2, which complicated the comparison. However, an analysis of the monitored end uses showed no correlation between equipment use and interior conditions.

It should be noted that homeowner feedback from occupants in homes without supplemental dehumidification indicated that while the homeowner were made aware of the absence of supplemental dehumidification in their HVAC systems, BSC received no reports of comfort complaints related to elevated interior humidity levels. This is of particular interest because these homeowners became distinctly aware, through participation in the study, that their HVAC systems did not have a supplemental dehumidification component, while others who received the same house did. However, it should also be noted that the possibility exists that these homeowners were reticent to complain about a house that they received, at no to low cost, as part of the PHA redevelopment program.

How much variability in interior \%RH is observed from house to house? Is variability correlated with hot water use, clothes dryer operation and/or cooking activities? Are there other explanations for variation in \%RH?

The \%RH frequency plot from Section 3.1, shown again here as Figure 68, illustrated the variability in RH levels between the three house groups. 


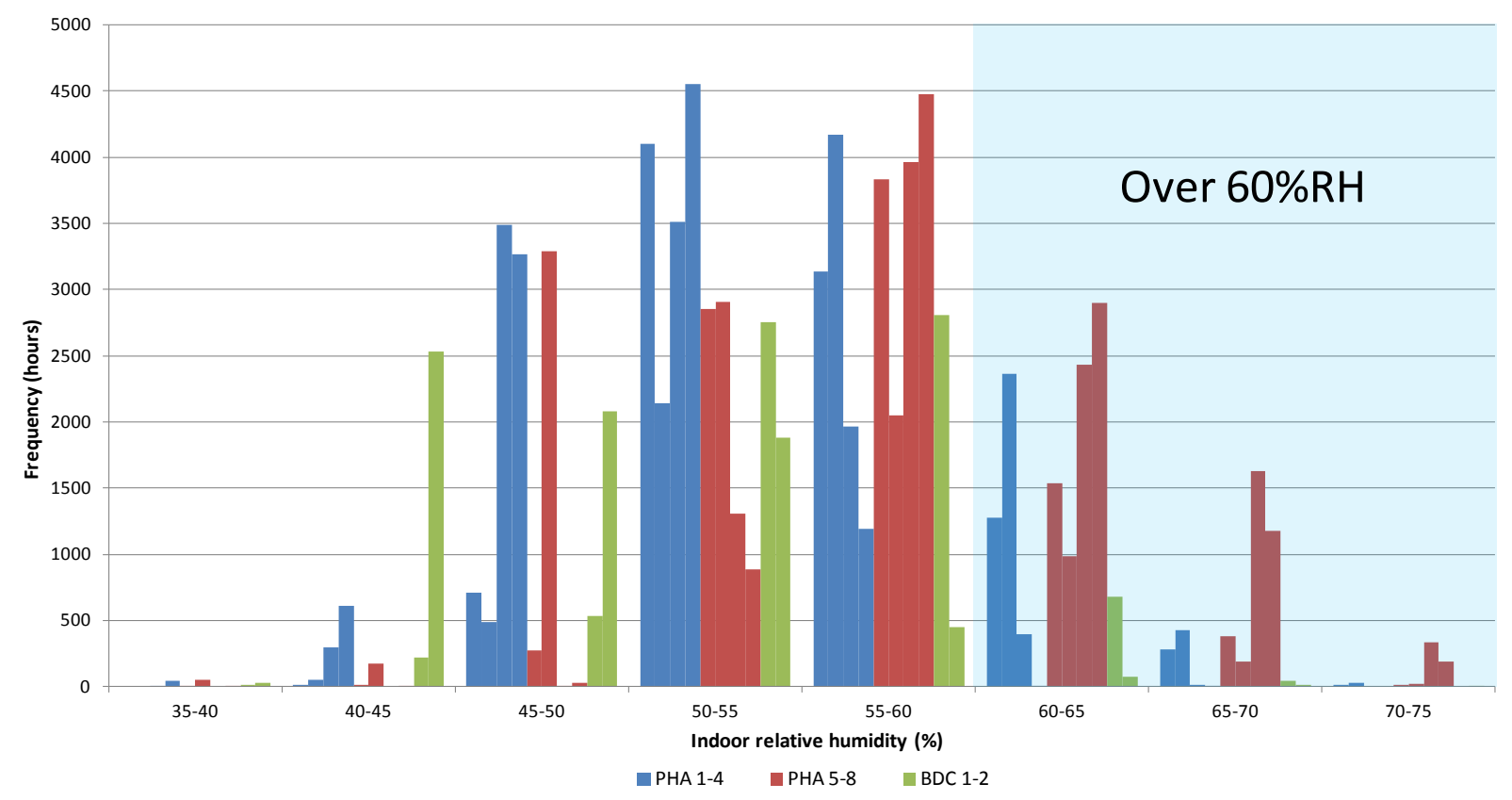

Figure 68. \%RH frequency plot for all 10 study homes, grouped into the three house types

In general, no single explanatory variable appears to provide a consistent understanding of the humidity control in each house. Indoor humidity is likely due to all of the factors we have examined, their interactions, and the specifics of how they are used by each occupant. The magnitude of this variability and the difficulty encountered in finding explanatory variables are important findings with implications for future research.

How much and when is supplemental dehumidification needed to control indoor RH to about $55 \%$, but less than $60 \%$, in these homes throughout the year?

PHA 4 is the sole house with supplemental dehumidification that controlled humidity levels in the living space throughout the study, limiting the hours above $60 \%$ RH to 12 hours out of 9,672 total hours $(0.1 \%$ of hours). The Aprilaire 1750 whole-house ducted dehumidifier operated around 1400 hours throughout the study period $(14.5 \%$ versus the $10 \%$ runtime that was predicted). The dehumidifier consumed 1,177 $\mathrm{kWh}$ of site energy, equivalent to around \$129 in utility costs.

The predicted $10 \%$ dehumidifier runtime could not be fully validated by the monitored data, due to the variability in the results.

The dehumidifiers at PHA 1-3 did not operate enough to limit the interior humidity levels to below $60 \% \mathrm{RH}$, due to a myriad of reasons that have been discussed. Those dehumidifiers consumed 161 to $537 \mathrm{kWh}$ of site energy, costing \$18-\$60 over the course of the study.

The Frigidaire FAD301NUD stand alone dehumidifier at BDC 1 operated for $110 \%$ of the predicted hours, consuming $444 \mathrm{kWh}$ of site energy, equivalent to around $\$ 49$ in utility costs. Similar to PHA 1-3, the interior conditions were not held strictly below $60 \% \mathrm{RH}$, with BDC registering 725 hours $(10.3 \%)$ and BDC 2 registering 534 hours $(7.6 \%)$. 
What metric is most appropriate for evaluating the extent of humidity problems and the success of supplemental humidity control?

Defining a specific humidity threshold (whether \% RH or DP), with the intent of quantifying the humidity performance, can result in data that are difficult to interpret or can be interpreted incorrectly. Setting a \% RH threshold can be especially misleading, as $\% \mathrm{RH}$ is a function of dry bulb temperature. BSC would not recommend this metric as a primary method of evaluating humidity levels in homes. DP appeared to have an advantage over $\% \mathrm{RH}$, as it is a better indicator of moisture levels in the air, but it is also dependent on temperature as well. Thus, comparing the humidity levels between homes that are operating at different dry bulb temperature set point is difficult.

Graphical representation of the data served to illustrate subtle differences between the humidity profiles of multiple homes. Rather than only summing the hours above a specific level, the entire dataset is displayed in a frequency plot like Figure 68.

\subsection{Lessons Learned}

A number of improvements were noted during that study that should be applied in future monitoring studies like these:

Ensure the dehumidifier set point is adequate for the intended performance.

$\mathrm{BSC}$ realizes that changing the dehumidistat setting on the Aprilaire model 70 from two bars to three bars would have lowered the DP set point from $60^{\circ} \mathrm{F}$ DP to $56^{\circ} \mathrm{F}$ DP. It is expected that this lowered set point would result in the dehumidifier operating more and would reduce the amount of hours above $60 \% \mathrm{RH}$ in homes like PHA $1-3$.

It is recommended that a research team undertaking a monitoring study of occupied homes be familiar with any policy on HSR and what code has adopted by the DOE National Research Laboratory associated with the study. BSC regrets not being able to request that the homeowners change the set point on the dehumidifiers, as this could have yielded more data on the performance of supplemental dehumidification systems. NREL advised against this, referring to the DOE HSR. In future studies like this, it is recommended to establish as soon as possible in the project whether HSR applies and the details of the policy.

\section{Improve homeowner education on dehumidifier operation and controls.}

Supplemental dehumidification systems, their purpose and controls, can be confusing to some homeowners. This unfamiliarity may have contributed to dehumidifier controls being improperly adjusted at two of the homes. Proper homeowner education is highly recommended should a builder choose to adopt supplemental dehumidification in their HVAC designs.

\section{Develop an improved method of capturing more detail on occupant behavior.}

As stated in Sections 3 and 4, there was little to no correlation observed between the monitored HVAC and equipment use and the interior conditions. It is estimated that occupant behavior may have contributed to the variability. Developing a method for monitoring more of the occupant behavior would be recommended. More data on occupant behavior, such as window opening, cooking habits other than oven/range hood operation, and daily/weekly occupancy profile could prove useful. 


\section{References}

AFPA (2006). Wood Frame Construction Manual: Guide to Wood Construction in High Wind Areas for One and Two Family Dwellings. Washington, DC: American Wood Council. www.awc.org/pdf/WFCM 130-B-Guide.pdf. Accessed December 10, 2013.

Arena, L.; Karagiozis, A.; Mantha, P (2010). “Monitoring of Internal Moisture Loads in Residential Buildings - Research Findings in Three Different Climate Zones" American Society of Heating Refrigeration and Air-Conditioning Engineers, Atlanta, GA.

http://web.ornl.gov/sci/buildings/2012/2010\%20B11\%20papers/75 Arena.pdf. Accessed December 10, 2013.

ASHRAE (2012). 2012 ASHRAE Standard 52.2 - Method of Testing General Ventilation AirCleaning Devices for Removal Efficiency by Particle Size. American Society of Heating, Refrigerating and Air Conditioning Engineers, Inc.

ASHRAE (2010). 2010 ASHRAE Standard 62.2 - Ventilation and Acceptable Indoor Air Quality in Low-Rise Residential Buildings. American Society of Heating, Refrigerating and Air Conditioning Engineers, Inc.

ASHRAE (2010). 2010 ASHRAE Standard 62.2 - Ventilation and Acceptable Indoor Air Quality in Low-Rise Residential Buildings. American Society of Heating, Refrigerating and Air Conditioning Engineers, Inc.

Baechler, M. Williamson, J.; Gilbride, T.; Cole, P.; Hefty, M.; Love, P. (2010). HighPerformance Home Technologies: Guide to Determining Climate Regions by County. Volume 7.1. Pacific Northwest National Laboratory. PNNL-17211. Prepared for the U.S. Department of Energy under Contract DE-AC05-76RLO 1830. http://apps1.eere.energy.gov/buildings/publications/pdfs/building_america/ba climateguide 7 _. pdf. Accessed December 10, 2013.

Gatley, D. (2004). Understanding Psychrometrics. Second Edition. Atlanta, GA: American Society of Heating, Refrigerating and Air Conditioning Engineers, Inc.

Hahn, R. (2010). “Moving Back to New Orleans.” Home Energy Magazine pp.32-38. www.buildingscience.com/documents/dtw-related-articles/cs-hem-moving-back-home-to-neworleans-project-home-again/view?searchterm=project $\% 20$ home $\% 20$ again. Accessed December 10, 2013.

Harriman, L.; Lstiburek, J. (2009). The ASHRAE Guide for Buildings in Hot and Humid Climates. Second Edition. Atlanta, GA: American Society of Heating, Refrigerating, and Air Conditioning Engineers, Inc. 
Kerrigan, P. (2009). Annual Report Building Science Corporation Industry Team: Project Home Again Phase II Community Scale Evaluations. Work Performed Under Funding Opportunity Number: DE-FC26-08NT00601. U.S. Department of Energy, Office of Energy Efficiency and Renewable Energy. www.buildingscience.com/documents/bareports/ba-2009-annual-reportfiles/ba-0911-2009-ba-annual-report-community-scaleevaluations/?searchterm $=$ Annual $\% 20$ Report $\% 20$ Building $\% 20$ Science $\% 20$ Corporation $\% 20$ Indust ry\%20Team. Accessed December 10, 2013.

Metzger, C.; Hendron, R., (2010). Building America House Simulation Protocols. DOE/GO102010-3141. Golden, CO: National Renewable Energy Laboratory.

http://apps1.eere.energy.gov/buildings/publications/pdfs/building_america/house_simulation_rev ised.pdf. Accessed December 10, 2013.

Rudd, A. (2004). Results of Advanced Systems Research: Supplemental Humidity Control Systems. Project 3, 5.C.1 Final Report to U.S. Department of Energy under Task Order number KAAX-3-32443-05. Midwest Research Institute/National Renewable Energy Laboratory, Golden, CO. www.buildingscience.com/documents/bareports/ba-0414-results-advancedsystems-research-supplemental-humidity-control-systems. Accessed December 10, 2013.

Rudd, A. (2013a). RR-0304: Central Fan Integrated Supply Ventilation-The Basics. Building Science Corporation, www.buildingscience.com/documents/reports/rr-0304-central-fanintegrated-supply-ventilation-the-basics. Accessed December 10, 2013.

Rudd, A. (2013b). Expert Meeting: Recommended Approaches to Humidity Control in High Performance Homes. Expert Meeting Report to U.S. Department of Energy under Task Order number KNDJ-0-40337-00. National Renewable Energy Laboratory, Golden, CO.

http://apps 1.eere.energy.gov/buildings/publications/pdfs/building_america/expt_mtg_humidity_c ontrol.pdf. Accessed December 10, 2013.

Rudd, A. (2009a). "Information Sheets \#610: Central Fan Integrated Supply Ventilation Systems.” Building Science Corporation, www.buildingscience.com/documents/informationsheets/information-sheet-ventilation-system?searchterm=is+610. Accessed December 10, 2013.

Rudd, A. (2009b). "Information Sheets \#620: Supplemental Humidity Control.” Building Science Corporation, www.buildingscience.com/documents/information-sheets/informationsheet-supplemental-humidity-control/?searchterm=dehumidification. Accessed December 10, 2013.

Rudd, A.; Lstiburek, J.; Ueno, K. (2003). "Residential dehumidification and ventilation systems research for hot-humid climates," Proceedings of 24th AIVC and BETEC Conference, Ventilation, Humidity Control, and Energy, Washington, US, pp.355-60. 12-14 October. Air Infiltration and Ventilation Centre, Brussels, Belgium. www.aivc.org/resource/residentialdehumidification-and-ventilation-systems-research-hot-humid-climates. Accessed December 10, 2013. 
Rudd, A.; Lstiburek, J.; Ueno, K. (2005). "Residential Dehumidification Systems Research for Hot-Humid Climates. U.S. Department of Energy, Office of Energy Efficiency and Renewable Energy, NREL/SR-550-36643. www.nrel.gov/docs/fy05osti/36643.pdf. Accessed December 10, 2013.

Rudd, A.; Henderson, H., Jr., 2007. "Monitored Indoor Moisture and Temperature Conditions in Humid Climate U.S. Residences.” ASHRAE Transactions (17, Dallas 2007). American Society of Heating Refrigerating and Air-Conditioning Engineers, Atlanta, GA. http://consensus.fsu.edu/FBC/HMCW/Rudd-Henderson_Indoor_environment_data_DA-07046.pdf. Accessed December 10, 2013.

Rudd, A.; Bergey, D. (2013). Ventilation System Effectiveness and Tested Indoor Air Quality Impacts." U.S. Department of Energy, Office of Energy Efficiency and Renewable Energy, BA1309. www.buildingscience.com/documents/bareports/ba-1309-ventilation-system-effectivenessand-indoor-air-quality-impacts/view?searchterm=62.2. Accessed December 10, 2013.

HHS (2009). "Code of Federal Regulations: Title 45 CFR Part 46, Protection of Human Subjects." Regulations (Revised January 15, 2009). U.S. Department of Health and Human Services, www.hhs.gov/ohrp/humansubjects/guidance/45cfr46.html.Accessed December 10, 2013.

Walker, I.; Sherman, M. (2007). "Humidity Implications for Meeting Residential Ventilation Requirements.” Environmental Energy Technologies Division - Ernst Orlando Lawrence Berkeley National Laboratory. http://epb.lbl.gov/publications/pdf/lbnl-62182.pdf. Accessed December 10, 2013. 


\section{Appendix}

\section{PHA Example Floor Plan}

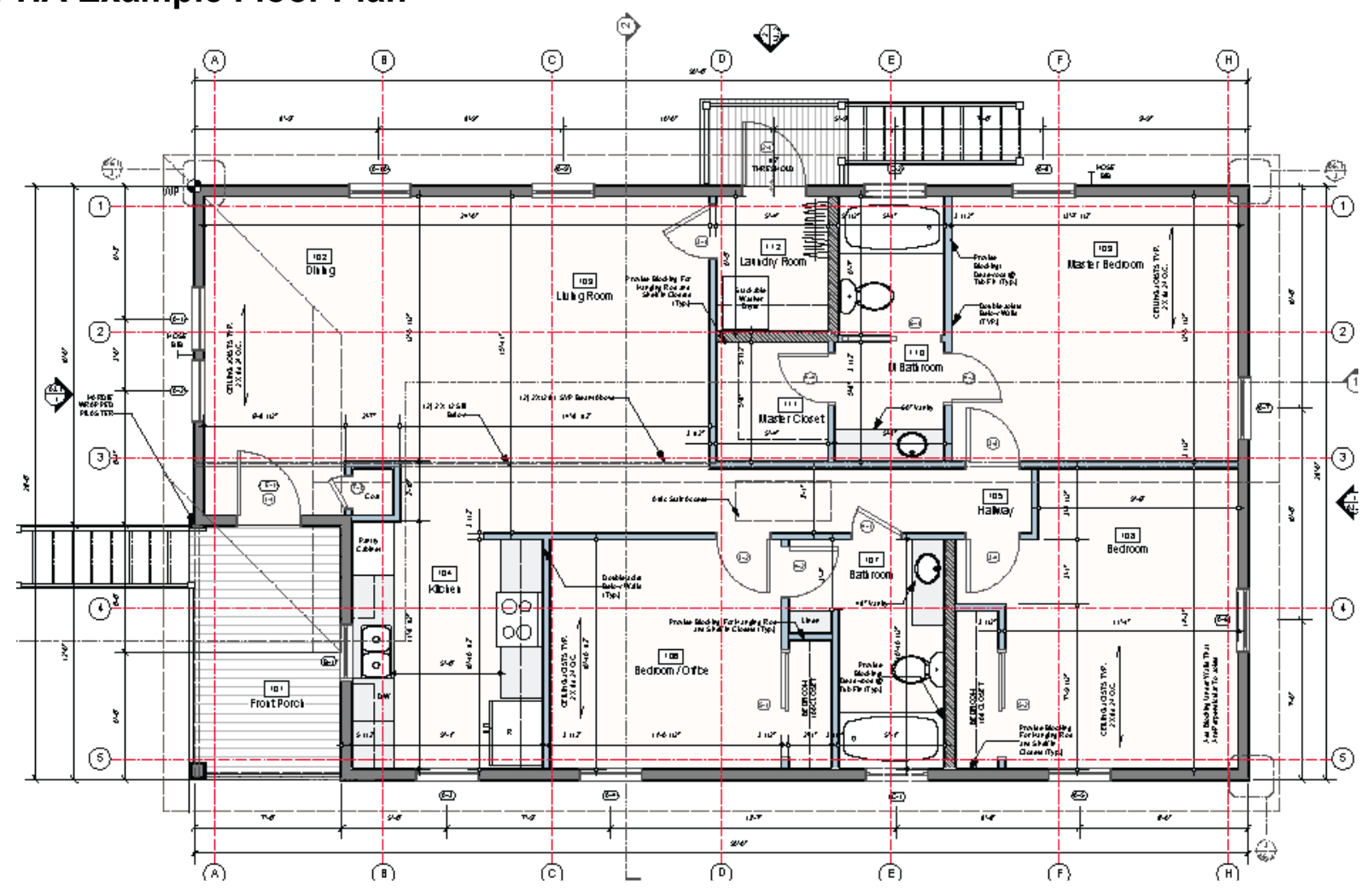


\begin{tabular}{l|l} 
u.s. DEPARTMEnt of & Energy Efficiency \& \\
ENERCY & Renewable Energy
\end{tabular}

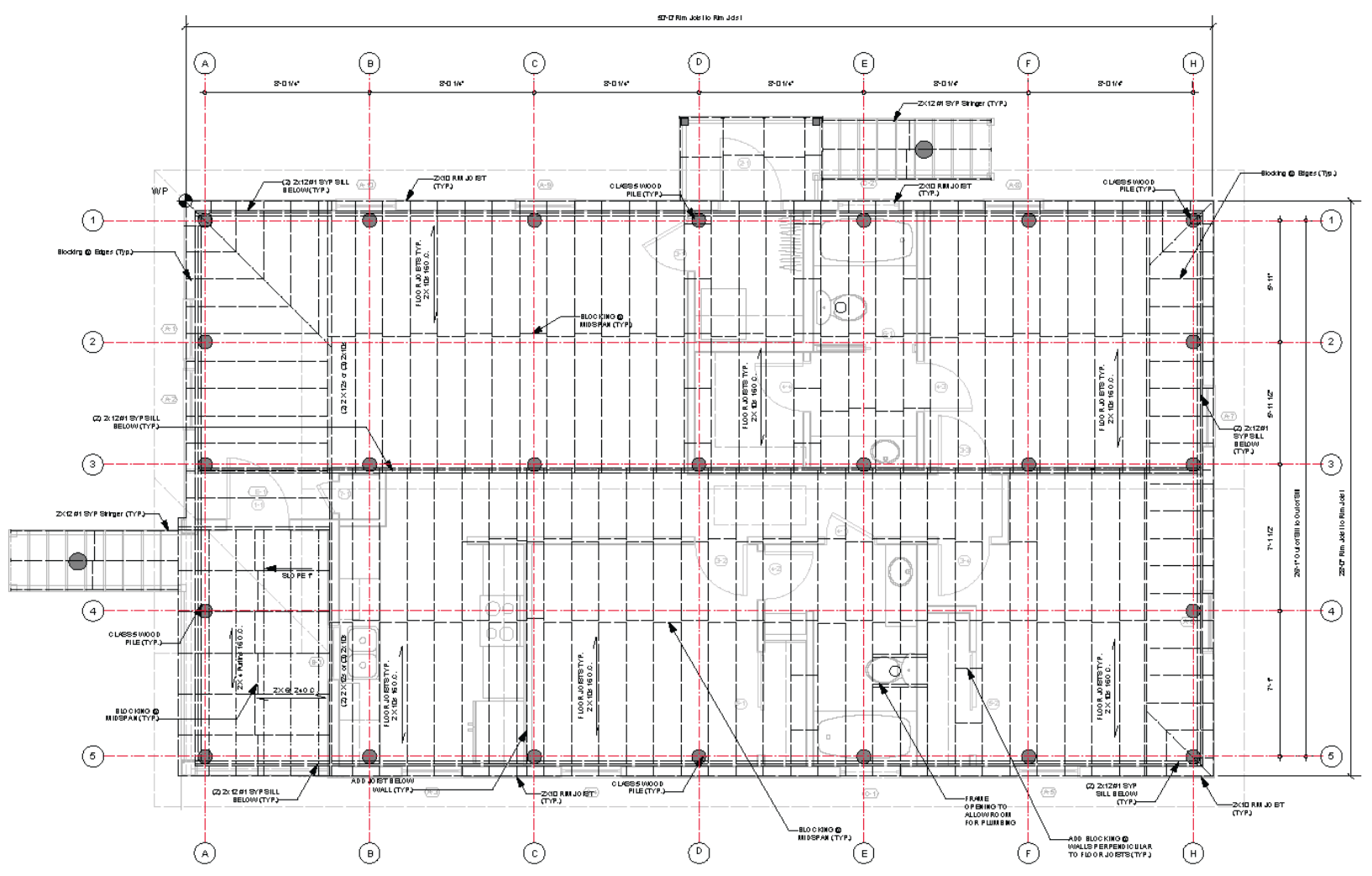




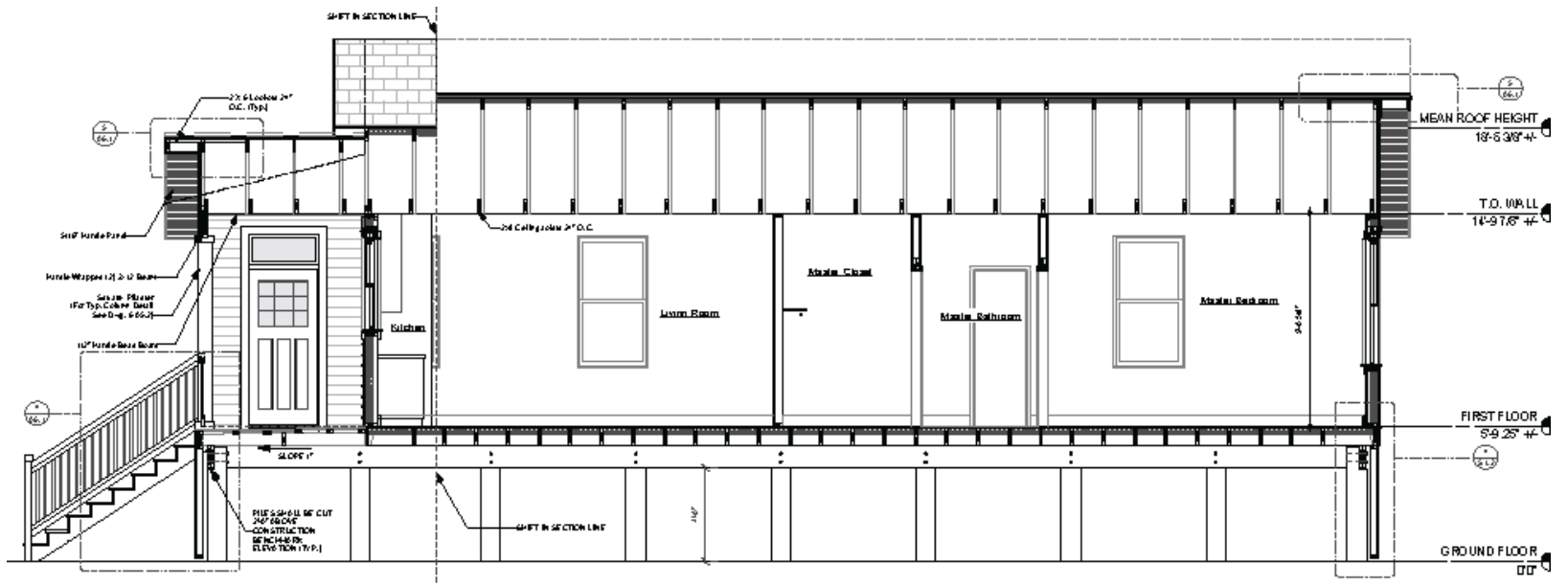

(1) Longitudinal Section

(2) Cross Section
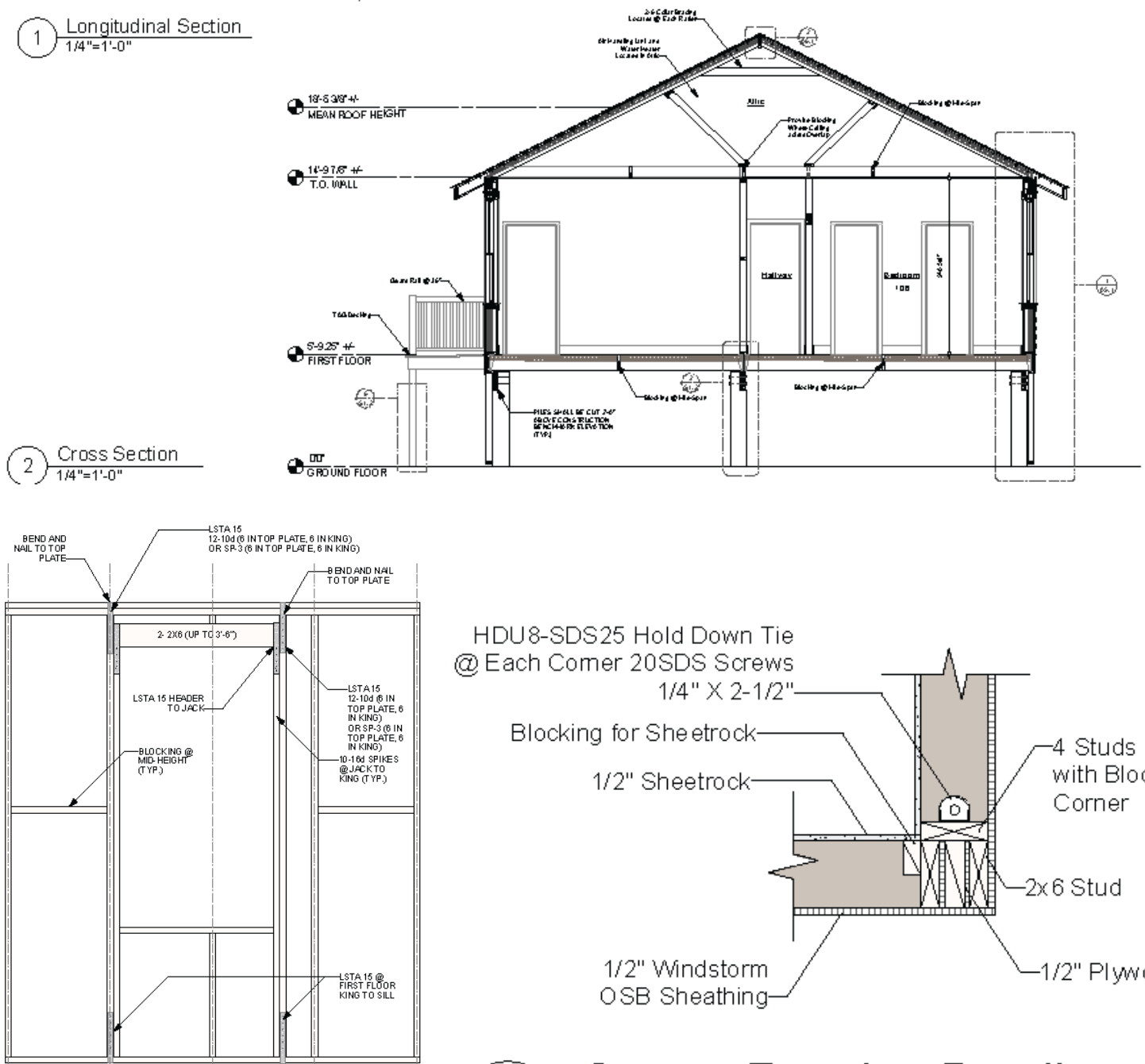

HDU8-SDS25 Hold Down Tie (a) Each Comer 20SDS Screws

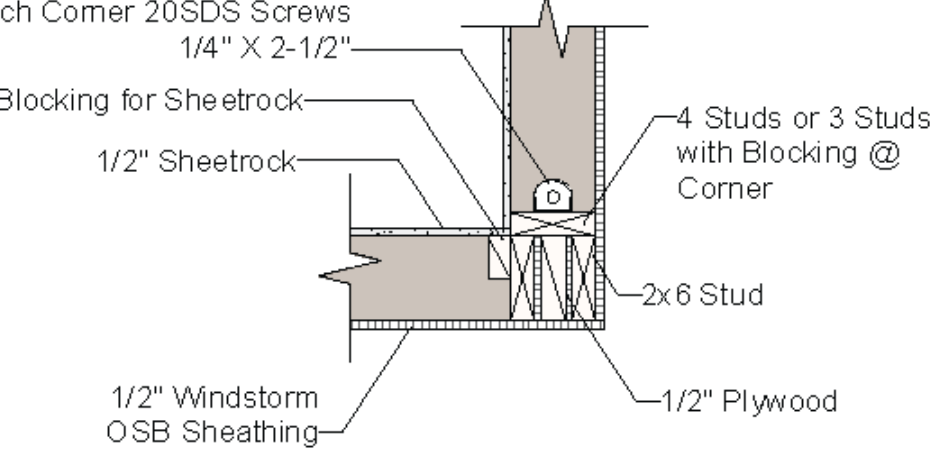

(1) Framed Wall Opening and Header Detail

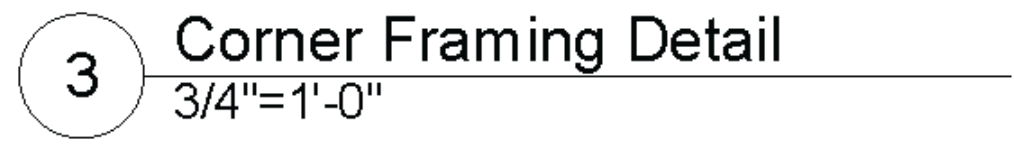




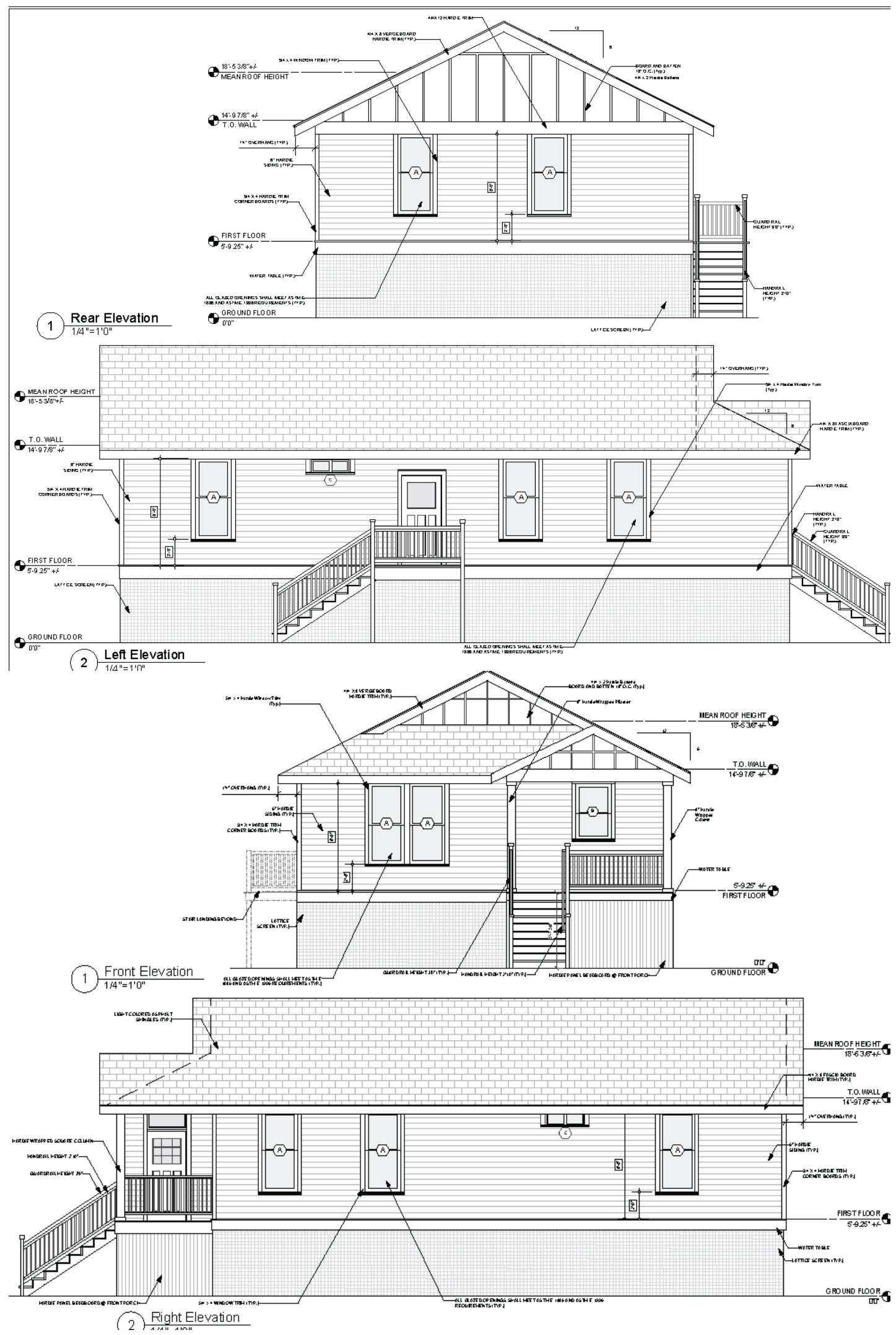




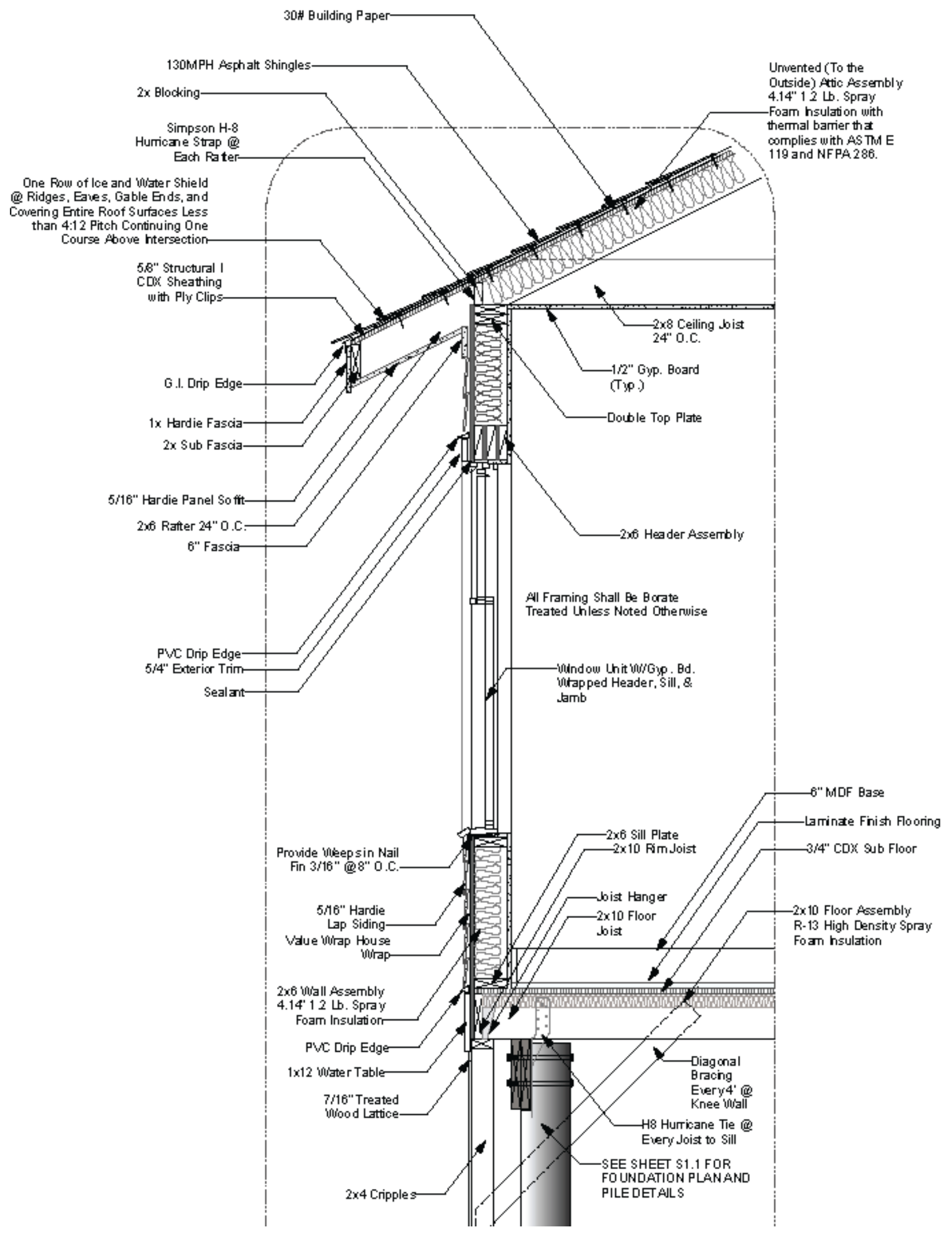




\section{BDC Example Floor Plan}
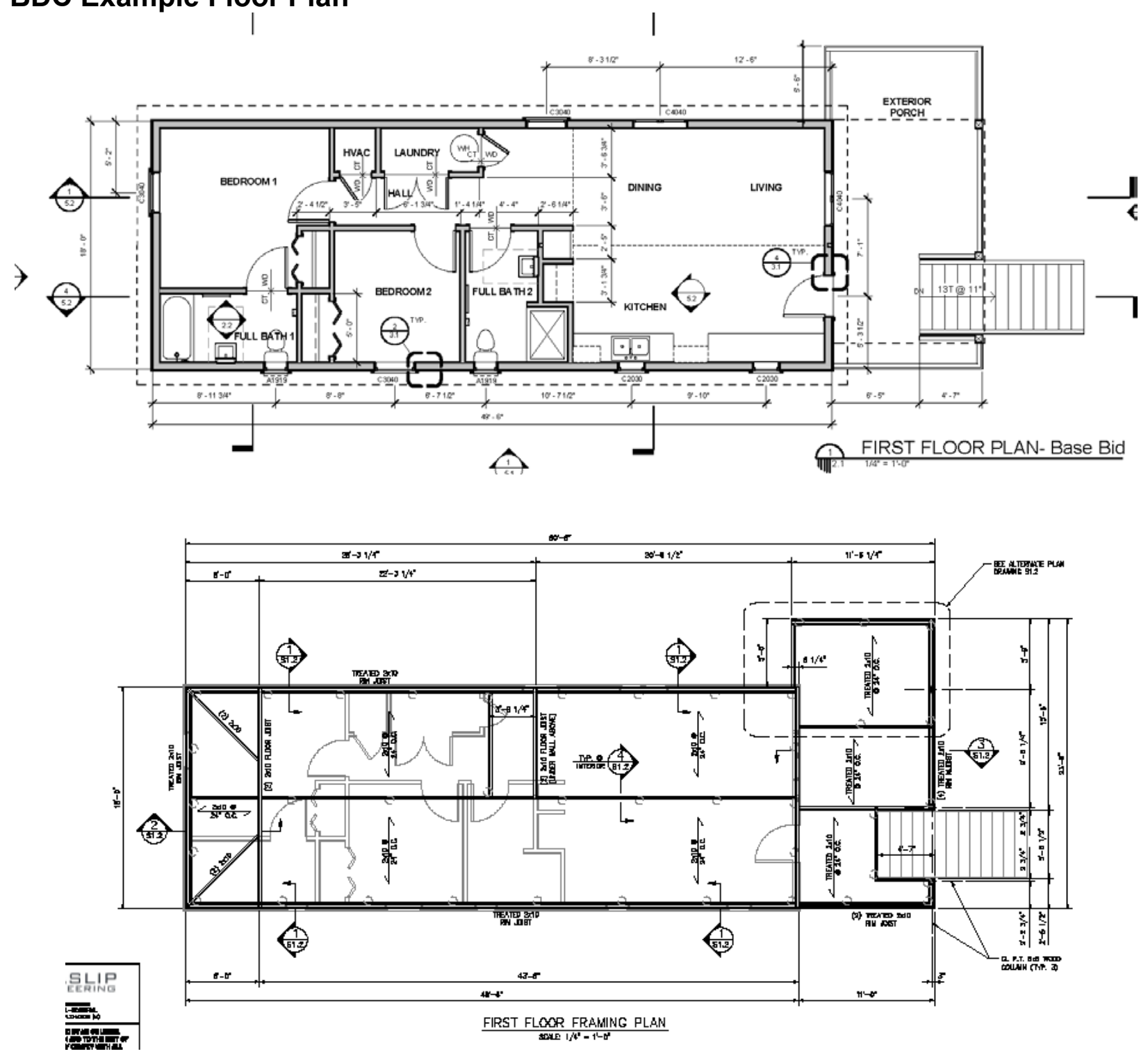

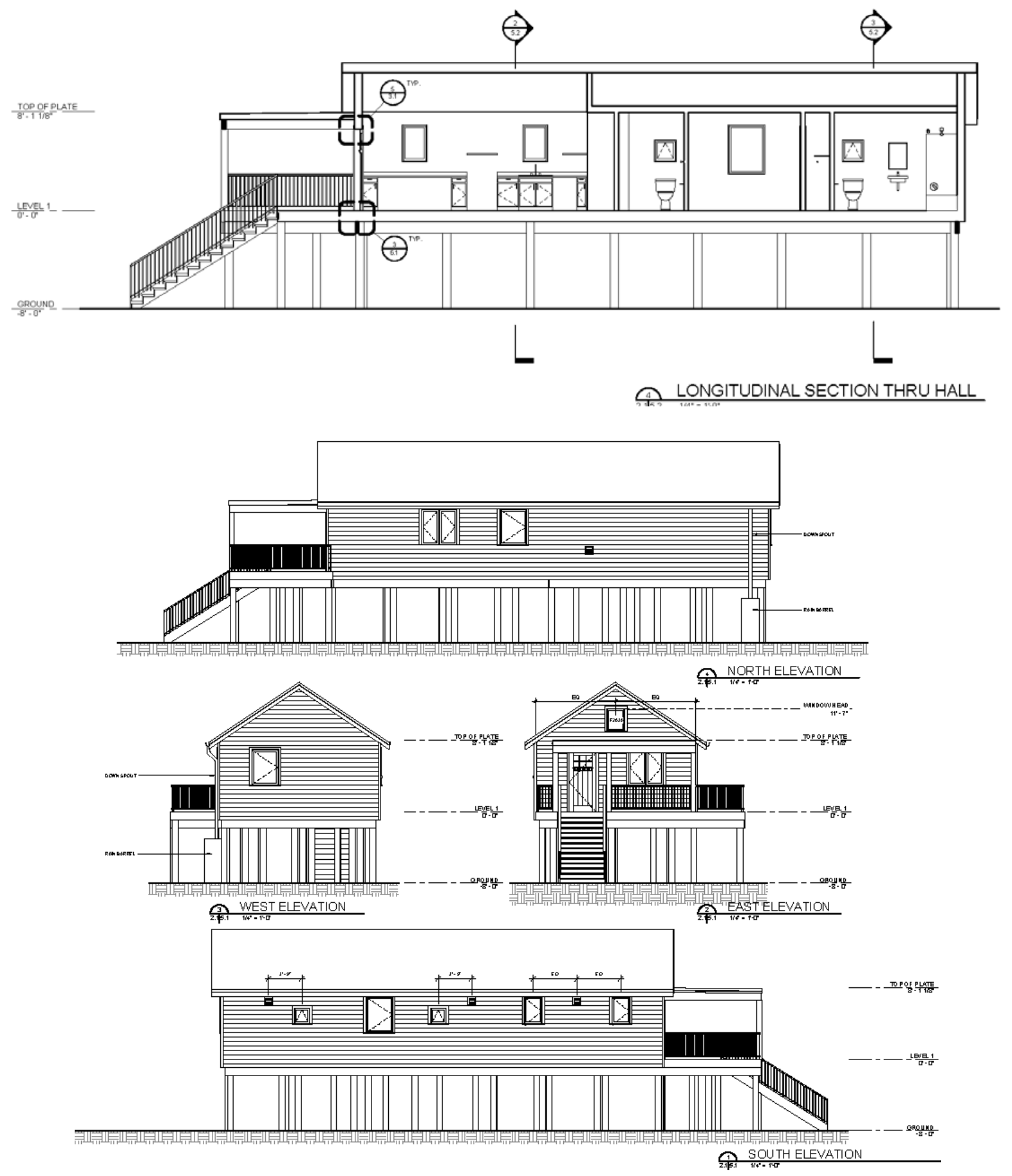

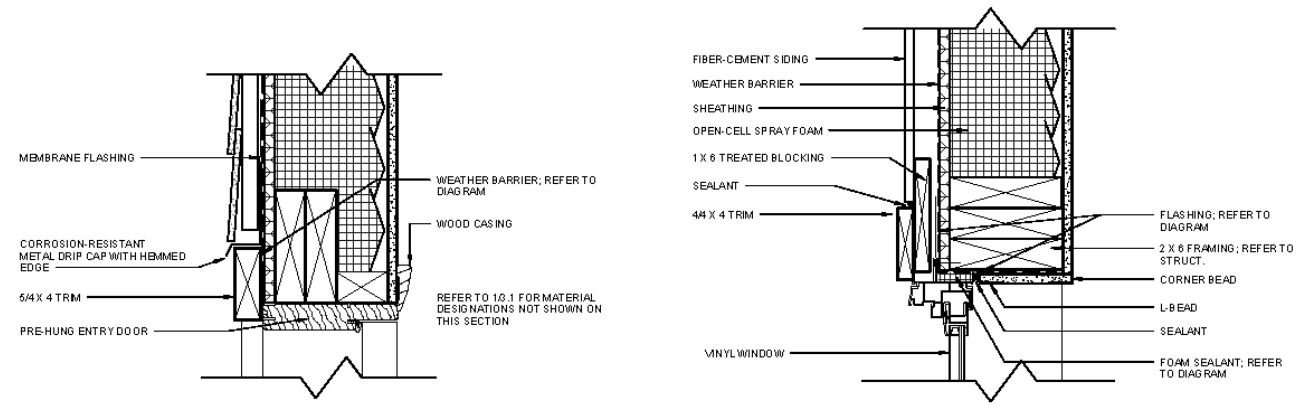

SECTION THRU DOOR AT HEAD

2. SECTION THRU WNDOW AT JAMB
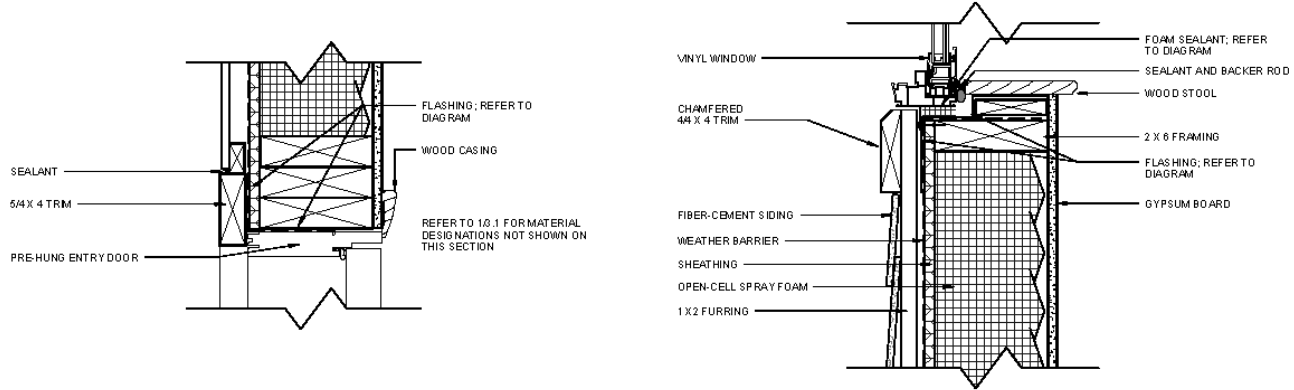

(4) SECTION THRU DOOR AT JAMB

Dि SECTION THRU WINDOW AT SILL

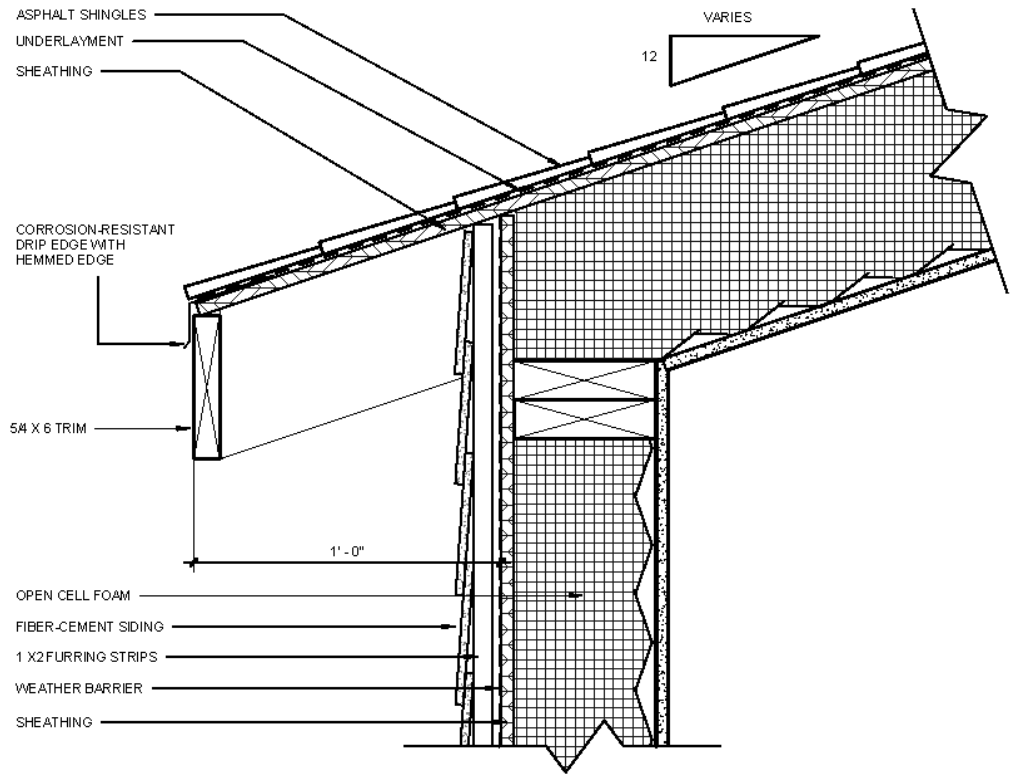

2 DETAIL AT ROOF 
